TIAGO PETERMANN FIGUEIREDO

EFFECT OF LUBRICANT PROPERTIES ON THE FRICTION

COEFFICIENT UNDER DIFFERENT TEMPERATURES, SPEEDS AND LOADS USING A BALL-ON-DISC TEST 


\section{EFFECT OF LUBRICANT PROPERTIES ON THE FRICTION COEFFICIENT UNDER DIFFERENT TEMPERATURES, SPEEDS AND LOADS USING A BALL-ON-DISC TEST}

Dissertation submitted for the Degree of Master of Science of the University of São Paulo. 


\section{EFFECT OF LUBRICANT PROPERTIES ON THE FRICTION COEFFICIENT UNDER DIFFERENT TEMPERATURES, SPEEDS AND LOADS USING A BALL-ON-DISC TEST}

Dissertation submitted for the Degree of Master of

Science of the University of São Paulo.

Department: Mechatronics and Mechanical System Engineering

Supervisor: Prof. Dr. Izabel Fernanda Machado 
Este exemplar foi revisado e corrigido, sob responsabilidade única do autor e com a anuência de seu orientador.
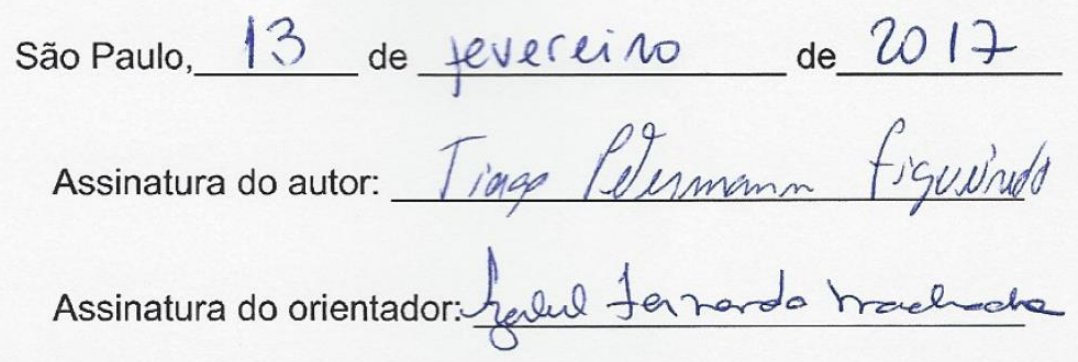

\section{Catalogação-na-publicação}

Figueiredo, Tiago Petermann

EFFECT OF LUBRICANT PROPERTIES ON THE FRICTION

COEFFICIENT UNDER DIFFERENT TEMPERATURES, SPEEDS AND

LOADS USING A BALL-ON-DISC TEST / T. P. Figueiredo -- versão corr. --

São Paulo, 2017. $113 \mathrm{p}$.

Dissertação (Mestrado) - Escola Politécnica da Universidade de São Paulo. Departamento de Engenharia Mecatrônica e de Sistemas Mecânicos.

1.Tribologia 2.Lubrificação 3.Ensaios de Materiais I.Universidade de São Paulo. Escola Politécnica. Departamento de Engenharia Mecatrônica e de Sistemas Mecânicos II.t. 


\section{ACKNOWLEDGEMENT}

I would like to appreciate the partnership between FCA and LFS ("Laboratório de Fenômenos e Superfícies") and USP, which make it possible to

pursue my master degree, specifically in the name of Guilherme Antônio Assis Machado and Izabel Fernanda Machado. I would also like to thank the FCA staff (Renato Coimbra and Jonny Salzgeber) for supporting the research performed at the university.

I could not forget to thank all teachers and classmates; I make friends during these past years, in particular Iramar Tertuliano for his friendship and all work we conducted together.

I would also like to thank my wife Daniele and my daughter Letícia for all support and patience for all this time. 


\section{RESUMO}

O presente estudo tem o objetivo de avaliar o efeito de propriedades dos lubrificantes sobre o coeficiente de atrito. Para tanto foram testados três lubrificantes diferentes (dois sintéticos e um mineral), que são utilizados em transmissões automotivas. Os experimentos foram conduzidos utilizando um sistema tribológico denominado "ball-on-disc". Os discos foram fabricados com as mesmas propriedades mecânicas das engrenagens de transmissão, já as esferas foram fabricadas com aço SAE 52100. Os parâmetros de teste foram definidos com base na análise dinâmica conduzida utilizando o software "ISOCAD", que leva em conta a geometria da engrenagem e a dinâmica do veículo (força aplicada e velocidade) durante os ensaios tribológicos. Para definir os parâmetros de temperatura, foram utilizadas as mesmas temperaturas encontradas durante o ensaio de economia de combustível padronizado. Experimentos foram realizados em duas condições de lubrificação diferentes: i) fornecimento limitado de lubrificante, ou "Starved" e ii) condição de lubrificação imersa, ou "Fully flooded". Depois dos parâmetros definidos, foi possível calcular a espessura de filme de óleo, de forma a definir o regime de lubrificação alcançado em cada condição. Lubrificação mista e limítrofe foi obtida todas as condições de testes. Os resultados mostraram a relação entre a velocidade e o filme de óleo específico usando uma formulação de Khonsari e Masjedi (2014), que leva em conta o efeito da rugosidade da superfície e baseia-se na formulação de Downson e Higginson (1981). A análise química do lubrificante mostrou que existe uma relação entre o coeficiente de atrito e os aditivos utilizados nos lubrificantes. Estes resultados também mostram o desempenho dos lubrificantes em diferentes temperaturas, velocidades e cargas. Os melhores resultados foram obtidos para um lubrificante sintético. 


\begin{abstract}
The present study has the objective of evaluating the effect of lubricant features on the friction coefficient by using three different lubricants (two synthetics and one mineral), which are used in automotive transmissions. In order to perform experiments, it was used a ball-on-disc system. The disc was manufactured with the same mechanical properties as transmission gears and the ball was made of 52100 SAE steel. The test parameters were defined based on a dynamic analysis conducted using "ISOCAD" which takes into account the geometry of the gear and vehicle dynamics (applied force and speed) during the tribological experiments. In order to set the temperature parameter, the lubricant testing temperature of a standard fuel economy was used. Experiments were conducted in two different lubrication conditions: i (starved) and ii (fully flooded). After the parameters were defined, it was possible to calculate the oil film thickness and, thus define the lubrication regime reached in each condition. Mixed and/or boundary lubrication was obtained in all the tests. Results showed the relationship between the speed and the specific oil film using a Khonsari and Masjedi formulation (2014), which takes into account the effect of surface roughness and, it is based on Downson and Higginson's (1981) formulation. The chemical analysis of the lubricant showed a relationship between friction coefficient and the additives used in lubricants. These results also showed the oil performance under different temperatures, speeds and loads. The best results were obtained for a synthetic lubricant.
\end{abstract}




\section{FIGURE LIST}

Figure 1 - Chain of mineral oils: a) straight paraffin, b) branched paraffin, c) naphthene, and d) aromatic, adapted from Stachowiak;Batchelor (2013).

Figure 2 - Common chemical structure of synthetic oils - Different types, adapted from Stachowiak;Batchelor (2013).

Figure 3 - Schematic of fluid viscosity - Adapted from Seabra, Campos and Sottomayor (2002)

Figure 4 - Kinematic viscosity $\mathrm{x}$ temperature define the Index Viscosity curve (STACHOWIAK;BATCHELOR,2013)

Figure 5 - Viscosity $X$ Temperature, temperatures below $50^{\circ} \mathrm{C}$ leads to a higher increase of viscosity - Seabra, Campos and Sottomayor (2002).

Figure 6 - Viscosity x Piezoviscosity for different oils (GOLD et al.,2001). Table 02 describes the different types of oil (M, ES and $\mathrm{SI})$.

Figure 7 - Additives typically consist of nitrogen, oxygen, phosphorus and/or sulfur (TORBACKE;RUDOLPHI;KASSFELDT, 2014).

Figure 8 - Adsorption friction modifiers lubrication mechanism (STACHOWIAK;BATCHELOR,2013).

Figure 9 - Molecule structure of ZnDDP (STACHOWIAK;BATCHELOR,2013).

Figure 10 - Lubrication regimes where EP, AW and FM are actives (TORBACKE; RUDOLPHI; KASSFELDT, 2014).

Figure 11 - Geometry of conformal and counterformal contacts (ASM HANDBOOK, Vol. 18,1992)

Figure 12- (a) Spur gears, (b) bevel gears, (c) helical gears. (WESSOL;PIRRO, 2001).

Figure 13- Mesh on involute gear teeth demonstrating the gear engagement (Author). 38

Figure 14 - the engagement contact during engagement 39

Figure 15 - Specific film thickness for gears (WESSOL; PIRRO, 2001). 40

Figure 16 - Stribeck curve - (Adapted from LECHNER AND NAUNHEIMER (1999)). 
Figure 17 - Two wheeled harvest cart with studded wheels in 1338 AD.

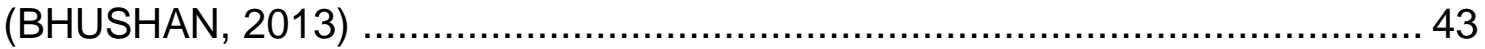

Figure 18 - Frictional force, (a) rolling, (b) sliding. (adapted from PROFITO, 2010)

Figure 19 - (a) Kinematic viscosity of the S1, S2 and M1 oil at temperatures ranging between 0 and $100^{\circ} \mathrm{C}$. Logarithmic description Temperature $\mathrm{X}$ kinematics viscosity lubricants (Author)

Figure 20 -Features and dimentions of the disc made of SAE 4320 steel and

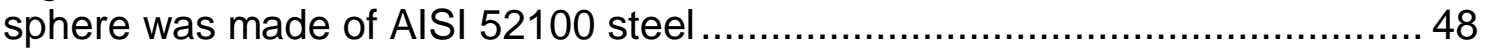

Figure 21 - a- Gear tooth engage shown red frame in Figures b and c. - B Constant speed (pure rolling) - c - Relative speeds (Sliding and rolling) adapted from Mazzo (2013). 50

Figure 22 - Gear speed X RPM - Example from a real vehicle, gear speed measured on pinion gear using ISOCAD program, the red frame is the region evaluated during tribological tests.

Figure 23 -pressure torque $\mathrm{x}$ maximum presure contact - Example from a real vehicle using ISOCAD program.

Figure 24 - Fuel economy test - Temperatate behavior during test. ............... 53

Figure 25 - Percentage of temperatures during fuel economy cycle................ 54

Figure 26- Tribometer TE-67 Plint \& Partners LTD (PLINT): Test ball - disc (LFS) (Reference: Author) ........................................................................ 55

Figure 27- (a) - Starved lubrication and (b) - Fully flooded lubrication...............55

Figure 28 - Pump system to maintain an oil film thickness during tribological tests. 56

Figure 29 - Chartflow with, lubricants, temperaturein loads and speeds used in tribological tests. The index 3,2,1-3 are displayed in Table 7 . 57

Figure 30 - Surface profilometer Taylor - Hobson CCl, author........................ 59

Figure 31 - Optical microscopy at LFS laboratory, author.............................. 60

Figure 32 - Scanning electron microscopy (SEM) - JEOL JSM-6010LA, author. 60

Figure 33 - EDX-720 Energy dispersive X-ray spectrometer, author...............61 61

Figure 34 - Example topography measurement of roughness surface ............. 62 
Figure 35 - Schematic view of transverse, indicating the direction of

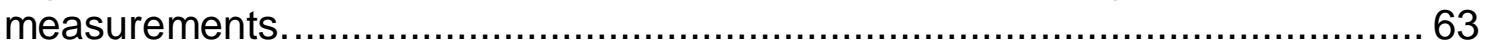

Figure 36 - Microhardness profile X surface depth for a disc. ........................ 63

Figure 37 - Difference between Hamrock and Dowson (1981) (black line) formulation and Khonsari e Masjedi (2014) (red line) formulation for the $20^{\circ} \mathrm{C}$ temperature condition.

Figure 38 - Specific film thickness $(\Lambda)$ resultsa functionee lubricants as a function

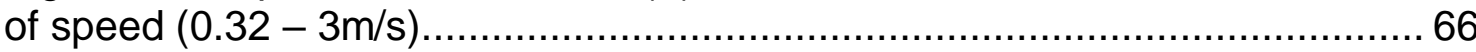

Figure 39 - Fourier Transformed Infra Red spectrums (FTIR) of: (a) S1,S2 and M1 oil (b) comparative oils.

Figure 40 - Coefficient of Friction and Speed X Time - S2 oil at $20^{\circ} \mathrm{C}$ and $30 \mathrm{~N}$ of

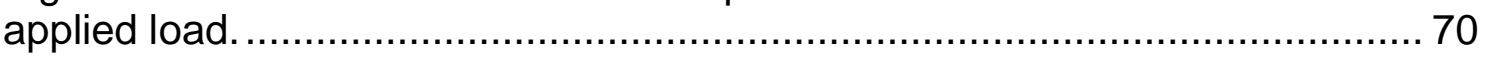

Figure 41 - Average coefficient of friction as a function of speed at $20^{\circ} \mathrm{C}$ and $30 \mathrm{~N}$

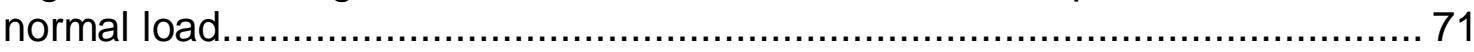

Figure 42 - Average coefficient of friction as a function of speed at $20^{\circ} \mathrm{C}$ and $50 \mathrm{~N}$ normal load 71

Figure 43 - Average coefficient of friction as a function of speed at $40^{\circ} \mathrm{C}$ and $30 \mathrm{~N}$

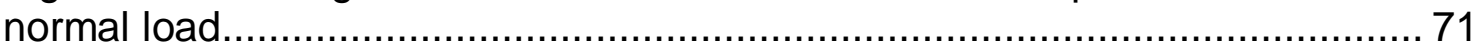

Figure 44 - Average coefficient of friction as a function of speed at $40^{\circ} \mathrm{C}$ and $50 \mathrm{~N}$

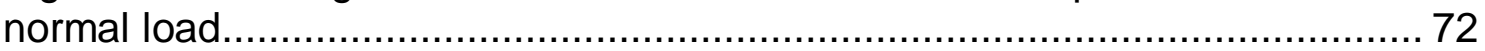

Figure 45 - Average coefficient of friction as a function of speed at $60^{\circ} \mathrm{C}$ and $30 \mathrm{~N}$

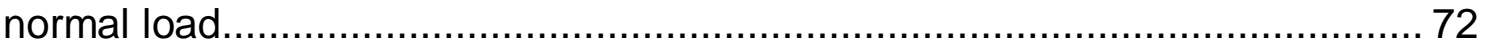

Figure 46 - Average coefficient of friction as a function of speed at $60^{\circ} \mathrm{C}$ and $50 \mathrm{~N}$

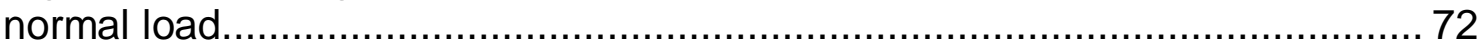

Figure 47 - Average coefficient of friction as a function of $\Lambda$ for all conditions tested in the starved condition - S1,S2 and M1 oil.

Figure 48 - Average coefficient of friction in function of $\Lambda$ for all conditions tested in the starved condition for S1,S2 and M1 oil in terms of temperatures and loads.

Figure 50 - Features on the wear scars on the steel balls (top) and discs. Surfaces (bottom) by optical microscopy, showing oxides (dark patches) and abrasion scratches, Tertuliano I.S et al.,2016 ............................................ 78

Figure 51 - SEM images of wear track, tested with S1 oil and $100 \mathrm{~N}$, present $\mathrm{S}$ and O in EDS map, Tertuliano I.S et al.,2016 ............................................ 78 
Figure 52 - SEM images of ball worn scar with corresponding chemical analysis by means of EDS. Oil S1, S2 and M1, respectively, Tertuliano I.S et al.,2016. 79

Figure 53 - Average coefficient of friction in function of velocity for $20^{\circ} \mathrm{C}$ temperature, $30 \mathrm{~N}$ normal load.

Figure 54 - Average coefficient of friction in function of velocity for $20^{\circ} \mathrm{C}$ temperature, $50 \mathrm{~N}$ normal load.

Figure 55 - Average coefficient of friction in function of velocity for $40^{\circ} \mathrm{C}$ temperature, $30 \mathrm{~N}$ normal load.

Figure 56 - Average coefficient of friction in function of velocity for $40^{\circ} \mathrm{C}$ temperature, $50 \mathrm{~N}$ normal load.

Figure 57 - Average coefficient of friction in function of velocity for $60^{\circ} \mathrm{C}$ temperature, $30 \mathrm{~N}$ normal load.

Figure 58 - Average coefficient of friction in function of velocity at $60^{\circ} \mathrm{C}$ temperature, $50 \mathrm{~N}$ normal load.

Figure 59 - Average coefficient of friction in function of $\Lambda$ for all conditions tested in a fully flooded test.

Figure 60 - Average coefficient of friction in function of $\Lambda$ for all conditions tested in a starved condition for S1,S2 and M1 oil in terms of temperatures and loads. 


\section{TABLE LIST}

Table 1 - Dynamic and kinematics viscosity units, ASM Handbook (1992) ..... 21

Table 2 - Piezoviscosity Parameters calculated by Gold et al. (2001) .............. 23

Table 3 - Lubrication regimes, full film, mixed and boundary lubrication as presented in Figure 13 EHD - (SEABRA;CAMPOS;SOTTOMAYOR, 2002) .. 33

Table 4 - Typical lubrication regimes values for bearing and gears (SEABRA;CAMPOS;SOTTOMAYOR, 2002)............................................ 34

Table 5 - Denomination and properties of gear oils evaluated. ....................... 47

Table 6 - Viscosity oils according to the temperatures used on tests............. 48

Table 7- Parameters selected to conduct ball on disc test in a tribometer........ 56

Table 8 - Roughness parameters of a disc evaluated before tribological test .. 62

Table 9 - Specific film thickness calculated based on and Khonsari e Masjedi

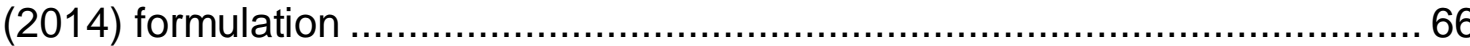

Table $10-$ Chemical composition in gear oils by using XRS analysis............67 67 


\section{SYMBOLS LIST}
A
Pre factor;
$\mathrm{A}_{\mathrm{r}}$
Real contact area;
$\mathrm{C}_{0}$
Ellipticity influence;
Dp Primitive diameter (mm);
$\mathrm{E}_{0} \quad$ Energy activation;
$\mathrm{E}$
Equivalent Young's Modulus;
E' Coefficient of elasticity;
$\mathrm{F}_{\mathrm{a}} \quad$ Force adhesion;
$\mathrm{F}_{\mathrm{t}} \quad$ Tangential friction force $(\mathrm{N})$;
$\mathrm{F}_{\mathrm{n}} \quad$ Normal load force $(\mathrm{N})$;
G Material parameter;
$\mathrm{H}_{0} \quad$ Central film thickness center for point contacts;
H kinematic viscosity at $98.9^{\circ} \mathrm{C}$ at Appendix A (ASTMD2270);
I Contact length (mm);
L k kinematic viscosity at $98.9^{\circ} \mathrm{C}$ at Appendix A (ASTMD2270);
L Thermal parameter
m Piezoviscosity coefficient by Gold et al. (2001);
n Piezoviscosity coefficient by Gold et al. (2001);
n $\quad$ Engine speed (rpm);
K Thermal conductivity;
$\mathrm{K}_{b} \quad$ Boltzmann constant;
Pin Input power;
Pout Output power;
$\mathrm{P}_{\mathrm{V}} \quad$ Power loss;
$\mathrm{P}_{\mathrm{VZ} 0} \quad$ load-dependent loss;
$\mathrm{P}_{\mathrm{VZP}} \quad$ load-independent loss;
$\mathrm{P}_{\mathrm{VL}} \quad$ Rolling bearing loss; 


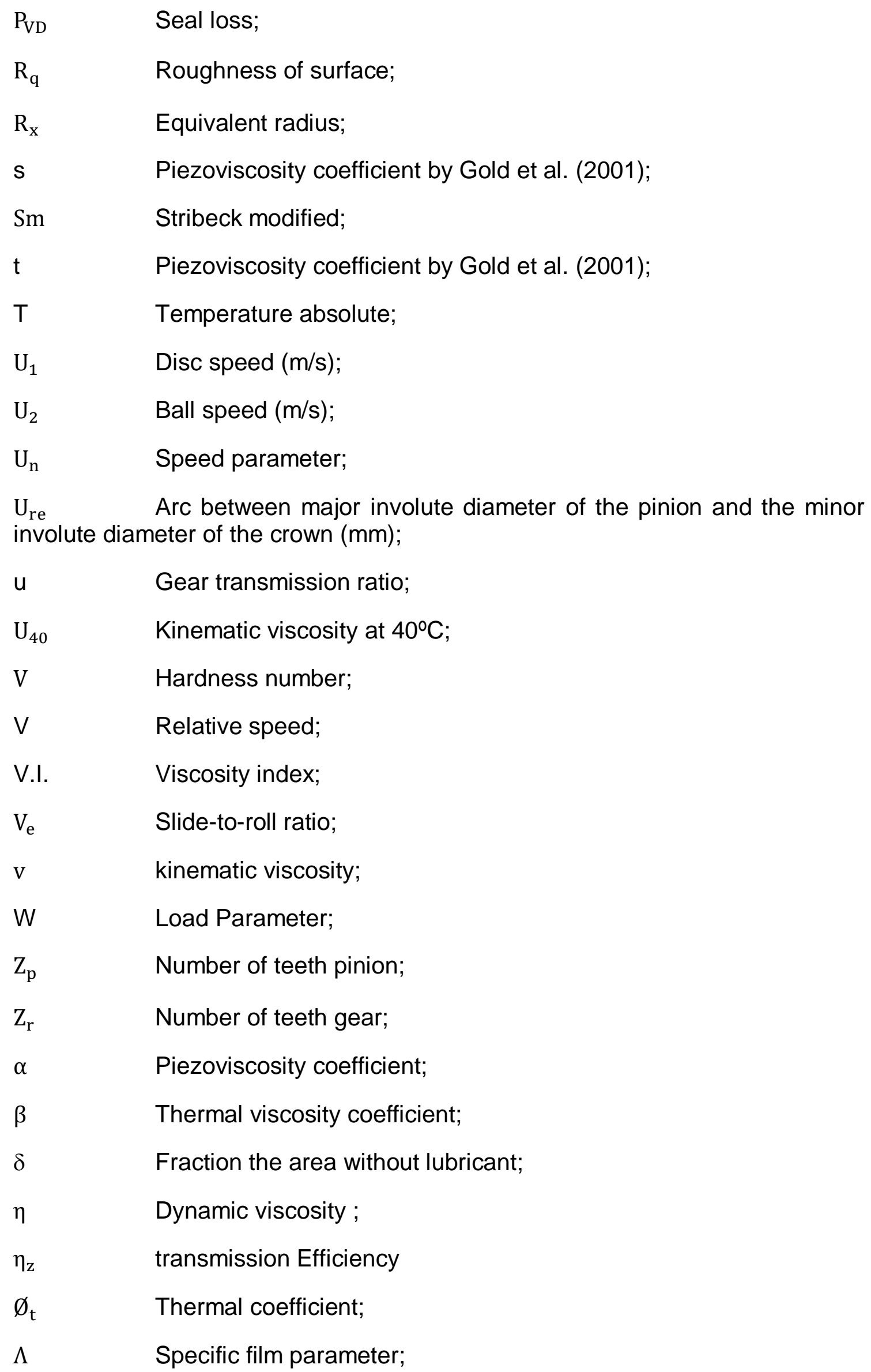


Friction coefficient;

v

Poisson ratio;

$\mathrm{k}$

Ellipticity number;

$\bar{\sigma}$

Dimensionaless surface roughness;

$\sigma$

Average roughness of the disc and ball system;

$\tau$

Shear stress;

$\tau_{1}$

Shear stress lubricated;

$\tau_{\mathrm{a}} \quad$ Shear stress for dry contact; 


\section{ABBREVIATIONS}

$\begin{array}{ll}\text { FM } & \text { Friction modifiers } \\ \text { AW } & \text { Antiwear } \\ \text { ZnDDP } & \text { Zinc dialkyldithiophosphate } \\ \text { EP } & \text { Extreme pressure } \\ \text { EDS } & \text { Energy Dispersive X-ray Spectrometer } \\ \text { FTIR } & \text { Fourier Transform Infrared Spectroscopy } \\ \text { VM } & \text { Viscosity modifier } \\ \text { SEM } & \text { Scanning electron microscope } \\ \text { SRR } & \text { Slide-to-roll ratio } \\ \text { SPD } & \text { Speed (m/s) } \\ \text { COF } & \text { Coefficient of Friction } \\ \text { S1 } & \text { Synthetic lubricant SAE 75W } \\ \text { S2 } & \text { Synthetic lubricant SAE 75W80 } \\ \text { M1 } & \text { Mineral lubricant SAE 80W }\end{array}$




\section{SUMMARY}

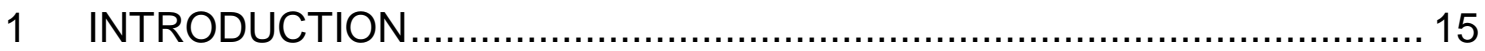

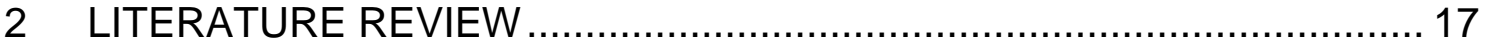

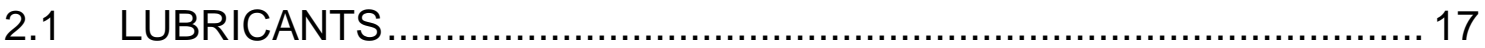

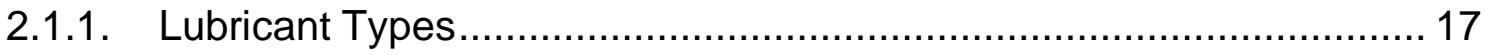

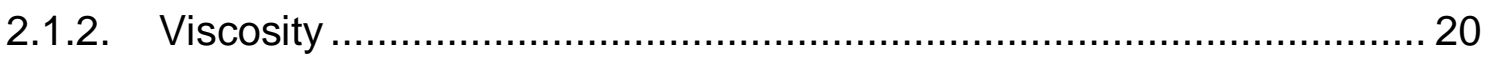

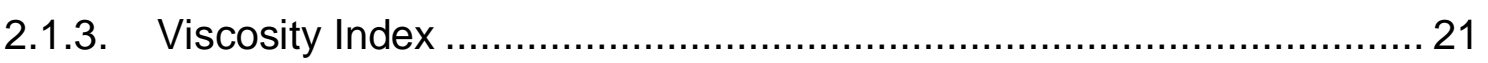

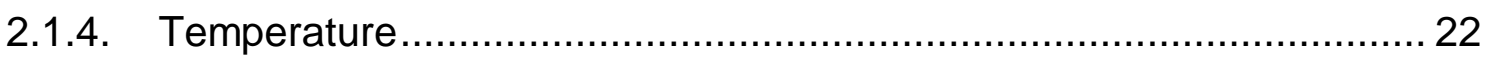

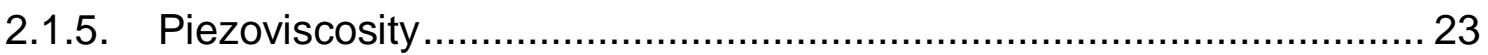

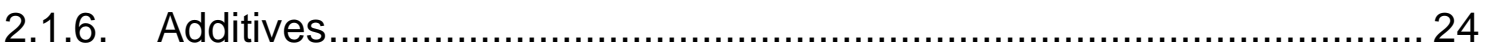

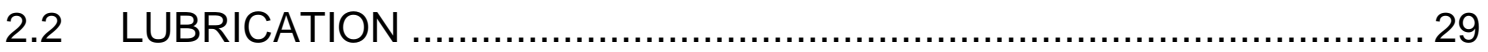

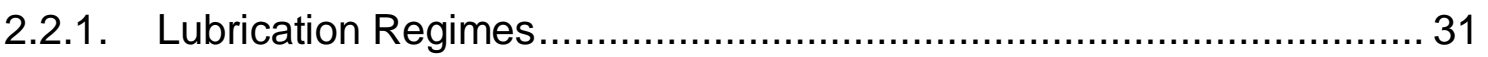

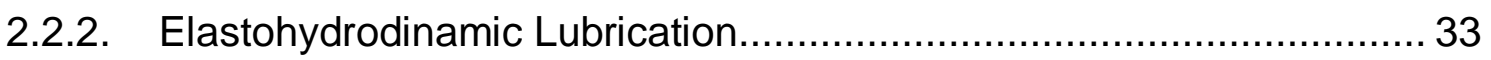

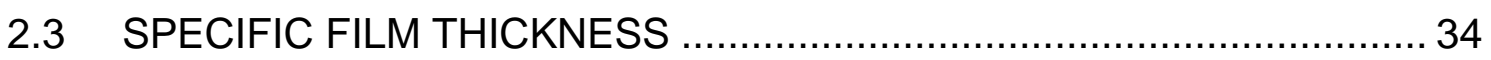

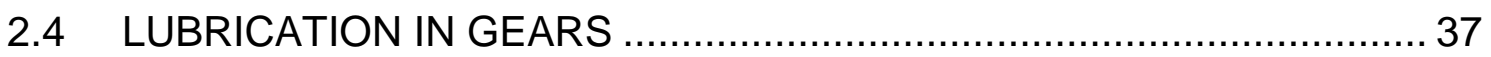

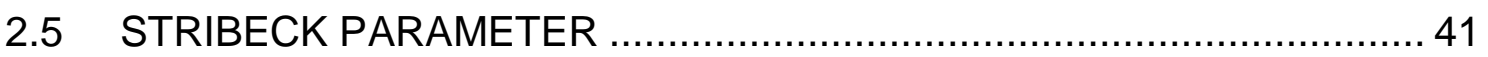

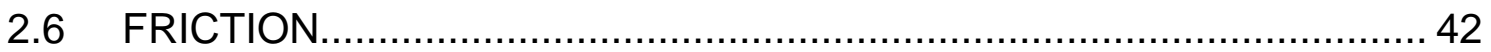

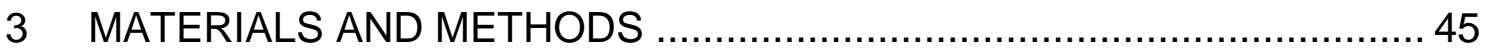

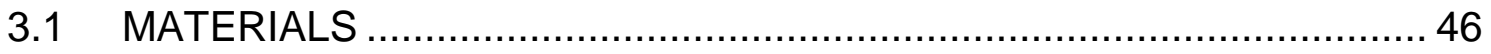

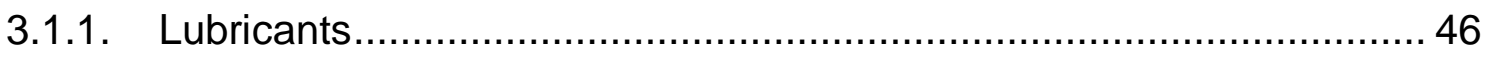

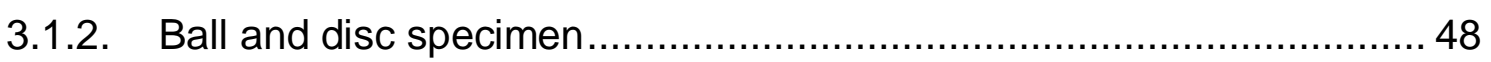

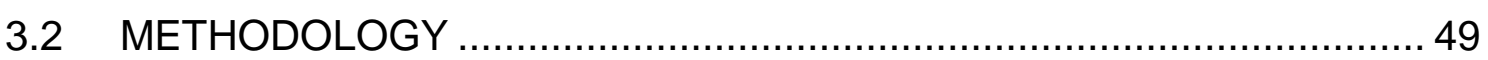

3.2.1. Test parameter definition for ball on disc tests ................................. 49

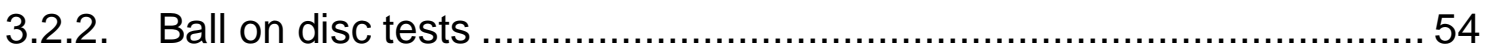

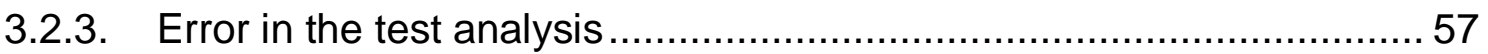

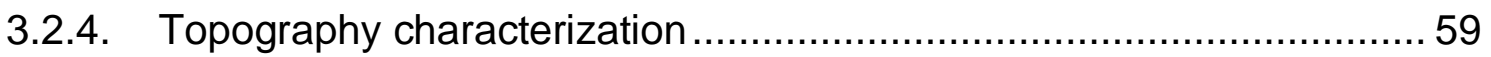

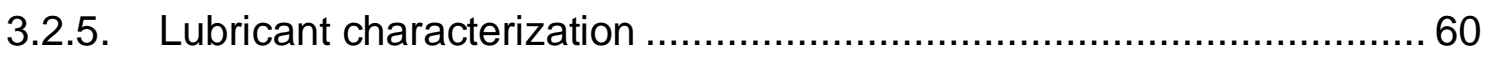

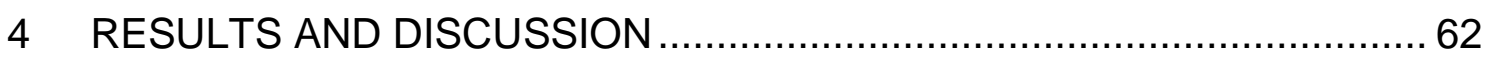

4.1 CHARACTERIZATION OF THE SURFACE TOPOGRAPHY .................. 62

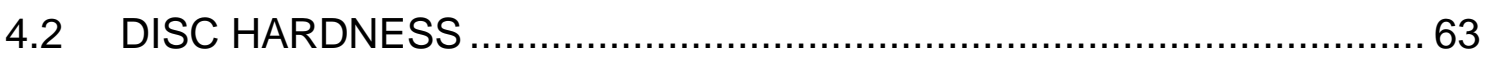

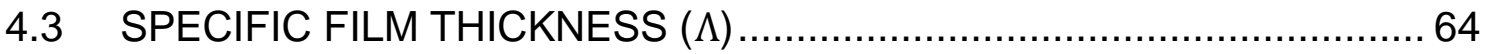

4.4 RESULTS OF CHEMICAL ANALYSIS OF LUBRICANTS …................. 67

4.5 TRIOBOLOGICAL RESULTS - STARVED CONDITION.......................... 69

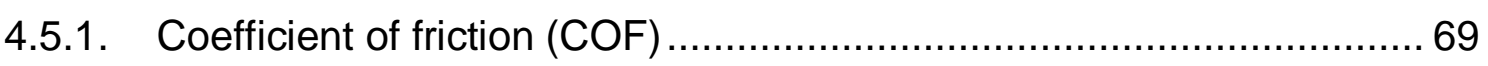

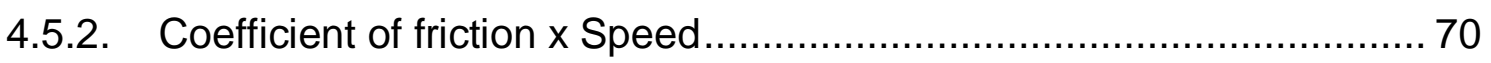


4.5.3. Coefficient of friction $\times$ Specific film thickness ................................... 73

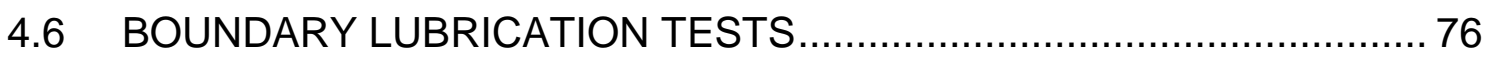

4.7 TRIOBOLGICAL RESULTS - FULLY FLOODED CONDITIONS............. 79

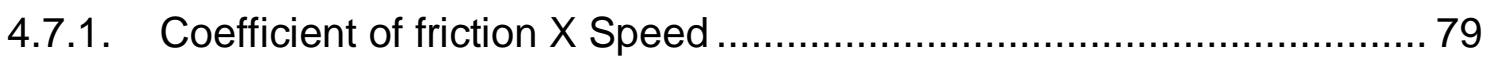

4.7.2. Coefficient of friction $X$ Specific film thickness.................................. 83

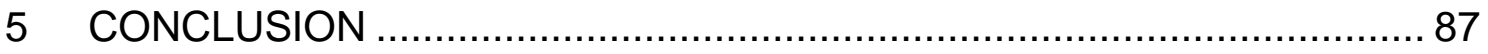

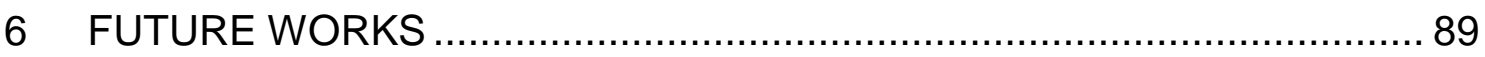

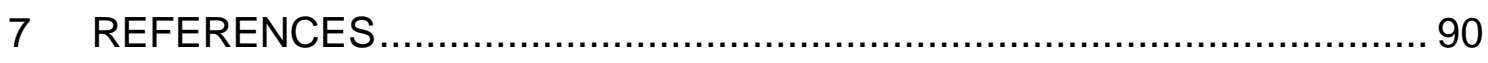




\section{INTRODUCTION}

Literature shows that one third of the fuel energy in a vehicle is lost due to friction since it is responsible for the dissipation and the loss of energy in moving machinery (ASM - Handbook, Vol. 18, 1992). In an automotive transmission system, the energy consumed to overcome friction is: i) $20 \%$ viscous losses in gear contacts, synchronizers and bearings; ii) $55 \%$ to overcome friction in gears; iii) $20 \%$ in bearings; iv) and the last $5 \%$ are related to the losses in seals and forks. Therefore, total transmission losses are about $5 \%$. Thus, an input power has to be continually provided in order to maintain the sliding motion. In addition, part of the energy is also dissipated due to damage, which will result in the wear of the sliding surfaces (HOLMBERG; ANDERSSON; ERDEMIR, 2014).

Regarding the friction losses, an increasing effort has been made to improve the efficiency in powertrain systems for vehicles. One of the features assessed is related to the evaluation and selection of lubricants. Lubricants used in vehicle transmissions provide a fluid film between components such as: gears, bearings, seals, forks, etc. They will assure the solid contact will be avoided and the wear will be reduced and, hence on improving efficiency and component fatigue, life enhancement is expected (LECHNER; NAUNHEIMER, 1999). Consequently, tribological studies have been carried out to control friction, improve the lubricant performance, and with the surface phenomena that occurs during the contact of steel-steel parts (BHUSHAN, 2013; TORBACKE, RUDOLPHI, KASSFELDT, 2014).

Emissions requirements are also important and, in addition to economic aspects, a Brazilian program denominated "Inovar Auto" has the objective of improving efficiency by different tax benefits. It is available in: < (http://inovarauto.mdic.gov.br/InovarAuto/public/inovar.jspx?_adf.ctrlstate=mlnvqo8m7_9) $>$. Accessed on 10/10/2016.

Regarding the improvement in the transmission efficiency, the objective of this study is to evaluate the behavior of coefficient of friction simulating a contact gear using a ball-on-disc device and three different lubricants throughout tribological tests. Lubricants are: i) two synthetics and, ii) one mineral with the same reference class, but with different viscosity index, viscosity and viscosity class. 
The specific objective of this work is to carry out ball-on-disc tribometer tests using sliding movement. Tests are carried out under different conditions such as: loads, temperatures and speeds by using the three selected lubricants. Disc samples were made and manufactured at the same thermochemical treatment and manufacturing steps of a regular gear. Therefore, the disc has the same hardness profile and microstructural features in the contact region of transmission gears. Moreover parameters of the tests were also determined to simulate conditions of the contact during the gears engagement as described in the Materials and Methods chapter.

This dissertation will be divided into the following chapters:

- Review of literature - At this point, it will be discussed lubricant types and properties, additives, lubrication regime, lubrication in gear contact, specific film thickness, Stribeck parameter and friction.

- Materials and Methods - In this chapter the lubricants, ball and disc specimen properties used, as well as the methodology to define the test parameters, will be discussed. The equipment and test conditions were also described.

- Results and discussion - In this chapter, the relationship between the friction coefficient and specific film thickness for each condition will be presented and discussed. These results display the oil performance at different temperatures, speeds and loads. The lubricant conditions are also discussed: i) starved and ii) fully flooded.

- Finally, the Conclusions, Future works and References are presented. 


\section{LITERATURE REVIEW}

Lubricating oils and prospective alterations in features of automotive transmission systems to improve their efficiency are the main points of this study. Friction, lubrication and gear contact concepts and definitions are presented through this chapter and they will be used later on in the results and discussion.

\subsection{LUBRICANTS}

The lubricant is made by using a mixture of two or more components, generally denominated as base stocks. Petroleum-derived lubricating oil is the most used lubricant base, although nowadays the quantity of other chemical fluids is increasing, such quantities are partial or total in the case of synthetic oil. (CAINES; HAYCOCK, 2004). The basic functions of a lubricant are: to reduce friction and prevent wear. Despite the continuous degradation of the lubricant, it holds other functions to fulfill. The automobile and engine manufacturer has listed at least another 40 properties required for engine/transmission oil (CAINES;HAYCOCK, 2004). Lubricants such as hydraulic or transmission oils will add other properties (LECHNER; NAUNHEIMER, 1999).

There are many different lubricants available in the market to fulfill most of applications. These lubricants are verified, analyzed and tested during their development as well as tested to assure quality by controlling new and used lubricant oils (TORBACKE; RUDOLPHI; KASSFELDT, 2014).

\subsubsection{Lubricant Types}

\section{Mineral Oil}

A detailed analysis of crude oil revealed 125 different compounds, of which only 45 have been analyzed in detail. The major parts of mineral oil consist of hydrocarbons with approximately 30 carbon atoms in each molecule. There are also many other compounds present in mineral oils such as waxes, which are nearly useless and can easily be oxidized to form organic acids. Consequently, 
special additives are needed to neutralize these waxes and related compounds (STACHOWIAK; BATCHELOR, 2013, KIMURA; OKABE, 1982).

Mineral oils differ from each other depending on the source of the crude oil and the refining process. The fundamental differences between mineral oils are based on: chemical forms, sulfur contents and viscosity. Figure 1 shows different types of mineral oil chains: straight and branched paraffinic, naphthenic and with aromatic components (STACHOWIAK; BATCHELOR, 2013).
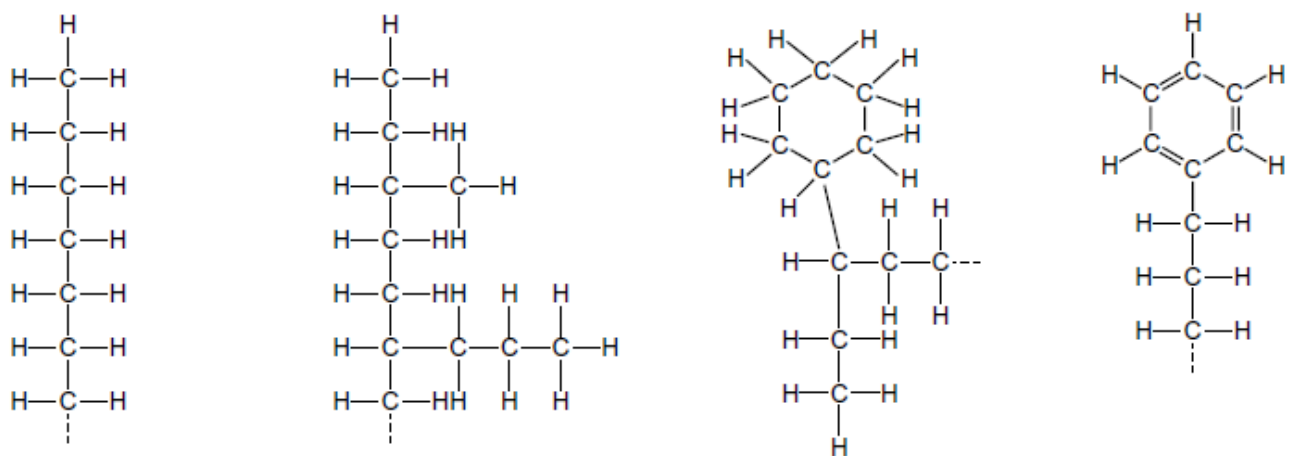

Figure 1 - Chain of mineral oils: a) straight paraffin, b) branched paraffin, c) naphthene, and d) aromatic, adapted from Stachowiak;Batchelor (2013).

It was mentioned above, that sulfur content in mineral oils differs, depending on the source of the crude oil and the refining process. Small amounts of sulfur in the oil are desirable to give better lubrication and oxidation properties. Although, the excess of sulfur can be removed from the oil by refining, this procedure can be expensive (STACHOWIAK; BATCHELOR, 2013).

Another way to classify mineral oil is by the viscosity, which depends on the degree of refining. For commonly used mineral oils, viscosity varies from about 5 [cSt] to 700 [cSt] at room temperature (STACHOWIAK; BATCHELOR, 2013).

\section{Synthetic oil}

Synthetic lubricants were originally developed in the early twentieth century to supply mineral oil. The use of synthetic oils has increased gradually, 
especially in more specialized applications for which mineral oils are insufficient, since mineral oils present more oxidation, viscosity loss at high temperatures and, solidification at low temperatures. Conversely, mineral oil is relatively low cost. Additionally, an increasing demand for high performance lubricants is ongoing, especially for applications in the aviation industry with high performance gas turbine engines. This led to the development of synthetic lubricants that can resist to high temperatures without decomposing and at the same time will provide a reduced fire hazard. (STACHOWIAK; BATCHELOR, 2013).

\begin{tabular}{|c|c|c|}
\hline \multirow{4}{*}{ 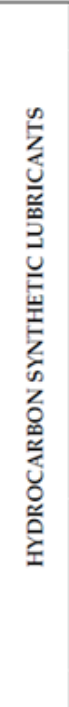 } & Polyalphaolefins e.g. & $\left(-\mathrm{CH}_{2}-\mathrm{CH}_{2}-\mathrm{CH}_{2}-\mathrm{CH}_{2}-\mathrm{ln}_{1}--\mathrm{CH}_{2}-\mathrm{CH}_{2}-\mathrm{CH}=\mathrm{CH}_{2}\right.$ \\
\hline & $\begin{array}{l}\text { ESTERS E.G. } \\
\text { - Diesters e.g. } \\
\text { - Phosphate esters e.g. } \\
\text { - Silicate esters e.g. } \\
\text { - Polyglycol esters e.g. } \\
\text { - Fluoro esters e.g. } \\
\text { - Fatty acid esters e.g. } \\
\text { - Neopentyl polyol esters e.g. }\end{array}$ & 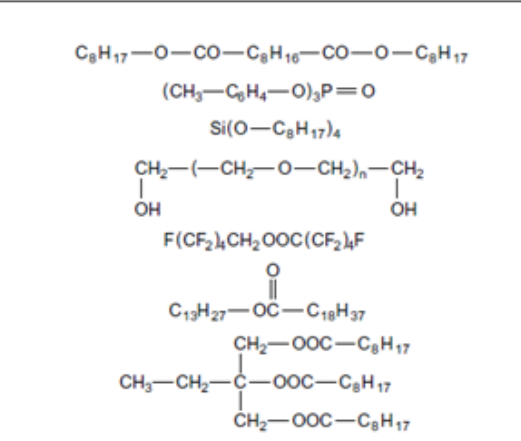 \\
\hline & Cycloaliphatic e.g. & \\
\hline & Polyglycols e.g. & $\mathrm{CH}_{3}-\mathrm{O} \cdots \mathrm{CH}_{3}-\mathrm{CH}_{3}-\mathrm{OH}$ \\
\hline \multirow{2}{*}{ 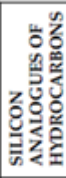 } & Silicones e.g. & 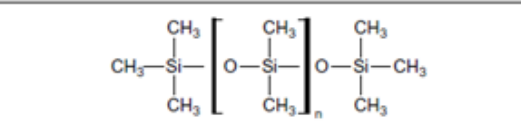 \\
\hline & Silahydrocarbons e.g. & $\left(\mathrm{C}_{12} \mathrm{H}_{25}\right) \mathrm{Si}_{\mathrm{i}}\left(\mathrm{C}_{6} \mathrm{H}_{13}\right)_{3}$ \\
\hline 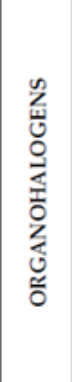 & $\begin{array}{l}\text { Perfluoropolyethers e.g. } \\
\text { Chlorofluorocarbons e.g. } \\
\text { Chlorotrifluoroethylenes e.g. } \\
\text { Perfluoropolyalkylethers e.g. }\end{array}$ & $\begin{array}{c}\mathrm{Cl}\left[\begin{array}{cc}\mathrm{C} & \mathrm{C} \\
-\mathrm{C} & \mathrm{C} \\
\mathrm{I} & \mathrm{l} \\
\mathrm{F} & \mathrm{F}\end{array}\right]_{0}^{\mathrm{Cl}} \\
\mathrm{F}-\left[\begin{array}{cc}\mathrm{F} & \mathrm{Cl} \\
1 & 1 \\
\mathrm{C} & \mathrm{C} \\
\mathrm{C} & \mathrm{C} \\
\mathrm{C} & 1\end{array}\right] \mathrm{O}-\mathrm{C}-\mathrm{CF}_{3}\end{array}$ \\
\hline
\end{tabular}

Figure 2 - Common chemical structure of synthetic oils - Different types, adapted from Stachowiak; Batchelor (2013).

There are three basic types of synthetic lubricant currently in use (Figure 2):

- Synthetic hydrocarbon lubricants,

- $\quad$ Silicon analogues of hydrocarbons,

- Organohalogens. 
Synthetic hydrocarbons made it possible to obtain a lubricant that is similar in price to mineral oil but has superior performance. Silicon analogues or silicones are resistant to extreme temperatures and vacuum on one side, but do not provide good adsorption or extreme-pressure lubrication and are expensive. Finally, the organohalogens can offer effective lubrication by adsorption and extreme-pressure lubrication mechanisms and resist extreme temperatures or chemical attack (STACHOWIAK; BATCHELOR, 2013).

\subsubsection{Viscosity}

According to ASM (1992), viscosity can be defined as the degree to which withstands a fluid flow and it is the most important property of the fluid. Viscosity relates directly to the lubricant's ability to separate the surfaces in contact and it can be correlated with other performance characteristics.

The other feature related to the viscosity of a fluid is the resistance of molecules sliding over one another (Figure 3). This resistance force may be calculated by Newton's formula on the laminar flow of a fluid between a moving surface at a velocity $V$ and a fixed surface (SEABRA; CAMPOS; SOTTOMAYOR, 2002).

Both surfaces of the different fluid film will move at speeds varying between 0 and $V$. If the distance $y$ from the fixed surface is related to the fluid velocity which is related to $v+d v$, then the tangential stress $\sigma_{x y}$, often referred to as shear stress and represented by $\tau$, is given by equation 01 :

$$
\sigma_{x y}=\tau=\eta \frac{d v}{d y}
$$

Where $\eta$ is the dynamical viscosity. 


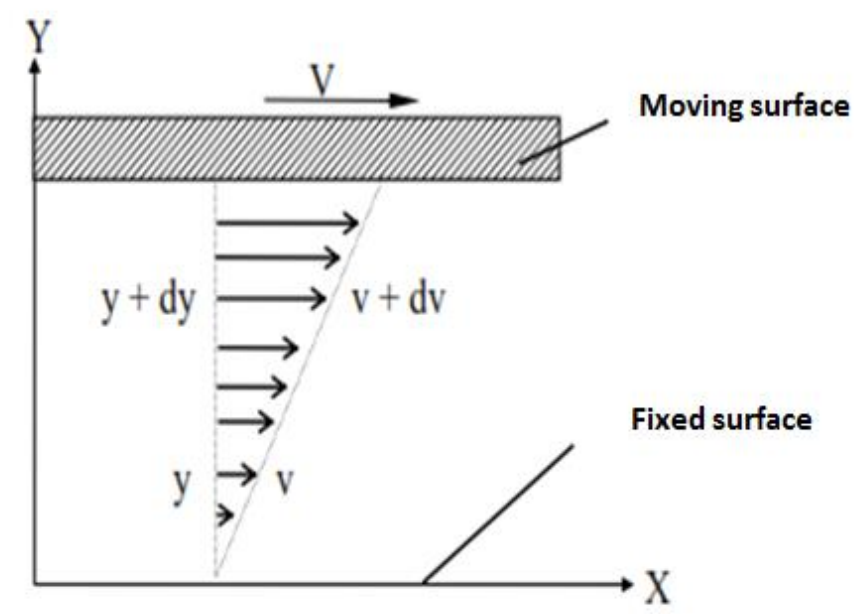

Figure 3 - Schematic of fluid viscosity - Adapted from Seabra, Campos and Sottomayor (2002)

According to ASM Handbook (1992) the dynamic viscosity unit in the international system (SI) is the Pascal-second (Pa.s). In the system C.G.S, the dynamic viscosity unit is the Poise (Po). Units commonly used for oils are the millipascal-second (mPa.s) and centipoise (cPo). Table 1 summarizes the viscosity units:

Table 1 - Dynamic and kinematics viscosity units, ASM Handbook (1992)

\begin{tabular}{|c|c|c|c|c|}
\hline Viscosity & Dimension & C.G.S & S.I & Comparison \\
\hline$\eta$ dynamic & $M L^{-1} T^{-1}$ & $\begin{array}{c}\text { Poise } \\
P_{0}=\frac{g}{c m} . s\end{array}$ & $\begin{array}{c}\text { Pascal } \\
\text { Segundo } \\
\text { Pa.s }=\frac{K g}{m} . s\end{array}$ & $1 c P_{0}=1 \mathrm{mPa} . \mathrm{s}$ \\
\hline $\begin{array}{c}v \\
\text { kinematics }\end{array}$ & $L^{2} T^{-1}$ & Stokes $=\mathrm{cm}^{2} / \mathrm{s}$ & $\mathrm{m}^{2} / \mathrm{s}$ & $1 c S t=1 \mathrm{~mm}^{2} / \mathrm{s}$ \\
\hline
\end{tabular}

\subsubsection{Viscosity Index}

The viscosity index is necessary to specify how the behavior of various types of oils is influenced by the temperature. The most common method was proposed by Stachowiack apud. Dan and Davis in 1929. These authors classified lubricants of different categories according to the values of kinematic viscosity at 
$98.9^{\circ} \mathrm{C}$. Among all the oils of the same viscosity at $98.8^{\circ} \mathrm{C}$, they separated two oils with lower and higher viscosity at $37.8^{\circ} \mathrm{C}$.

Figure 4 shows the line $100 \mathrm{VI}$, which corresponds to paraffinic oil, whose viscosity varies little with temperature. The line $0 \mathrm{VI}$ corresponds to a naphthenic oil, whose viscosity is highly temperature dependent. Arbitrarily, it was assigned 100 to the first and zero to the second, respectively. The viscosity index (VI) of intermediate oil, between 0 and 100, can be calculated by the equation (02):

$$
\text { V.I. }=\frac{L-U_{40}}{L-H} \cdot 100
$$

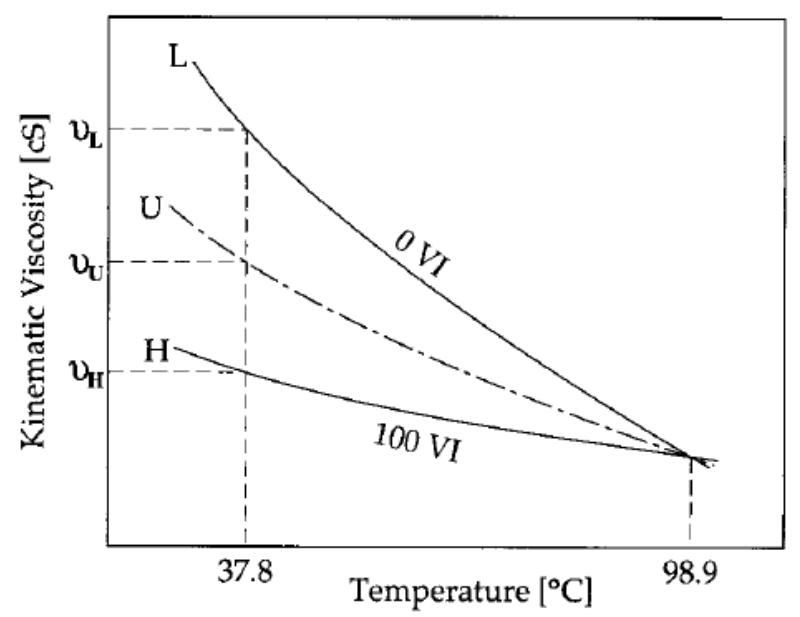

Figure 4 - Kinematic viscosity $x$ temperature define the Index Viscosity curve (STACHOWIAK; BATCHELOR, 2013)

Where $L$ and $H$ are the reference for oil viscosities at $98.9^{\circ} \mathrm{C}$ and they can be determined using the Table of Appendix A (ASTM D2270), and $U$ is the viscosity at $37.8 \stackrel{\circ}{\circ}$.

\subsubsection{Temperature}

The viscosity of mineral and synthetic oils decreases when the temperature increases. In the case of water, this variation is around $2.5 \%$ per $C$ near to $20^{\circ} \mathrm{C}$, reaching 15 to $20 \%$ per ${ }^{\circ} \mathrm{C}$ for mineral oils (SEABRA; CAMPOS; SOTTOMAYOR, 2002). Figure 5 shows an example of the viscosity of a paraffinic mineral oil as a function of temperature variation. 


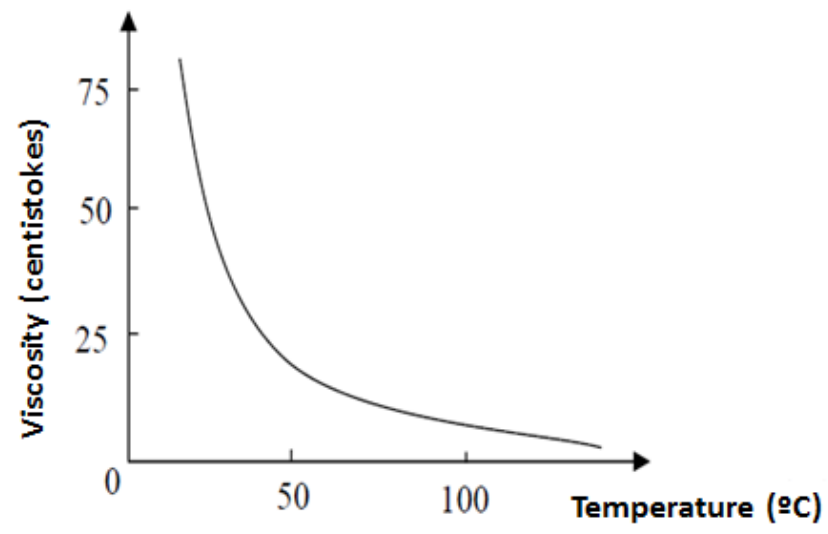

Figure 5 - Viscosity $X$ Temperature, temperatures below $50^{\circ} \mathrm{C}$ leads to a higher increase of viscosity - Seabra, Campos and Sottomayor (2002)

\subsubsection{Piezoviscosity}

The piezoviscosity coefficient ( $\alpha$ ) was evaluated by Gold et al. (2001), where empirical formulas were developed (see equation 03 and 04 ) :

$$
\begin{aligned}
& \alpha=m \ln (v)+n \\
& \alpha=s \cdot v^{t}
\end{aligned}
$$

The coefficients $\mathrm{m}, \mathrm{n}, \mathrm{s}$ and $\mathrm{t}$ are displayed in Table 2; they usually vary with the lubricant type.

Table 2 - Piezoviscosity Parameters calculated by Gold et al. (2001)

\begin{tabular}{|c|c|c|c|c|c|c|c|c|}
\hline & \multicolumn{5}{|c|}{$0.2 \mathrm{GPA}$} & \multicolumn{5}{c|}{$0.6 \mathrm{GPA}$} \\
\hline Oil type & $\mathrm{m}$ & $\mathrm{N}$ & $\mathrm{S}$ & $\mathrm{T}$ & $\mathrm{m}$ & $\mathrm{n}$ & $\mathrm{s}$ & $\mathrm{T}$ \\
\hline $\begin{array}{c}\text { Naphtenic } \\
\text { mineral }\end{array}$ & 0.471 & 0.738 & 1.2517 & 0.1803 & 0.496 & 0.559 & - & - \\
\hline $\begin{array}{c}\text { Paraffinic } \\
\text { mineral (M) }\end{array}$ & 0.252 & 0.746 & 0.9904 & 0.1390 & 0.223 & 0.616 & 0.8097 & 0.1534 \\
\hline Polyalphaolefin & 0.197 & 0.473 & 0.7382 & 0.1335 & 0.108 & 0.612 & 0.7008 & 0.0984 \\
\hline $\begin{array}{c}\text { Rapidly } \\
\text { biodegradable } \\
\text { ester (ES) }\end{array}$ & 0.164 & 0.496 & 0.6605 & 0.1360 & 0.109 & 0.513 & 0.5897 & 0.1173 \\
\hline $\begin{array}{c}\text { Polyethylene } \\
\text { (SI) }\end{array}$ & 0.168 & 0.329 & 0.5489 & 0.1485 & 0.097 & 0.495 & - & - \\
\hline & 0.751 & -1.61 & 0.4104 & 0.3208 & - & - & - & - \\
\hline
\end{tabular}


The variation of viscosity with pressure is an exponential factor (see equation 04), and this behavior depends on the nature of the lubricant. This phenomenon is important for some practical applications such as bearings and gears, whose pressures in use can reach $10^{9} \mathrm{~Pa}$ (SEABRA; CAMPOS; SOTTOMAYOR, 2002).

Since the viscosity-pressure coefficient for mineral and synthetic lubricating oils decreases with temperature, and increases with viscosity in atmospheric pressure, the Piezo viscosity is given by equation 03 and 04 . Changing to another higher viscosity lubricant will increase the Piezoviscosity. By decreasing the temperature, the viscosity will increase and, consequently, the Piezoviscosity will also increase. Both variables have a similar impact without changing the base oil. Figure 6 presents values for different oils (GOLD et al., 2001).

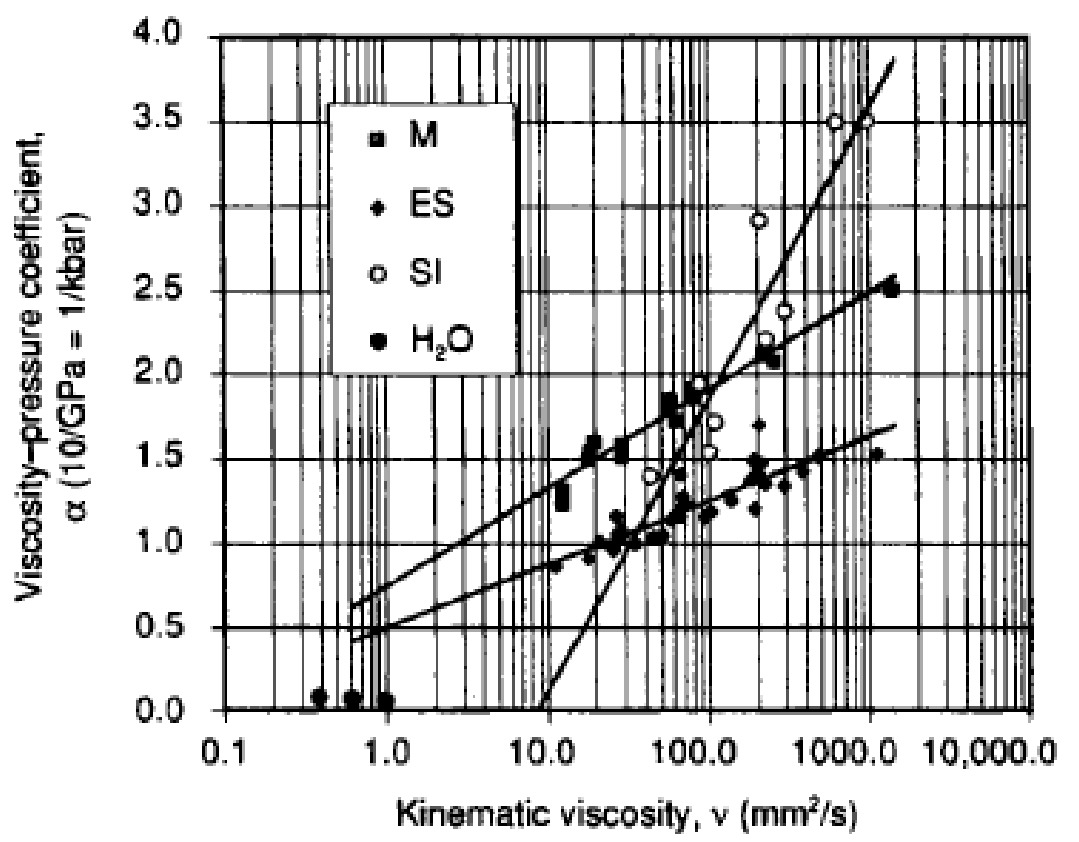

Figure 6 - Viscosity x Piezoviscosity for different oils (GOLD et al., 2001). Table 02 describes the different types of oil (M, ES and SI).

2.1.6. Additives 
It was mentioned previously; the base fluid holds properties to reduce friction and wear. However, the base fluid by itself will not cover all requirements, thus additives which improve wear and friction properties are already used in oil formulation. The use of additives gained general acceptance in the 1940s. (STACHOWIAK; BATCHELOR, 2013).

Lubricant additives are nearly always organic or organometallic chemical composition, that are added to oils in quantities of a little weight percent to improve the lubricating capacity and durability of the oil. (STACHOWIAK; BATCHELOR, 2013). They are mainly added to the base fluid to enhance the viscosity index and the pour point; the friction and wear properties under boundary and, mixed lubrication (TORBACKE; RUDOLPHI; KASSFELDT, 2014).

The surface active additives have a polar moiety and an oil-soluble hydrocarbon chain. The polar moiety is the active part of the additive. The hydrocarbon chain length determines the solubility of the additive in the lubricant. A long hydrocarbon chain allows for good solubility with the base fluid and short hydrocarbon chain is preferred for the additive to migrate in the base fluid and the surface active in the application (TORBACKE; RUDOLPHI; KASSFELDT, 2014).

Polarity is another important feature, it implies that the molecule is asymmetrical and has a different chemical affinity at both ends of the molecule. The polar part consists of nitrogen, oxygen, phosphorus and/or sulfur as shown in Figure 7.
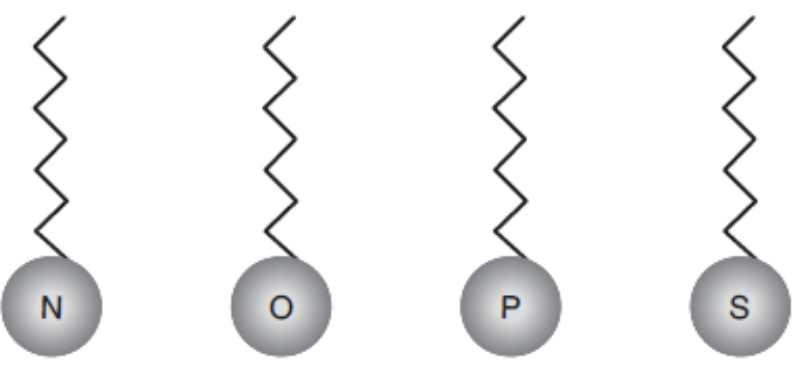

Figure 7 - Additives typically consist of nitrogen, oxygen, phosphorus and/or sulfur (TORBACKE; RUDOLPHI; KASSFELDT, 2014).

\section{Friction Modifiers}


Friction modifiers (FMs) are added to lubricants in order to modify friction in the mixed lubrication regime. FMs are usually added in a proportion of $1-3 \%$. They are active in the mixed lubrication at moderate temperatures and loads, but they will desorb at high temperatures and high loads. Friction modifiers adsorb in monolayers or multilayers. The FM molecules adsorb strongly to the surface than to neighborhood FM molecules (Figure 8). The FM layers are easily sheared and, thereby, reduce friction; this combination of strong and compressive properties and low resistance to shear gives FMs their superior properties (TORBACKE; RUDOLPHI; KASSFELDT, 2014, STACHOWIAK; BATCHELOR, 2013).

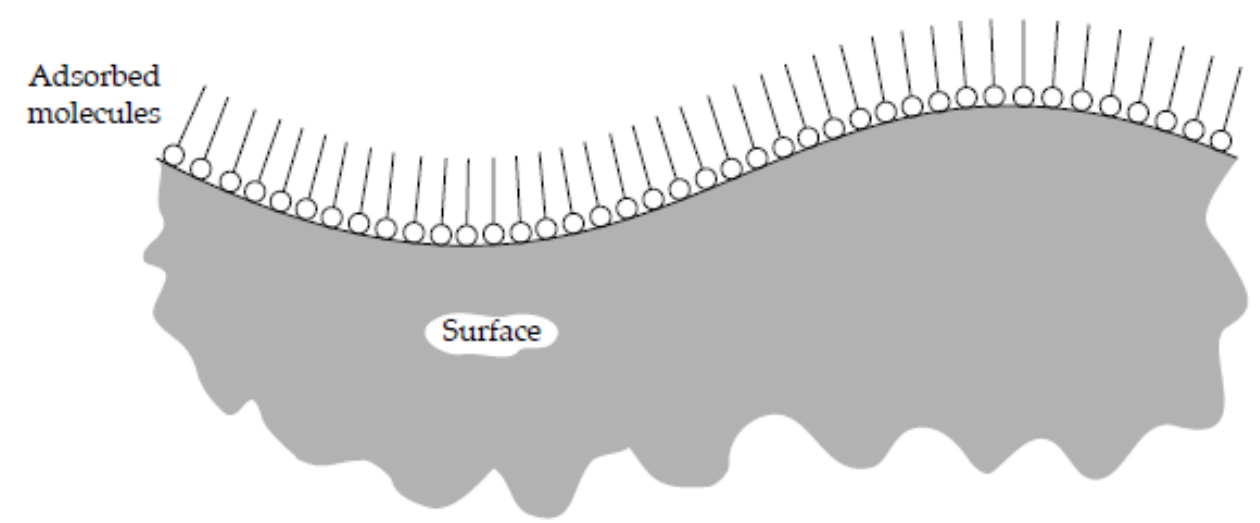

Figure 8 - Adsorption friction modifiers lubrication mechanism (STACHOWIAK; BATCHELOR, 2013).

The important characteristic of these additives is an unbranched chain of carbon atoms with sufficient length to ensure a stable and durable film. Specialized additives which combine adsorption or boundary properties with some other function, such as corrosion protection, are also used (STACHOWIAK; BATCHELOR, 2013).

\section{Antiwear additives}

Antiwear additives (AWs) act to modify the metal surface and, thereby reducing wear in the mixed/boundary lubrication regime. AW mainly chemisorb to the metal surfaces, offering durable wear protection of the surface in the mixed lubrication regime. They are active at higher temperatures and loads than the FMs, $1-3 \%$ by weight is usually added to AWs and, it has nitrogen, phosphorus 
and/or sulfur as its chemical composition. Phosphorus offers antiwear protection at relatively low loads. The most frequently used AW has been the ZnDDP (i.e. Zinc dialkyldithiophosphate), which is shown in Figure 9. ZnDDP is an important additive, frequently used in engine oil formulations. It was originally developed as an anti-oxidant and detergent, but it was found later that it can also act as an antiwear and mild extreme-pressure (TORBACKE; RUDOLPHI; KASSFELDT, 2014, STACHOWIAK; BATCHELOR, 2013).

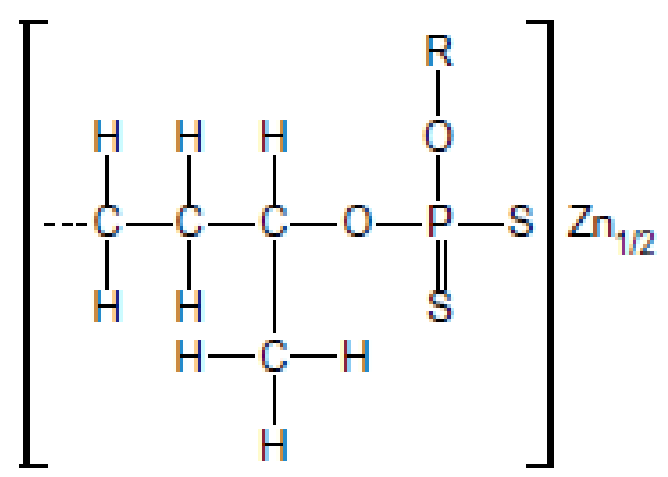

Figure 9 - Molecule structure of ZnDDP (STACHOWIAK; BATCHELOR, 2013).

ZnPPD additives are used to control wear and inhibit oxidation in almost all engine oils as well as many other types of lubricant. They limit wear primarily by forming a thick, protective, and phosphate glass-based tribofilm on rubbing surfaces. This film formation can occur at low temperatures and is relatively indifferent to the chemical nature of the substrate. There has been considerable debate as to what drives ZDDP tribofilm formation, why it occurs only on surfaces that experience sliding and whether the film formation is controlled primarily by temperature, pressure, triboemission or some other factor (ZHANG; SPIKES, 2016).

The shear stress present in a high-pressure contact can reduce the thermal activation energy for ZDDP by at least half, increasing the reaction rate. This mechanism explains the origins of many practically important features of ZDDP films. 
Quite recently, a few researchers have suggested that the reaction of ZDDP and other additives to form tribofilms may be driven directly by the shear stress present during rubbing. Since shear stresses are always present in rubbing contacts, the stress-promoted thermal activation concept has a particular relevance to Tribology. (ZHANG; SPIKES, 2016)

In the absence of an applied stress, the influence of temperature on the probability of molecules undergoing many physical and chemical processes is provided by the Boltzmann distribution to give an Arrhenius expression of the form in equation 05 :

$$
\text { Probability }=A e^{-E_{0} / K_{b} T}
$$

Where $E_{0}$ the activation energy in the process is, $K_{b}$ is the Boltzmann constant, $T$ is the absolute temperature, and $A$ is a pre-factor. (ZHANG; SPIKES, 2016)

\section{Extreme Pressure (EP) Additives}

Extreme pressure additives modify the surface in order to avoid scuffing and control wear in the boundary lubrication regime. They form protective low shear strength surface films that reduce friction and wear. There are mild EP and strong EP additives. Mild EPs require lower temperatures than the strong EPs to become activated. EP additives require higher activation temperatures, loads and shear rates than AWs (TORBACKE; RUDOLPHI; KASSFELDT, 2014).

EP additives chemisorb to surface. However, high temperatures, high loads and high shear in boundary lubrication will remove the hydrocarbon chains. Therefore, a reaction between the polar moiety and the surface metal will occur, for instance, sulfur polar moiety and iron surface forming iron sulfide (TORBACKE; RUDOLPHI; KASSFELDT, 2014).

Different chemistries are used for obtaining EP performance. They are all surface active with a polar moiety of nitrogen, phosphorus, sulfur and/or halogens, where phosphorus and primarily sulfur are predominant. Halogens are less widely used due to their poor environmental properties. Phosphorus EP additives react with the metal surface, forming a metal phosphate. The 
phosphorus additives require higher temperatures than sulfur additives to form a protective layer (TORBACKE; RUDOLPHI; KASSFELDT, 2014).

The action of these surface active additives is presented in Figure 10. In the mixed lubrication regime both FMs and AWs are active, which can give rise to a competition for available surface. However, at increased loads FMs are removed, promoting adsorption of primarily AWs. EP additives require even more severe conditions to be activated, such as high temperatures and high loads, to react with the iron surface. This is the situation in the boundary lubrication regime (TORBACKE; RUDOLPHI; KASSFELDT, 2014).

The following topics demonstrate the concept and formulation of film parameter and their importance to define lubrication regimes.

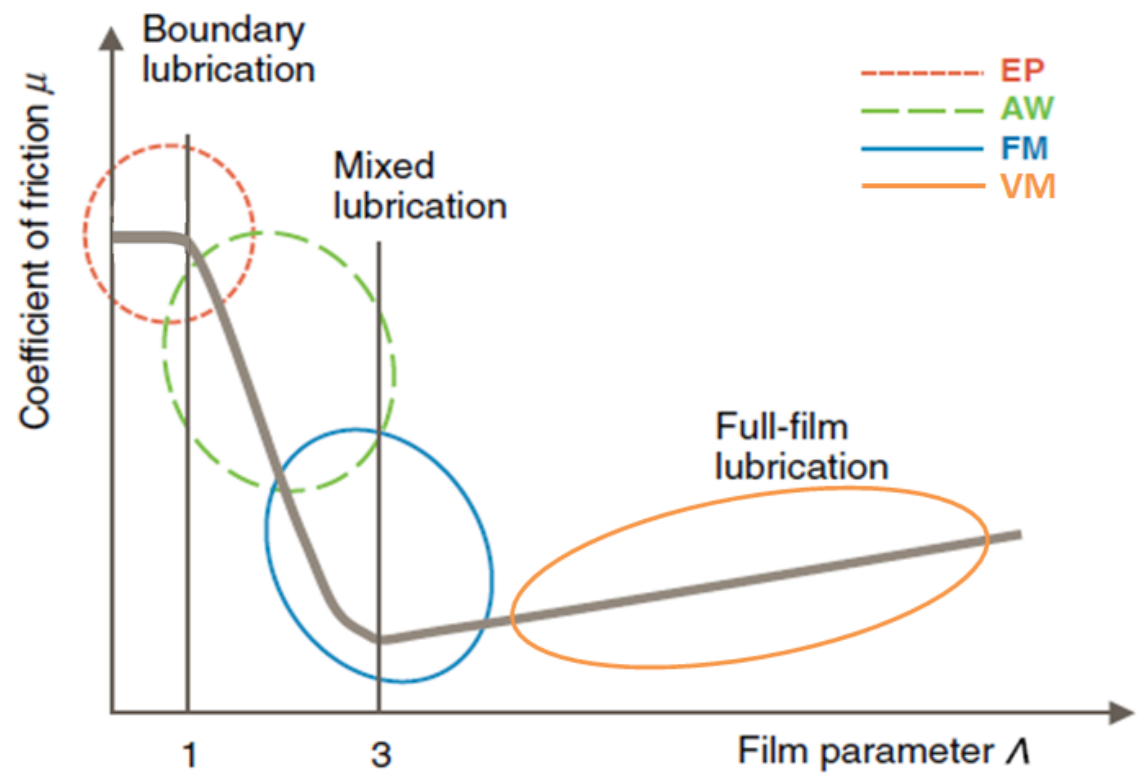

Figure 10 - Lubrication regimes where EP, AW and FM are actives (TORBACKE; RUDOLPHI; KASSFELDT, 2014).

\subsection{LUBRICATION}

Lubricants have several functions in tribological systems. The main purpose of lubricants is to control friction and wear; however the lubricants have other functions such as (LECHNER; NAUNHEIMER, 1999):

- Separate moving parts;

- Transfer heat; 
- Transfer power;

- Prevent corrosion;

- Carry away contaminants and debris;

- Reduce noise and vibration.

The separation of moving parts is the key to reduce friction and avoid wear. In order to entirely separate the surfaces, the contact has to be transferred into the full film lubrication regime and, the lubricant film thickness has to exceed a minimum value. When a thin lubricant film separates the two surfaces in a sliding contact, moving closer to each other, an increase in the friction will result due to the contact. (TORBACKE; RUDOLPHI; KASSFELDT, 2014).

The two basic geometries for lubricated surfaces are conformal and counter formal (Figure 11). Conformal surfaces are usually found in sliding journal and trust bearings, machine guideways and, seals. In conformal bearings, surfaces are usually separated by a thick oil or gas film generated hydrodynamically by the surface velocities or hydrostatically by an externally pressurized lubricant. Lubrication of counter formal contacts occurs in an extremely small concentrated area known as the Hertzian conjunction. In these contacts, film thickness is very thin and it is of the same order as the surface roughness, and lubricant pressure is very high. Lubricant performance is affected strongly by the elastic deformation of the bearing surface. The lubricant film thickness and pressure and their distribution in the conjunction can be determined by elastohydrodynamic theories (ASM - HANDBOOK, Vol. 18, 1992). 


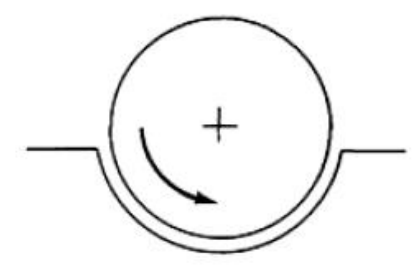

Conformal

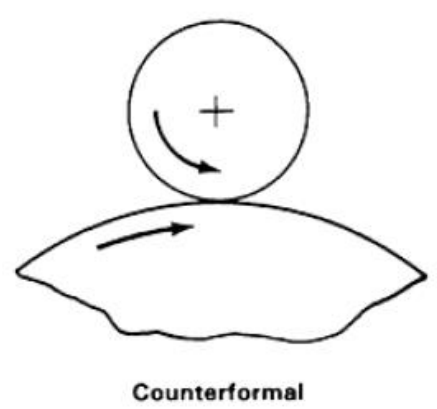

Figure 11 - Geometry of conformal and counter formal contacts (ASM - HANDBOOK, Vol. 18, 1992)

Lubrication in counter formal contacts is also influenced by the relationship between the sliding and the rolling speeds, which is known as the slide-to-roll ratio (SRR). The film thickness is generated primarily by the rolling velocity, which draws the lubricant into the conjunction. Sliding velocity has no effect on film generation unless the viscosity is reduced significantly by the heat generated by sliding. The friction and contact temperature in the conjunction is influenced strongly by the sliding velocity (ASM - HANDBOOK, Vol. 18, 1992).

Gears present counter formal contact and, therefore, this will be considered through this dissertation.

\subsubsection{Lubrication Regimes}

The counterformal contact, such as between gear teeth or a cam system, develops intense contacts in a very small area. Therefore, in these cases the local pressure between steel components typically ranges up to a little GPa (25). Under these conditions, the dependence of the lubricant viscosity on pressure plays an important role, as does the elastic deformation of the surfaces. Lubrication in these conditions is known as elastohydrodynamic (EHD) (HUTCHINGS, 1992). 


\section{Full Film lubrication}

In full film lubrication the solid bodies are lubricated by a thick film, which is enough to ensure a full separation between asperities. The friction coefficient is small and it depends on the lubricant viscosity. Full film lubrication is the most desired type of lubrication.

\section{Mixed Lubrication}

Mixed lubrication occurs due to the presence of small amounts of lubricant at the contact point. Direct contact of a body against the other body exists in the mixed lubrication regime, but this contact occurs in alternated areas having lubricated separating surfaces as described by Pirro and Wessol (2001), ASM(1992) and Hutchings(1992). Therefore, the mixed lubrication is characterized by dry and lubricated contact. In such lubrication, friction and wear are influenced by lubricant ability to create protective layers by chemical reactions on the friction surface. Friction levels will be halfway between hydrodynamic and boundary regimes.

\section{Boundary Lubrication}

With increased operating severity by decreasing speed and lower viscosity values, the lubrication becomes unable to generate an oil film to support the entire load. The contact surfaces of the body and the counter body collide into each other, generating plastic deformation and wear of materials in contact (KHONSARI; BOOSER, 2008).

According to ASM (1992) in boundary lubrication, the friction coefficient is insensitive to speed, viscosity and contact pressure for almost applications. The contact pressure is fully supported by the contact surfaces. The coefficient of friction values are between 0.1 and 0.15 for ferrous material surfaces. Three surface film types are commonly known to be effective boundary lubrication: physical adsorption, chemical absorption and chemical reaction. 


\subsubsection{Elastohydrodinamic Lubrication}

The friction behavior in a lubricated contact can be seen in Figure 10, where the dependence of the friction coefficient and specific film thickness $\Lambda$ is presented.

The specific film thickness $\Lambda$ is calculated as described in equation (06):

$$
\Lambda=\frac{H_{0}}{\sqrt{R_{q A}^{2}+R_{q B}^{2}}}
$$

Where $H_{0}$ is the center lubricant film thickness and $R_{q A}^{2}$ and $R_{q B}^{2}$ are the RMS surface roughness (combined) of the two surfaces $A$ and $B$, which are in contact. The contact is classified as boundary, mixed or full film lubricated depending on the contact between the solid surfaces, as described in Table 3. The determination of $H_{0}$ will be presented in the chapter 2.3. The main variables to determine the lubricant film thickness are: viscosity, speed, load, piezoviscosity, and material properties.

The values of $\Lambda_{0}$ and $\Lambda_{1}$ vary according to the application. Typical values for bearings and gears are presented in Table 4.

Table 3 - Lubrication regimes, full film, mixed and boundary lubrication as presented in Figure 13 EHD - (SEABRA; CAMPOS; SOTTOMAYOR, 2002)

\begin{tabular}{|c|c|c|}
\hline$\Lambda=\frac{H_{0}}{\sqrt{R_{q A}^{2}+R_{q B}^{2}}}$ & Regime & Observation \\
\hline$\Lambda>\Lambda_{1}$ & Full film & $\begin{array}{c}\text { Contact surfaces completely separate } \\
\text { by lubricant film. }\end{array}$ \\
\hline$\Lambda_{0}<\Lambda<\Lambda_{1}$ & Mixed film & $\begin{array}{c}\text { Contact surfaces partially separated by } \\
\text { lubricant film, occurring contacts at } \\
\text { some point between metal- metal. }\end{array}$ \\
\hline$\Lambda<\Lambda_{0}$ & $\begin{array}{c}\text { Boundary } \\
\text { film }\end{array}$ & $\begin{array}{c}\text { There is no lubricant film separating } \\
\text { the contact surfaces, predominating } \\
\text { contact metal vs. metal. }\end{array}$ \\
\hline
\end{tabular}


Table 4 - Typical lubrication regimes values for bearing and gears - (SEABRA; CAMPOS;

\begin{tabular}{|c|c|c|}
\hline$\Lambda=\frac{H_{0}}{\sqrt{R_{q A}^{2}+R_{q B}^{2}}}$ & Bearing & Gears \\
\hline Full film & $\Lambda>3$ & $\Lambda>2$ \\
\hline Mixed film & $1<\Lambda<3$ & $0.7<\Lambda<2$ \\
\hline Boundary film & $\Lambda<1$ & $\Lambda<0.7$ \\
\hline
\end{tabular}

\subsection{SPECIFIC FILM THICKNESS}

The first specific film thickness calculation was carried out by Hamrock and Dowson (1981). The specific film thickness is related to the RMS roughness of the surface tested. Khonsari and Masjedi (2014) proposed a new model considering the effect of surface roughness in a contact point to elastohydrodinamic lubrication and additionally to this formulation the author include the thermal coefficient.

The formulation of central film thickness was developed by Hamrock and Dowson's (1981):

$$
\begin{gathered}
\Lambda=\frac{H_{0}}{\sigma} \\
\mathrm{H}_{0}=\frac{\left(\mathrm{h}_{0}\right)}{R_{x}}=1.345 \cdot R_{x} \cdot C_{o} \cdot\left(\mathrm{U}_{n}\right)^{0.67} \cdot \mathrm{G}^{0.53} \cdot \mathrm{W}^{-0.067} \cdot \emptyset_{t} \\
\mathrm{C}_{0}=1-0.61 \cdot \exp \left(-0.752\left(\frac{R_{y}}{R_{x}}\right)^{0.64}\right)
\end{gathered}
$$

Where,

$\mathrm{H}_{0}$ is the central film thickness center for point contacts;

$\sigma$ is the composed RMS roughness

$C_{o}$ is ellipticity influence

The formulation of central film thickness was developed by Khonsari and Masjedi (2014); this formulation will be used on results to determine the specific film thickness: 


$$
\begin{gathered}
\Lambda=\frac{H_{0}}{\bar{\sigma}} \\
\left(\mathrm{H}_{0}\right)_{\text {smooth }}=\frac{\left(\mathrm{h}_{0}\right)_{\text {smooth }}}{R_{x}}=3.672 \mathrm{~W}^{-0.045 \cdot k^{0.18}} \cdot\left(\mathrm{U}_{n}\right)^{0.663 \cdot k^{0.025}} \\
. \mathrm{G}^{0.502 . k^{0.064}} \cdot\left(1-0.573 \cdot \mathrm{e}^{-0.74 . k}\right) \cdot \emptyset_{t}
\end{gathered}
$$

Where,

$\bar{\sigma}-$ is dimensionaless surface roughness

$\bar{\sigma}=\frac{\sigma}{R_{x}}$

$R_{x}-$ is the equivalent radius:

$$
\begin{gathered}
\mathrm{R}_{x}=\left(\frac{1}{\mathrm{R}_{x 1}}+\frac{1}{\mathrm{R}_{x 2}}\right) \\
H_{0}=\frac{\left(\mathrm{h}_{0}\right)}{R_{x}}=\left(\mathrm{H}_{0}\right)_{\text {smooth }} \mathrm{x}\left(1+0.025 \cdot \bar{\sigma}^{1.248} \cdot V^{0.119} \cdot \mathrm{W}^{-0.133} .\right. \\
\left.\mathrm{U}_{n}{ }^{-0.884} \cdot G^{-0.977} \cdot k^{0.081}\right) \cdot \emptyset_{t}
\end{gathered}
$$

Where,

$\emptyset_{t}$ - is the thermal coefficient:

$$
\begin{aligned}
& \emptyset_{t=}\left(1+0.1\left(1+14.8 V_{e}^{0.83}\right) L^{0.64}\right)^{-1} \\
& V_{e}=\frac{\left|U_{1}-U_{2}\right|}{\left(U_{1}+U_{2}\right)}
\end{aligned}
$$

For a sliding movement $U_{2}$ is 0 , and hence $V_{e}$ is equal 1;

$L=\frac{\beta \eta_{0} U^{2}}{K}$

Where, 
$\mathrm{U}$ is velocity in $\mathrm{m} / \mathrm{s}$;

$\eta$ is dynamic viscosity;

$K$ is the thermal conductivity;

$\beta$ is the thermal viscosity coefficient;

$V$ is hardness number:

$V=\frac{v}{E}$

Where,

$v$ is the Poisson ratio;

$E$ ' is the coefficient of elasticity;

$k$ is ellipticity number:

$k=\frac{a}{b}$

$\mathrm{U}_{n}$ - is speed parameter:

$$
\mathrm{U}_{n}=\frac{\eta\left(U_{1}+U_{2}\right)}{2 \mathrm{R}_{x} \mathrm{E}^{*}}
$$

Where,

$U_{1}$ is the disc speed;

$U_{2}$ is the ball speed;

$\mathrm{E}^{*}$ - is equivalent Young's Modulus:

$$
\frac{1}{\mathrm{E}^{*}}=\frac{1}{2} \cdot\left(\frac{1-v_{1}^{2}}{\mathrm{E}_{1}}+\frac{1-v_{2}^{2}}{\mathrm{E}_{2}}\right)
$$

$\alpha-$ is piezoviscosity coefficient;

$$
\alpha=\mathrm{sv}^{t} x 10^{-9}\left[P a^{-1}\right]
$$


Where,

$\mathrm{s}$ is the constant piezoviscosity calculated as Gold et al (2001);

$\mathrm{t}$ is the constant piezoviscosity calculated as Gold et al (2001);

$G$ - Material parameter:

$$
G=\alpha \mathrm{E}^{*}
$$

W - Load Parameter:

$$
\mathrm{W}=\frac{F_{n}}{\mathrm{R}_{x}^{2} \quad \mathrm{E}^{*}}
$$

Where,

$\mathrm{Fn}$ is the load in N;

Equation (07) was developed for elastohydrodynamic lubrication and can be used to determine which system developed in permanent condition. This concept of lubricant film thickness is complemented with the concept of the three lubrication regimes already mentioned in the item 2.3.2.

\subsection{LUBRICATION IN GEARS}

Gears are designed to transmit motion and power from one rotating shaft to another or from a rotating shaft to a reciprocating element. Gears can be classified as spur, bevel and helical, schematics of running gears are shown in Figure 12.

The gear teeth mesh has two different motions, both rolling and sliding. The contact with a gear teeth pair in progression during a usual design engage is presented in Figure 13. As contact progresses, the teeth roll and slide on each other. Rolling occurs from the root to the tip of the driver and from the tip to the root of the driven tooth. In view "a" of figure 16, it is presented the gear 
engagement and, in red it can be seen the line of action. The view " $b$ " shows the first contact between a point near the root of the driven tooth and a point at the tip of the driven tooth. In view " $c$ " the engagement is near to pitch line, where there is pure rolling (no sliding) movement. In view " $d$ " is exhibited the approximate end of the contact and it should be noted, that the direction of sliding reverses after the pitch line. (WESSOL; PIRRO, 2001).
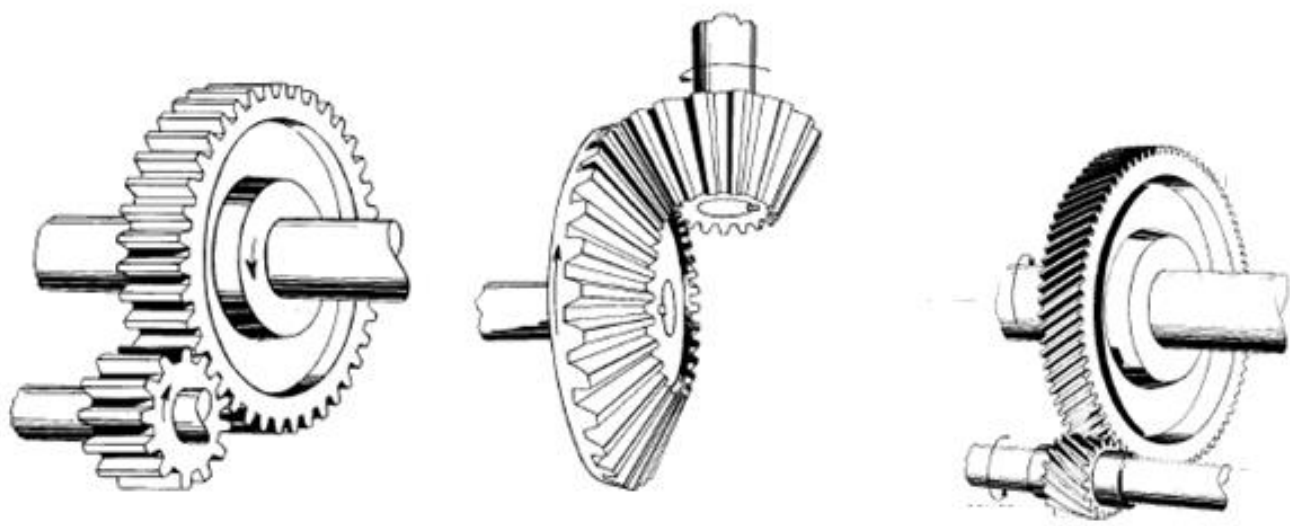

Figure 12- (a) Spur gears, (b) bevel gears, (c) helical gears. (WESSOL; PIRRO, 2001).

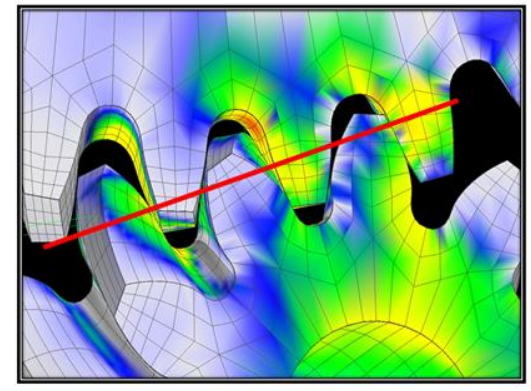

(a)

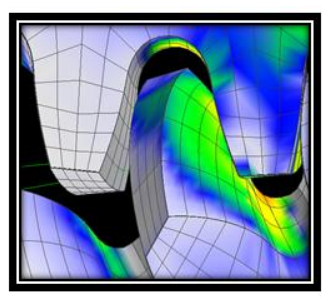

(b)

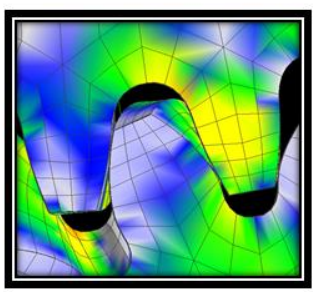

(c)

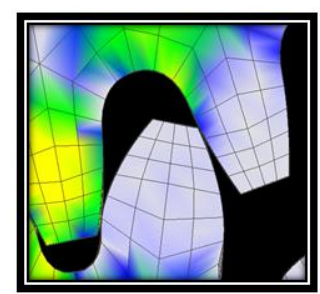

(d)

Figure 13- Mesh on involute gear teeth demonstrating the gear engagement (Author). 


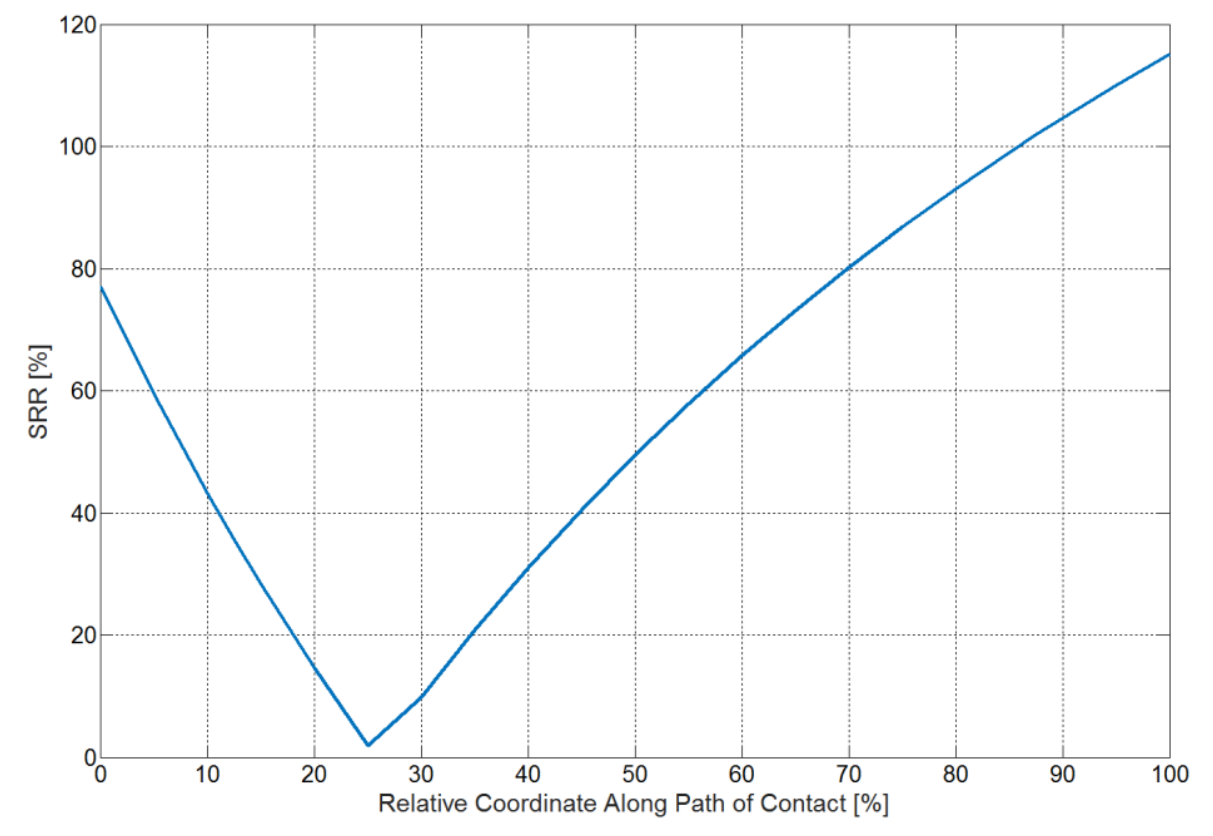

Figure 14 - the engagement contact during engagement

This combination of sliding and rolling occurs with all meshing gear teeth, regardless of its type. The two factors that vary are the amount of sliding in proportion to the amount of rolling (SRR) as showed in Figure 14, and the direction of slide relative to the lines of contact between tooth surfaces. At the present work, it was considered only sliding movement during ball-on-disc tests.

The critical specific film thickness $(\Lambda)$ for gears is not only considerably low for rolling element bearings, but it is also a function of the pitch line speed. The curve of Figure 15, developed from experimental data, shows that at low speed values of $\Lambda=0.1$ or lower can be tolerated without surface distress in the form of pitting or wear. At higher speeds, values of $\Lambda>2.0$ or higher may be required for equal freedom from tooth distress (WESSOL; PIRRO, 2001). 


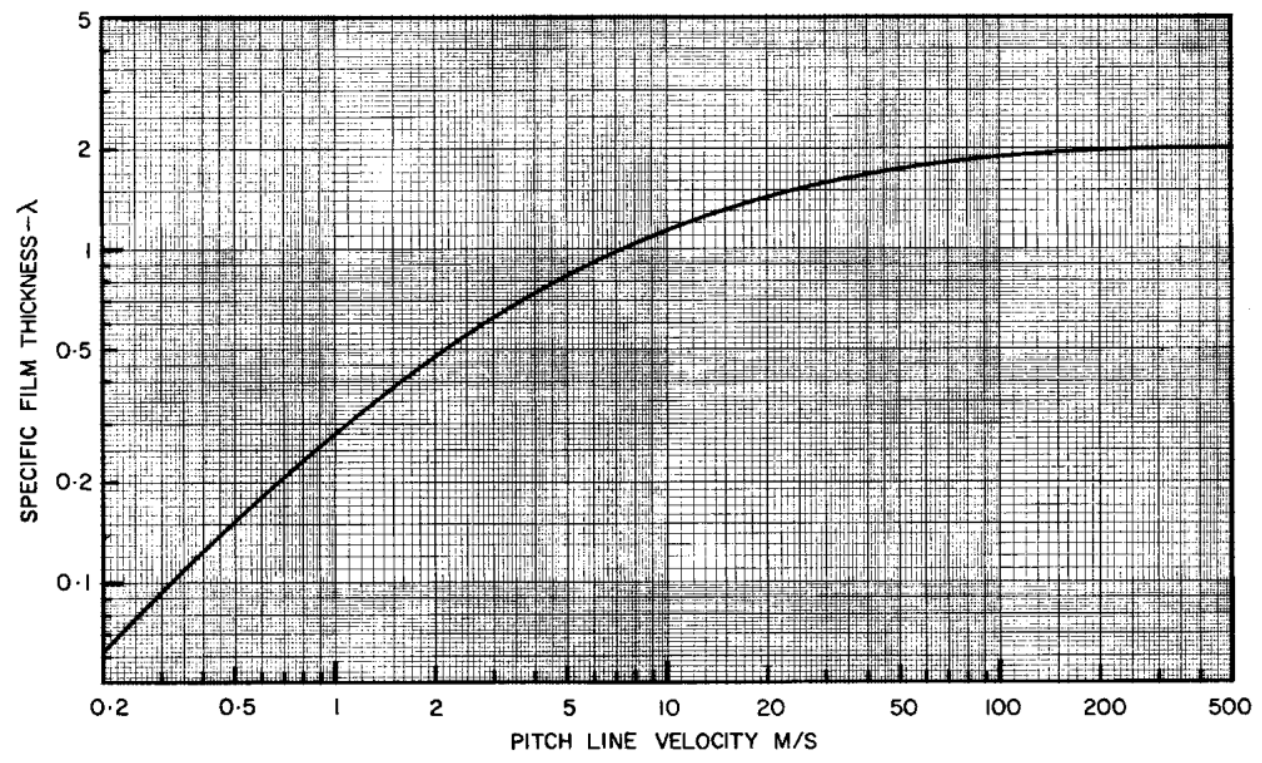

Figure 15 - Specific film thickness for gears (WESSOL; PIRRO, 2001).

A gearbox transmits a given input power (Pin) from the input shaft of the driving gear. The mechanism dissipates energy and the driven gear only transmit an output power (Pout) lower than the input power. The efficiency of such gear pair is then given by the equation below:

$$
\eta_{z}=\frac{\text { Pin-Pout }}{\text { Pin }}
$$

The difference between the input power (Pin) and the output power (Pout) is called the total power loss $\left(P_{V}\right)$, which is the sum of different sources of power loss. According to Fernades apud Höhn (2016) the gearbox power loss is due to gear load-dependent $\left(P_{V Z 0}\right)$ and load-independent losses $\left(P_{V Z P}\right)$, rolling bearing losses $\left(P_{V L}\right)$ and seal losses $\left(P_{V D}\right)$ as described in the following equation:

$$
P_{V}=P_{V Z 0}+P_{V Z P}+P_{V L}+P_{V D}
$$

The present study will be concerned about power loss of gear loaddependent, considering a pure sliding movement. 


\subsection{STRIBECK PARAMETER}

In a work published by Brandão et al. (2011), the Stribeck curve is described as another way to demonstrate the changes between the lubrication regimes. Developed by Stribeck in the twentieth century, this parameter is used to represent the evolution of the friction coefficient with sliding speeds for rolling bearings. Figure 16 shows an example of a Stribeck curve where the product of the speed $(U)$ and the viscosity $(\eta)$ divided by the normal contact force $(F n)$ is used as abscissa. The boundary regime is between $10^{-7}$ and $5 \times 10^{-6}$, the mixed lubrication regime is between $5 \times 10^{-6}$ and $5 \times 10^{-5}$ and the full film values higher than $5 \times 10^{-5}$.

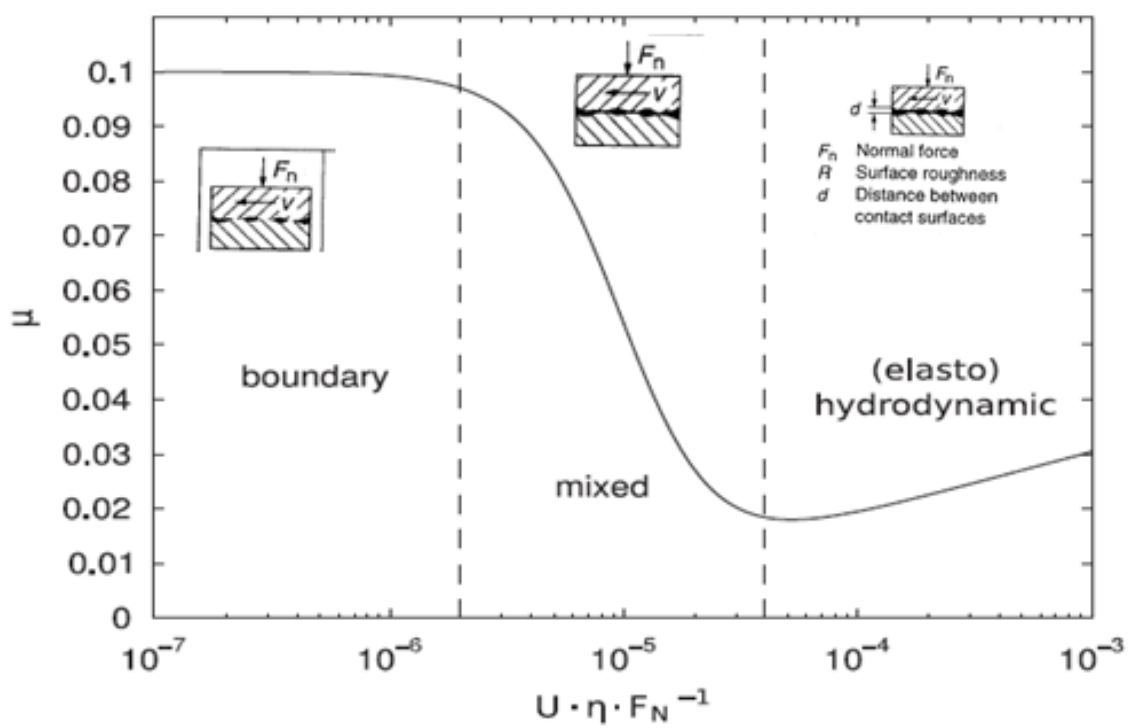

Figure 16 - Stribeck curve - (Adapted from LECHNER AND NAUNHEIMER (1999)).

In the study conducted by (BRANDÃO et al. (2011)) a modification of the Stribeck parameter, has been proposed since the gear operates in the hydrodynamic lubrication regime, the mixed regime and the boundary regime, in which the piezoviscosity parameter $(\alpha)$ has an influence on the thickness of the oil film and COF. This coefficient is part of Stribeck parameter formula. The value of the coefficient depends on the piezoviscosity of the base oil and it may present significant differences even considering the same kinematic viscosities, as described by Gold at al. (2001). Equation 27 shows the Modified Stribeck 
parameter $(\mathrm{Sm})$, which is a dimensionless parameter that allows a better study of the influence of the thickness of the oil film.

$$
\mathrm{Sm}=\mathrm{U} \cdot \eta \cdot \alpha^{1 / 2} \cdot \mathrm{Fn}^{-1 / 2}
$$

Brandão et al. (2011) and B. Vengudusamy at al. (2013), tested different fully formulated gear lubricants with different base stocks and additive packages, which were submitted to tribological tests under a wide variety of operating conditions.

The proposed formula Modified Stribeck $(\mathrm{Sm})$ values were obtained from tribological tests. They were examined in order to analyze the influence of the operating conditions in gear oils on the coefficient of friction under mixed and boundary film lubrication. Particular attention was given to the COF under boundary film lubrication. These Stribeck curves might be helpful on understanding the evolution of the COF between gear teeth along the meshing line (BRANDÃO et al. 2011).

\subsection{FRICTION}

The onset of efficiency evaluation is related to friction. The word friction comes from the Latin verb fricare, which means to rub. Therefore, the friction can be defined as the resistance to movement of one body over another body. The coupled bodies in contact can be constituted by a gas and a solid, a liquid and solid, solid and a solid, in which friction can be related to internal energy dissipation (ASM - HANDBOOK, Vol. 18, 1992).

Friction approach can be made in two different forms: i) friction allows most of the applications such as the use of wheels; ii) the disadvantage is the occurrence of the wear and the loss of efficiency. It is worth mentioning the losses due to friction are directly dependent on the tribological system or tribosystem, which consists of three elements: i) the contacting body; ii) the opposing contacting body and iii) the interface between them. The variables related to tribosystem are: movement type, forces, temperatures, speeds, loads and test length and time. Tribological processes occur in the contact area, between the 
contact area and they can be physical, physicochemical or chemical in nature. (MAXNG; DRESEL, 2007).

The use of tribological systems is antique; records indicate the use of wheels since $3500 \mathrm{BC}$. The Egyptians, in $1880 \mathrm{BC}$, transported heavy statues using wheel systems. A war machinery was constructed during the Roman empire based on tribological principles. Figure 17 shows a two wheeled harvest cart with studded wheels in 1338 AD. Leonardo da Vinci (1452-1519) was the first to postulate a scientific approach to friction. He deduced the rules using a rectangular block sliding over a flat surface. Then, the concept that the coefficient of friction as the ratio of the friction force to normal load was introduced. In 1699 the French physicist Guillaume Amontons rediscovered the rules of friction studying sliding between two flat surfaces (BHUSHAN, 2013).

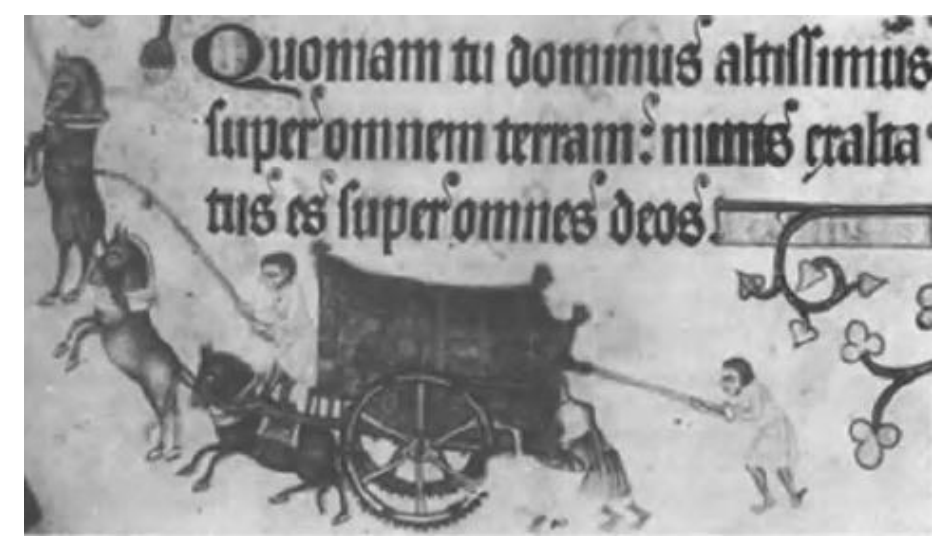

Figure 17 - Two wheeled harvest cart with studded wheels in 1338 AD. (BHUSHAN, 2013)

The fundamental laws that govern friction of solid bodies are usually denominated Coulomb laws, who formulated them in 1785 (although part of this work was conducted previously by Leonardo da Vinci and Amontons). He added a third law: the friction force is independent of sliding velocity. The laws can be stated in very general terms:

- Static friction may be greater than kinetic friction;

- Friction is independent of sliding velocity;

- The frictional force is proportional to applied load;

- The frictional force is independent of contact area; 
It is worth emphasizing these laws are very general, while they are applicable concerning in many instances. However, there are also numerous conditions under which they break down (ASM - HANDBOOK, Vol. 18, 1992).

Regarding the lubricating effects, the essential laws of viscous flow were postulated by Isaac Newton (1668), but scientific knowledge of lubricated bearing operations did not occur until the end of the nineteenth century. The beginning of the understanding of the principle of hydrodynamic lubrication was made possible by the experimental studies of Beauchamp Tower in 1884 and, the theoretical interpretations of Osborne Reynolds in 1886 and N.P. Petroff in 1883. (BHUSHAN, 2013).

Moving gears and teeth gear contact leads to rolling, sliding and combinations of both movements. Concerning the rolling and the sliding motion (Figure 18), a friction force $\left(F_{T O T A L}^{a t r}\right)$ is necessary to move the upper body over the stationary counterparts, these two movements are not mutually exclusive. It is worth noting, this study will consider only sliding movement due to equipment limitation. The ratio between this frictional force and the normal load $\left(F_{\text {ext }}\right)$ is denominated the coefficient of friction (COF) (equation 28):
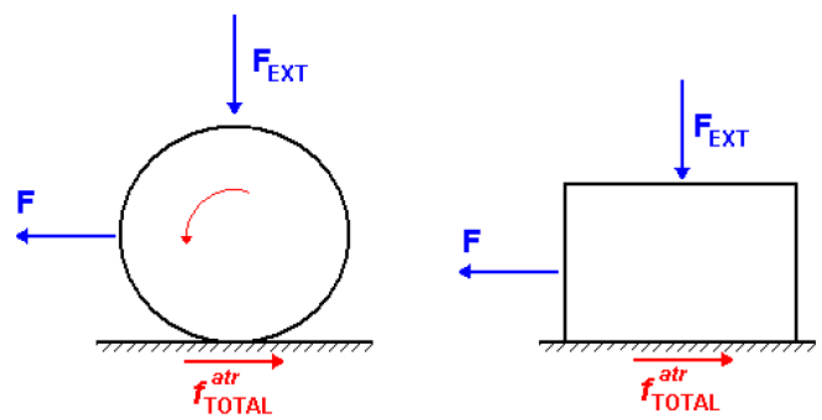

Figure 18 - Frictional force, (a) rolling, (b) sliding. (adapted from PROFITO, 2010)

$$
C O F=\frac{F_{T O T A L}^{a t r}}{F_{\text {ext }}}
$$

Since gears are usually lubricated, abrasion wear mechanisms are not usually found. On the other hand, adhesion is more prone to occur, but also has to be avoided. The term adhesion of the materials was modeled as a force associated with the shear joints created by adhesion, thus the strength or shear 
$F_{a}$ (equation 29) was calculated as the product of the real area contact $\left(A_{r}\right)$ and the shear strength of materials $\left(\tau_{a}\right)$ (BOWDEN, TABOR, 1950):

$$
F_{a}=A_{r} \tau_{a}
$$

In lubricated surfaces the load might be supported by an oil film. The equation (30) shows the relationship between $\mathrm{Fa}$ and $\delta$ :

$$
F_{a}=A_{r}\left[\delta \tau_{a}+(1-\delta) \tau_{1}\right]
$$

Where:

$$
\tau_{1}=\frac{\eta V}{h_{0}}
$$

Where $\tau_{a}$ and $\tau_{1}$ are the shear strength for the dry contact and the oil film respectively, $\delta$ is the fraction of area without lubricant, $\eta$ is the dynamical viscosity, $\mathrm{V}$ is the relative speed, $h_{0}$ is the film thickness of the lubricant.

In this study and in most practical applications, sliding surfaces are lubricated in some way, and the wear is denominated lubricated sliding wear. The term adhesive wear is sometimes used to describe sliding wear, but its use can be misleading. Adhesion plays an important role in sliding wear, but it is only one of the several chemical and physical processes involved. (HUTCHINGS, 1992).

Several modes of lubrication such as adsorption, surface localized viscosity enhancement, amorphous layers and sacrificial films are usually involved in the boundary lubrication regime to ensure the smooth-functioning and reliability of machinery. Many vital items of engineering equipment such as steel gears, piston-rings and metalworking tools depend on one or more of these lubrication modes in order to prevent severe wear or high COF.

\section{MATERIALS AND METHODS}


Gears materials, manufacturing as well as lubricant evaluation in automotive transmission are usually conducted in bench test rigs or vehicle tests. However, bench tests do not always reproduce and/or indicate clearly the mechanism of damage or friction occurring during vehicle tests. Nevertheless, wear mechanisms evaluation has to be taken into account. Therefore, the use of tests such as ball on disc could provide a better understanding and representation of the wear or friction mechanisms in vehicle tests. Moreover, the costs involved are usually smaller than bench tests.

This chapter will address issues concerning the properties of materials, lubricants as well as the methodology used in the tribological tests - ball on disc - by using different lubricants, which are applied in automotive transmission systems. These tribological tests allowed friction coefficient evaluation throughout sliding under different applied loads, speeds and temperatures.

\subsection{MATERIALS}

Material features, sample manufacturing and, lubricants used in the tribological tests conducted in this work are as follows:

\subsubsection{Lubricants}

Three types of gear oils were selected to conduct the tribological tests. Oils were fully formulated and they belong to the same classification. The differences among the oils were found in the base of oil, which could be mineral or synthetic. The viscosity levels, viscosity index and additive package's effects were also evaluated. For the sake of simplicity, the three different oils were denominated $\mathrm{S} 1, \mathrm{~S} 2$ and M1. Table 5 shows the main features and properties as well as the denomination of each oil.

It is worth mentioning, the kinematic viscosity values were measured according to ASTM D445 (see Figure 19). The results were obtained from viscosity tests conducted at FCA Group Company. The viscosity of the S1 oil is approximately 2 times lower than the viscosity of the $\mathrm{S} 2$ and $\mathrm{M} 1$ oils at $100^{\circ} \mathrm{C}$. 
Table 5 - Denomination and properties of gear oils evaluated.

\begin{tabular}{cccc}
\hline & \multicolumn{3}{c}{ Oils } \\
\cline { 2 - 4 } & S1 & S2 & M1 \\
\hline Lubricant type & Synthetic & Synthetic & Mineral \\
Classification & API-GL4 & API-GL4 & API-GL4 \\
Viscosity class & SAE75W & SAE75W85 & SAE80W \\
Density at $15^{\circ} \mathrm{C}\left(\mathrm{g} / \mathrm{cm}^{3}\right)$ & 0.850 & 0.863 & 0.890 \\
Kinematic Viscosity at & 7.28 & 15.07 & 12.25 \\
$100^{\circ} \mathrm{C}(\mathrm{cSt})$ & & & \\
Kinematic Viscosity at & 34.63 & 105.45 & 107.82 \\
$40^{\circ} \mathrm{C}(\mathrm{cSt})$ & 182 & 150 & 108 \\
Viscosity index & 210 & 220 & 200 \\
Flash point $\left({ }^{\circ} \mathrm{C}\right)$ & & &
\end{tabular}

The lowest value for the $\mathrm{S} 1$ viscosity is at $40^{\circ} \mathrm{C}$ and at $100^{\circ} \mathrm{C}$, and, $\mathrm{S} 1$ viscosity index presents the highest value when compared to the other ones. The kinematic viscosity is important to discuss transmission efficiency.

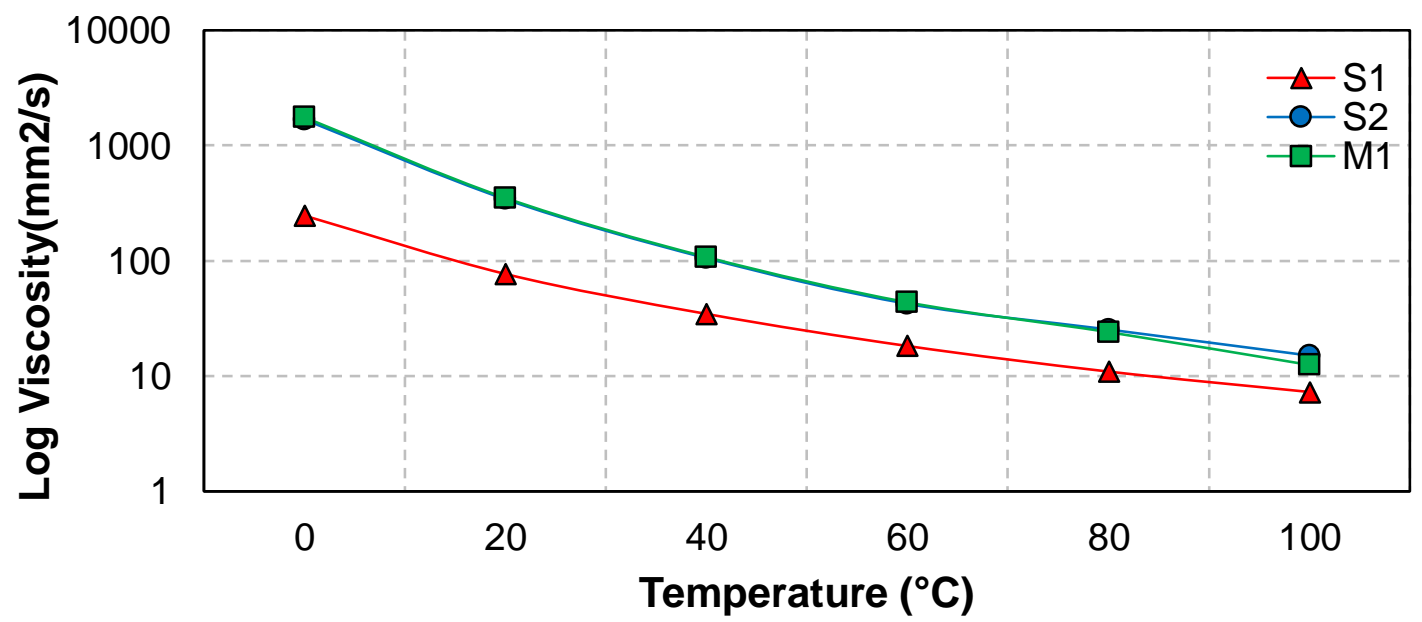

Figure $19-$ (a) Kinematic viscosity of the S1, S2 and M1 oil at temperatures ranging between 0 and $100^{\circ} \mathrm{C}$. Logarithmic description Temperature $\mathrm{X}$ kinematics viscosity lubricants (Author).

Table 6 displays the variation of the viscosity and of the piezoviscosity versus temperature for the evaluated oils. It is worth observing that the increase of the temperature leads to an exponential decrease of the viscosity. These values of viscosity and Piezoviscosity will be used through the tribological test and are input values for specific oil film calculation. 
Table 6 - Viscosity oils according to the temperatures used on tests.

\begin{tabular}{|c|c|c|c|c|c|c|}
\hline \multirow{2}{*}{$\begin{array}{c}\text { Temperature } \\
\left({ }^{\circ} \mathrm{C}\right)\end{array}$} & \multicolumn{3}{|c|}{ Viscosity (cSt) } & \multicolumn{3}{c|}{$\begin{array}{c}\text { Piezoviscosity } \\
\left(10^{-9} \mathrm{GPa}\right)\end{array}$} \\
\cline { 2 - 7 } & $\mathrm{S} 1$ & $\mathrm{~S} 2$ & $\mathrm{M} 1$ & $\mathrm{~S} 1$ & $\mathrm{~S} 2$ & $\mathrm{M} 1$ \\
\hline 20 & 76.95 & 342.23 & 351.54 & 13.18 & 16.10 & 16.14 \\
\hline 40 & 34.63 & 105.45 & 107.82 & 11.85 & 13.74 & 13.78 \\
\hline 60 & 18.25 & 42.4 & 43.68 & 10.87 & 12.17 & 12.22 \\
\hline
\end{tabular}

\subsubsection{Ball and disc specimen}

To perform the sliding tests, two different components were used: balls and discs. Balls are $(10.0 \pm 0.1) \mathrm{mm}$ in diameter and are made of SAE 52100, for which the quadratic surface roughness $(\mathrm{Sq})$ was measured as $0.08 \mu \mathrm{m}$.

Discs were made of SAE 4320 steel, which is the steel usually employed to manufacture automotive gears. In order to present the same mechanical properties, the surface finishing and the thermochemical heat treatments of discs followed the same steps and parameters carried out during gear manufacturing. Therefore, discs were obtained with the same profile of hardness and microstructural features of transmission gears surface. The roughness is also set by the manufacturer and, the Sq values were also of about $0.8 \mu \mathrm{m}$. Figure 20 shows the details of the geometric dimensions and the macroscopic features of the disc and the ball used in the tribological tests.
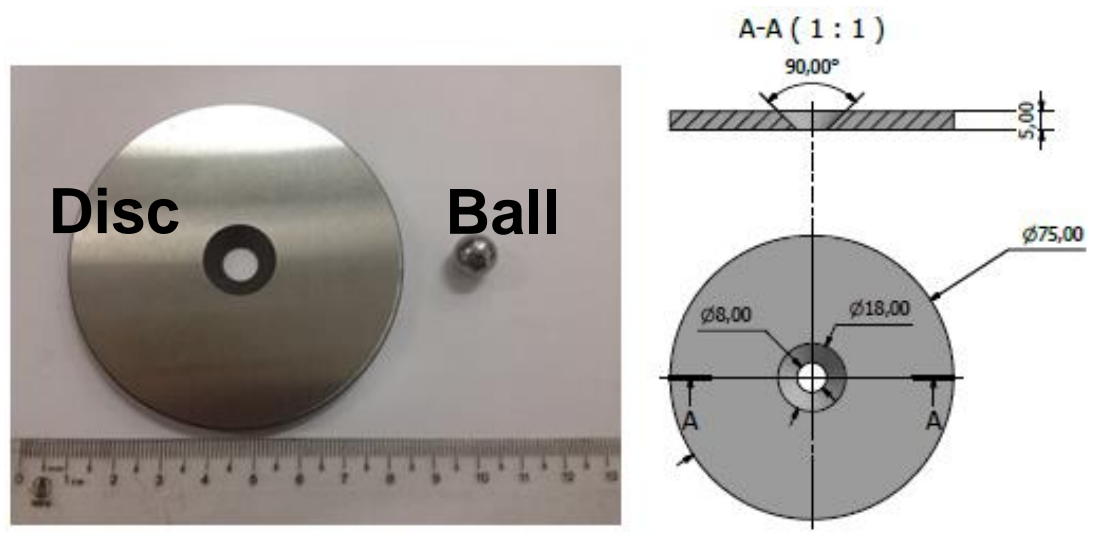

Figure 20 -Features and dimensions of the disc made of SAE 4320 steel and sphere was made of AISI 52100 steel 


\subsection{METHODOLOGY}

\subsubsection{Test parameter definition for ball on disc tests}

The evaluation of friction coefficient was carried out by ball on disc tests. The selection/definition of parameters were based on the analysis conducted by dynamical analytic calculation for gears using a software "ISOCAD" that takes into account the gear geometry and the dynamic of the vehicle. Therefore, the relation between the selected parameters for the ball on disc tests and the conditions of load and the speed in the contact of the gears in a transmission of an automotive vehicle was established. The selection of each parameter is essential to calculate the specific oil film thickness and to find which lubrication regime will be tested. The parameters will be presented in the following section.

Moreover, the "fuel economy test", which is an international standard test (NBR6601 and NBR7024), was used to determine the tested temperatures in the ball on disc test, as shown in the next section.

\section{Gear Speed - Definition of disc speed (ball on disc)}

Figure 21 shows the division on the base circle and their corresponding profile. For the sake of simplicity, the contact region was divided by numbers making the comparison and identification easier. Also in Figure 20 are shown the regions that come into contact during the movement of the transmission gear. The difference between the lengths of the corresponding arcs is the relative speeds between the tooth flanks. One can also note that on the pitch circles, there is pure rolling. 


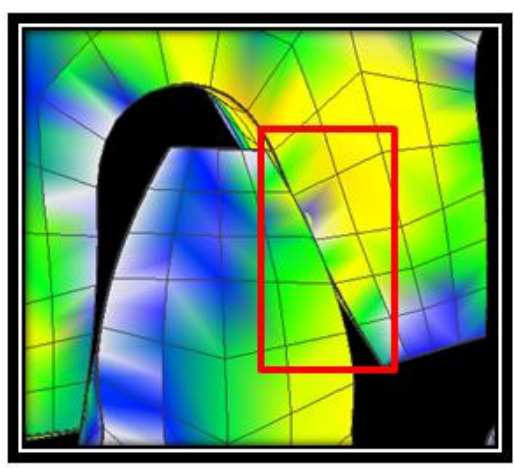

(a)

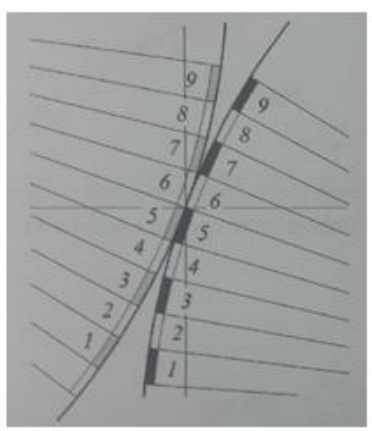

(b)

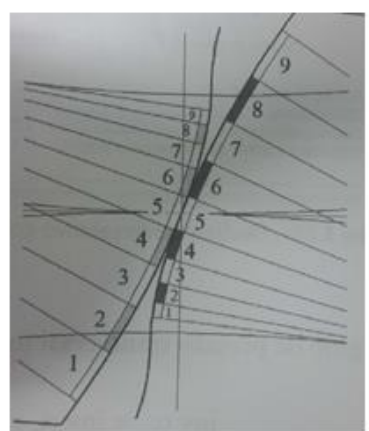

(c)

Figure 21 - a- Gear tooth engage shown red frame in Figures b and c. - B - Constant speed (pure rolling) - c - Relative speeds (Sliding and rolling) adapted from Mazzo (2013).

The schematic showed in Figure 21 was used in the dynamical analytical calculation in a program named "ISOCAD" used by FCA Group. The calculation performed (Figure 22) made it possible to establish a criteria to define the speeds during ball on disc tests. In the red frame insets, which shows the first to fifth gear of an automotive transmission are envisaged. The tests were conducted at velocities $<3 \mathrm{~m} / \mathrm{s}$, corresponding to $3500 \mathrm{rpm}$.

The program calculates the gear speed taking account the parameters of the equation (32) as follows:

$$
\text { gear speed }=f\left(Z_{p}, Z_{r}, n, U_{r e}\right)
$$

Where,

$Z_{p}=$ number of teeth pinion

$Z_{r}=$ number of teeth gear 
$\mathrm{n}=$ engine speed

$U_{r e}=$ arc between major involute diameter of the pinion and the minor involute diameter of the crown

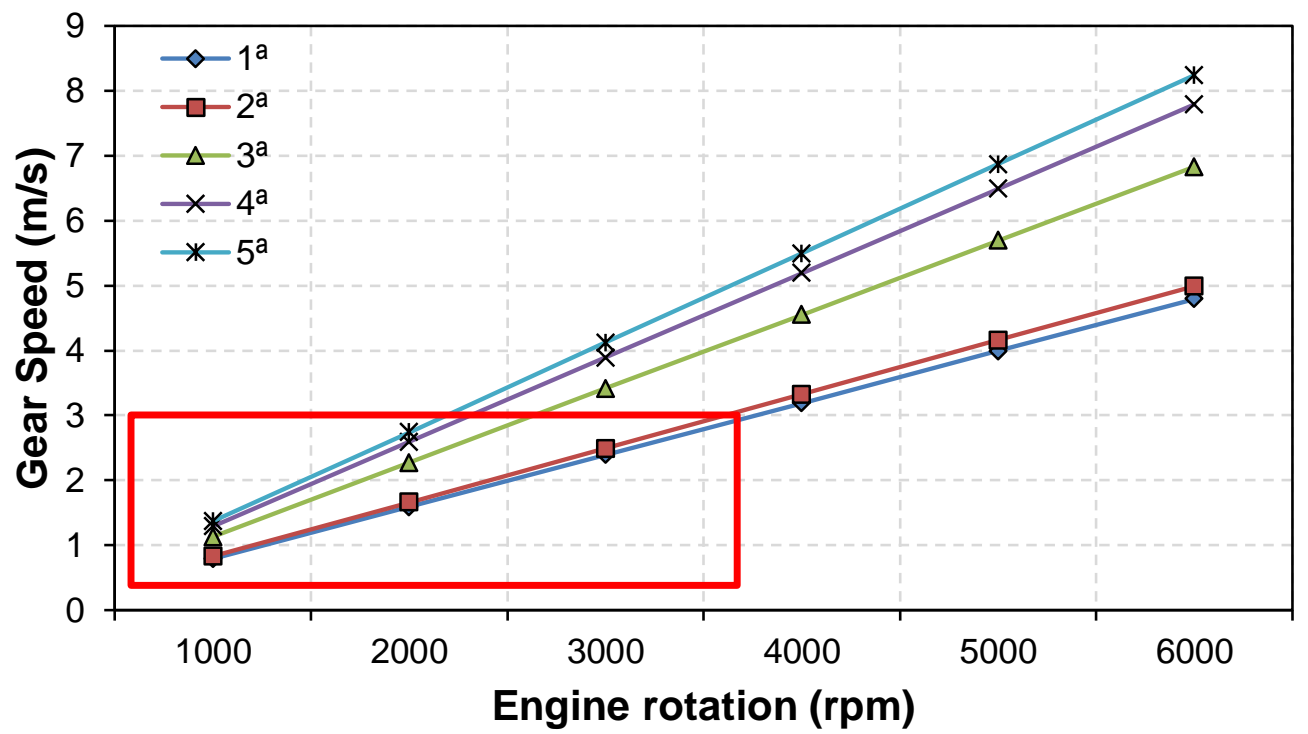

Figure 22 - Gear speed X RPM - Example from a real vehicle, gear speed measured on pinion gear using ISOCAD program, the red frame is the region evaluated during tribological tests.

\section{Applied load - Definition of contact pressure (ball on disc)}

A similar analysis described above was performed taking into account the applied loads and was conducted the same analytic method. Figure 23 shows the relation between the engine torque $(\mathrm{Nm})$ as a function of gear pressure contact (MPa).

The frame inset in Figure 23 displays the contact pressure used in the ball on disc tests and it comprises the $1^{\text {a }}$ and $2^{a}$ gear (where it can be found the highest pressure contacts). The formula describing the gear pressure contact is presented in equation 33:

$$
\begin{gathered}
\text { ohefetiva }=\mathrm{Zh} * \mathrm{Ze} * \mathrm{Z} \varepsilon * \mathrm{Z} \beta * \mathrm{Zp} * \\
\sqrt{\mathrm{Ka} * \mathrm{Kv} * \mathrm{Kh} \beta * \mathrm{Kh} \alpha} * \sqrt{\frac{\mathrm{Ft}}{(\mathrm{dp} * \mathrm{l})} * \frac{(\mathrm{u}+1)}{\mathrm{u}}}
\end{gathered}
$$

Where: 
Ft: Tangential Force $[\mathrm{N}]$;

dp: Primitive diameter [mm];

I: Contact length [mm]

u: Gear transmission ratio;

The other variables are influenced by factors that vary depending on the characteristics of gears and gearing dynamics, they are presented in ISO 6336.

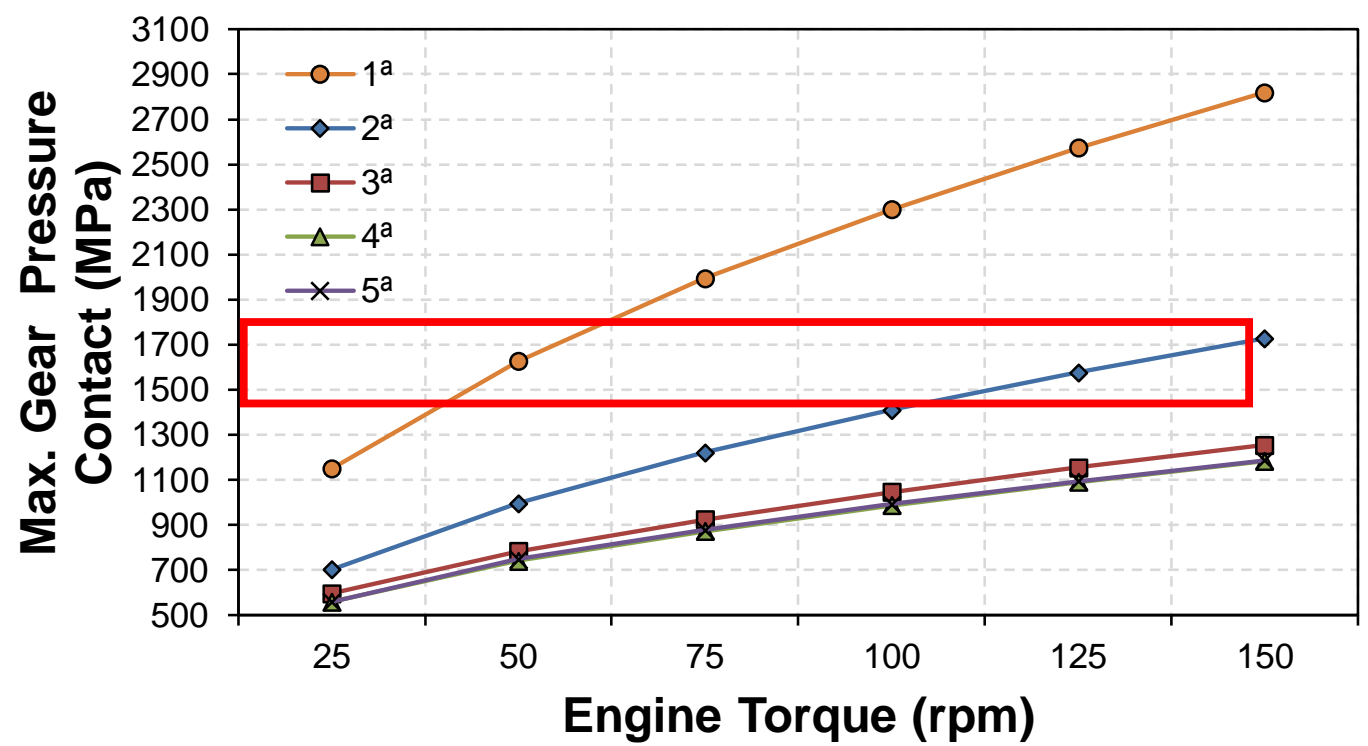

Figure 23 -pressure torque $x$ maximum pressure contact - Example from a real vehicle using ISOCAD program.

\section{Fuel economy test - Definition of temperature (ball on disc)}

The third variable studied on this topic was the lubricant temperature during the fuel economy test in the denominated "Urban cycle" and in the "Highway cycle", that are an international test for fuel economy measurement (NBR6601 and NBR7024), and it is also used in Brazil to the emission homologation. Figure 24 exhibits result of temperature in a real vehicle, which measurements were conducted by using three thermocouples, two of them were placed in the engine and transmission oil and, the third was used as reference out of the engine at room temperature.

The fuel economy test is split in four subtests displayed in Figure 24. Phases I, II and III follow the NBR6601 standard, and phase IV follows the NBR7024 standard. 
The first phase (I) characterizes an engine in a cold start in a transient phase, the second phase (II) characterizes the stabilized cold start, at the end the engine is turned off during ten minutes. The third phase (III) characterizes a worm start phase in a transient phase, the stabilized phase is equal the phase II, and for this reason is not performed, but the fuel economy results are taken into consideration. The fourth phase (IV) represents the Highway cycle and consists in not repeated sequences of acceleration, constant speeds and deceleration.

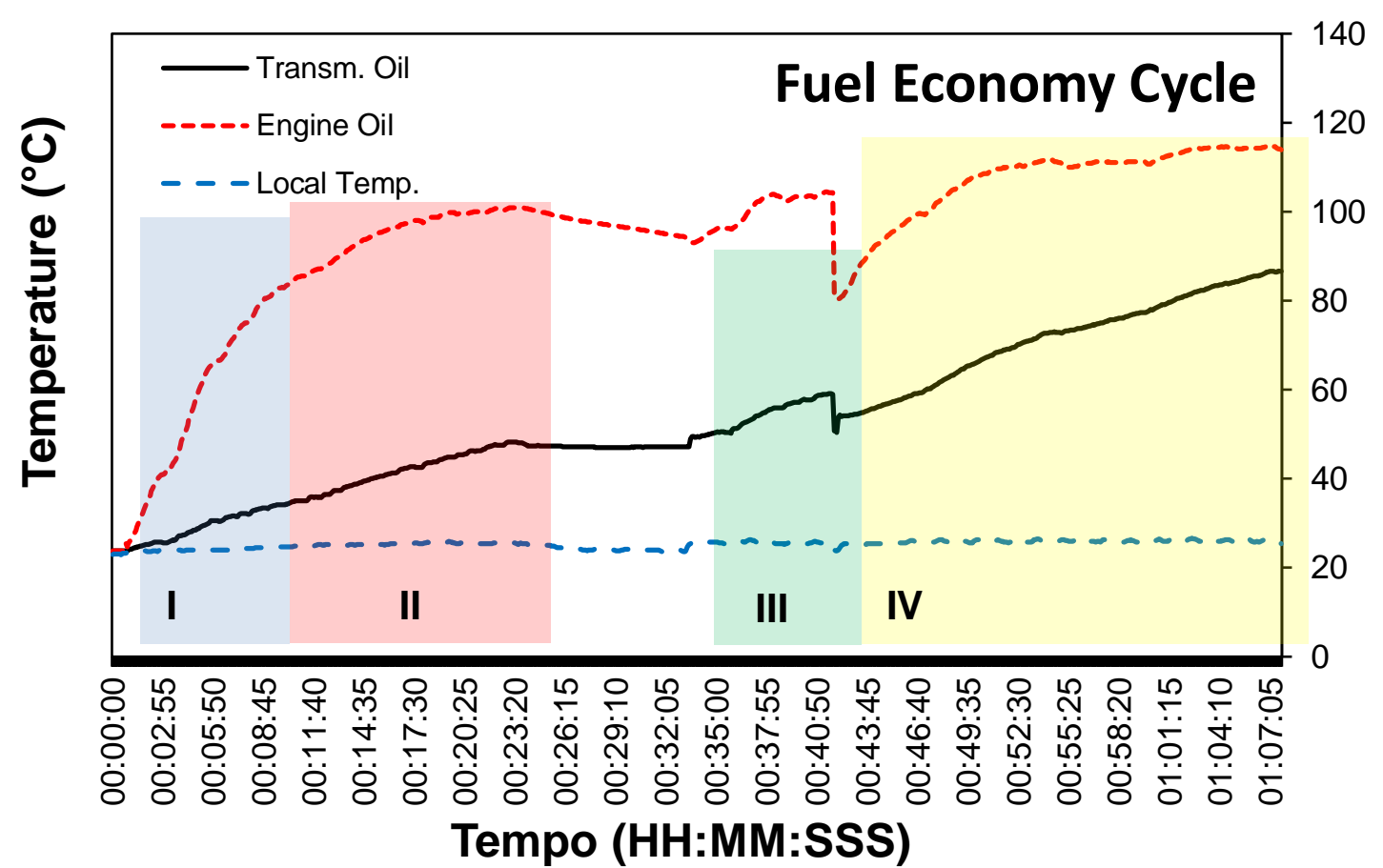

Figure 24 - Fuel economy test - Temperature behavior during test.

The data obtained in a fuel economy test allowed providing a histogram, in which temperatures evaluated in the tests are representative in the vehicle transmissions (Figure 25), 70 percent of the temperatures of the test are below $60^{\circ} \mathrm{C}$, and nearly 30 percent are between 41 and $50^{\circ} \mathrm{C}$. 


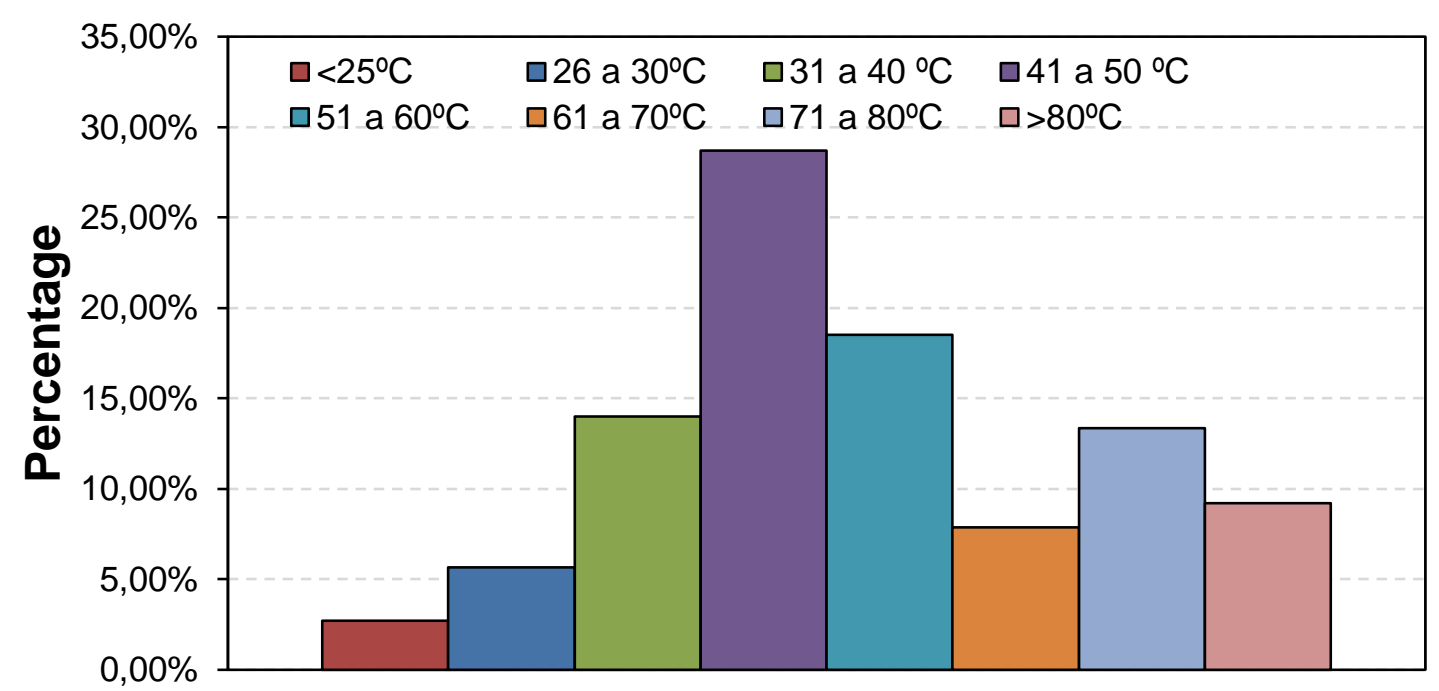

Figure 25 - Percentage of temperatures during fuel economy cycle.

\subsubsection{Ball on disc tests}

The selection of the parameters (speed, load, temperature and specific calculated film thickness) was carried out taking into account data obtained in standard test in engines and transmissions of vehicles so that the analysis conducted in the laboratory tests could be related to vehicles as showed in Figure 21 to 25.

Ball on disc tests were carried out by TE-67 tribometer Plint \& Partners LTD (PLINT) available in the Surface Phenomena Laboratory (LFS) of Escola Politécnica of University of São Paulo (Figure 26). This tribometer allows the measurement of the coefficient of friction during the sliding motion at a constant velocity by applying a load in the disc through the sphere. The acquisition rate during the tests was $10 \mathrm{~Hz}$ and the minimum resolution of the load cell is $0.1 \mathrm{~N}$. A heating system allowed testing temperatures ranging from room temperature to about $60^{\circ} \mathrm{C}$. Tests were conducted in order to understand the Stribeck curve behavior of the lubricants. 


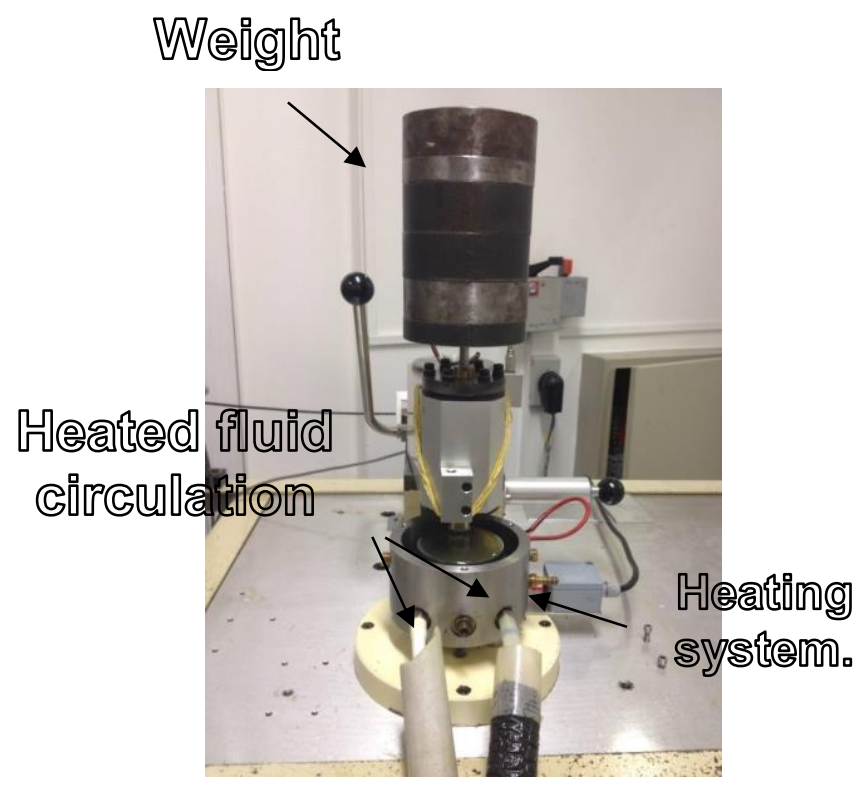

Figure 26- Tribometer TE-67 Plint \& Partners LTD (PLINT): Test ball - disc (LFS) (Reference: Author)

In the first step, tests were performed under starved lubrication conditions, where the amount of lubricant available is insufficient to fill the inlet conjunction as can be observed in Figure 27 (a). Under these conditions, the oil film thickness is often much lower than predicted by fully flooded theory.

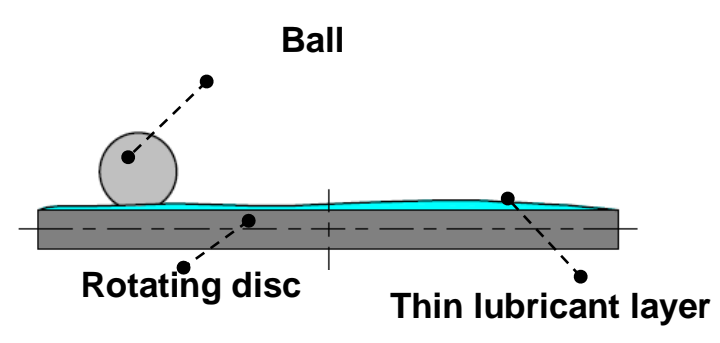

(a)

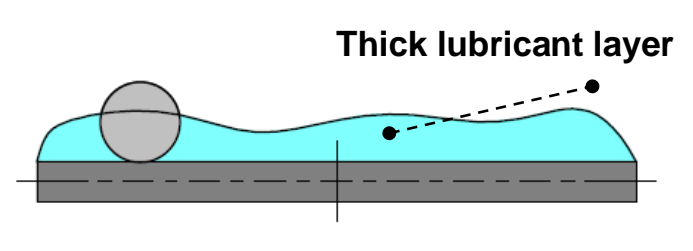

(b)

Figure 27- (a) - Starved lubrication and (b) - Fully flooded lubrication

In a second step, fully flooded conditions were used (Figure 27(b)). A peristaltic pump circulates an oil film thickness on the disc surface (Figure 28). During the test the oil leaves the disc surface, driven by the centrifugal force. This oil is replaced on the reservoir and pumped back, keeping on the cycle. This configuration allows using higher speeds and ensures the lubricated contact during the test. 


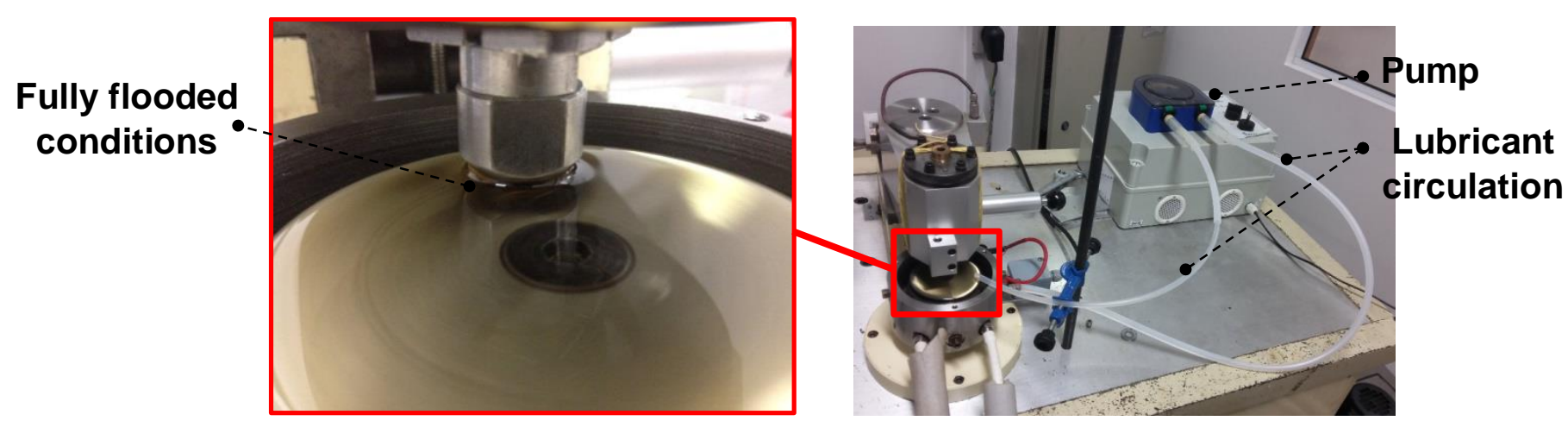

Figure 28 - Pump system to maintain an oil film thickness during tribological tests.

On the third and final set of tests, tests were performed under boundary lubrication regime. The load and the tangential speed were selected to guarantee the boundary regime. The main difference between first step tests and the second step tests was the lower tangential disc speed value $(0,1 \mathrm{~m} / \mathrm{s})$ and loads of $100 \mathrm{~N}$ (instead $50 \mathrm{~N}$ loads).

Test parameters for these three conditions are shown in Table 7 (the tangential speed, temperature and load used in the tests). Figure 29 shows a flowchart illustrating these parameter variations.

Table 7- Parameters selected to conduct ball on disc test in a tribometer.

\begin{tabular}{cccccc}
\hline $\mathbf{N}$ & Type & Temperature $\left({ }^{\circ} \mathbf{C}\right)$ & Load $(\mathbf{N})$ & $\begin{array}{c}\text { Contact } \\
\text { pressure }(\mathrm{GPa})\end{array}$ & $\begin{array}{c}\text { Tangential speed } \\
(\mathbf{m} / \mathbf{s})\end{array}$ \\
\hline 1 & Starved & $20-40-60$ & $30-50$ & $1.46-1.73$ & $0.32-0.66-1$ \\
2 & $\begin{array}{c}\text { Boundary } \\
\text { condition }\end{array}$ & 60 & $50-100$ & $1.73-2.18$ & 0.1 \\
3 & Fully flooded & $20-40-60$ & $30-50$ & $1.46-1.73$ & $0.32-0.66-1-2-3$ \\
\hline
\end{tabular}

Tests were set to begin at the highest speed of the disc, which decreased the speed after each five minutes. This time was enough to verify that the coefficient of friction can be considered stable, and made it possible to determine an average coefficient of friction. Although the speed varied, the load remained constant. Figure 29 summarizes the ball on disc test parameters. 


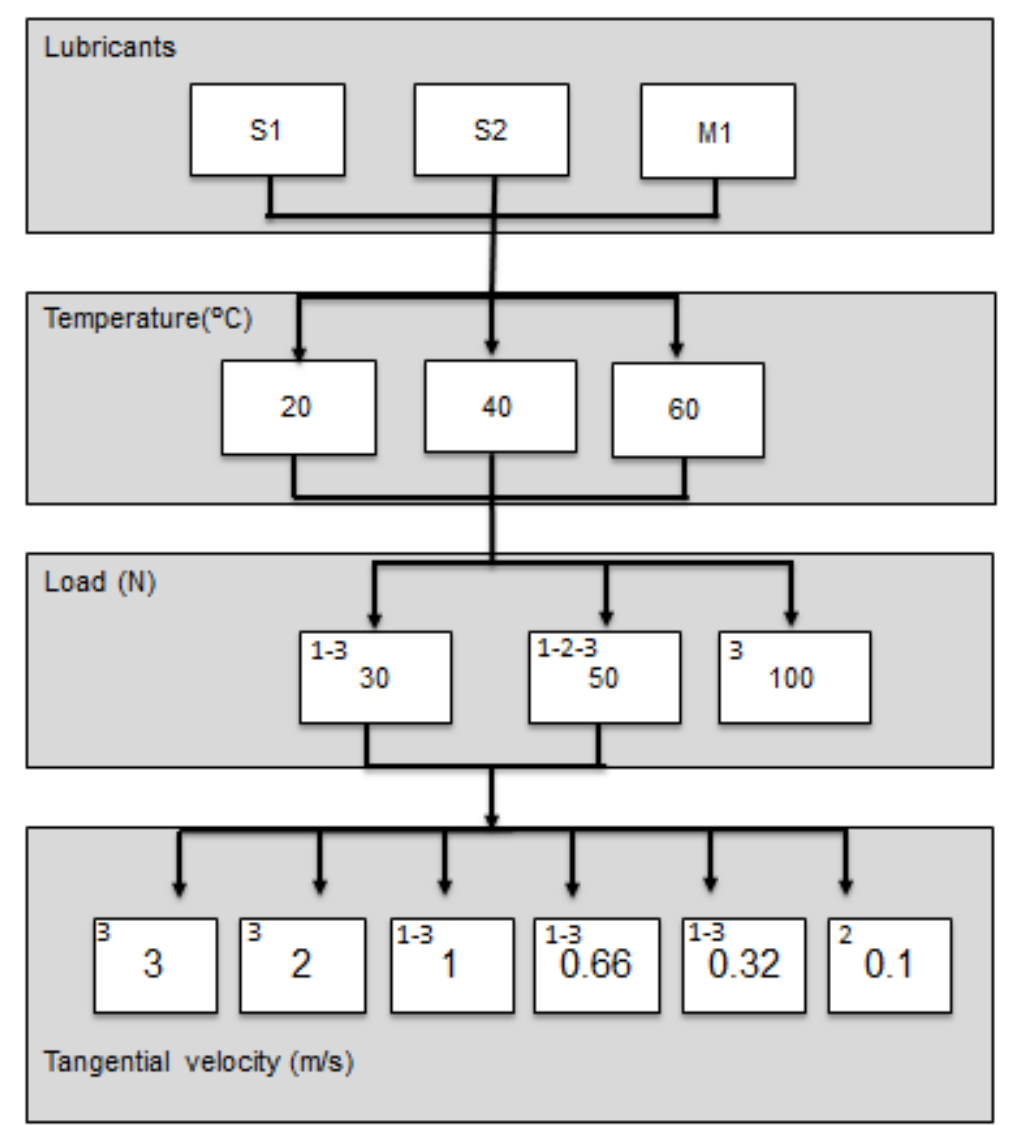

Figure 29 - Chart flow with, lubricants, temperature in loads and speeds used in tribological tests. The index 3, 2, 1-3 is displayed in Table 7.

\subsubsection{Error in the test analysis}

The equipment has a variation of the tangential friction force of $0.1 \mathrm{~N}$ due to it is resolution. This range configures a measurement error during the test. Three normal forces $(30,50 \mathrm{~N}$ and $100 \mathrm{~N})$ were evaluated, where $\mathrm{Fn}$ is the load applied. Equation 34 to Equation 42 depicts the error:

$$
\begin{gathered}
\text { Error }+=\frac{F t}{F n}=\frac{F t+0,1}{F n}-\frac{F t}{F n}=\frac{0.1}{F n} \\
\text { Error }-=\frac{F t}{F n}=\frac{F t}{F n}-\frac{F t-0,1}{F n}=\frac{0.1}{F n} \\
\text { Error }_{30 N}=\frac{0,1}{30}=0.00333 \\
\operatorname{Error}_{30 N}(\%)=\frac{\text { Error } 30 N}{\left(\frac{F t}{F n}\right)} .100
\end{gathered}
$$




$$
\begin{gathered}
\operatorname{Error}_{50 N}=\frac{0,1}{50}=0.002 \\
\text { Error }_{50 N}(\%)=\frac{\text { Error } 50 N}{\left(\frac{F t}{F n}\right)} \cdot 100 \\
\text { Error }_{100 N}=\frac{0,1}{100}=0.001 \\
\text { Error }_{100 N}(\%)=\frac{\text { Error } 100 N}{\left(\frac{F t}{F n}\right)} \cdot 100
\end{gathered}
$$

Besides the resolution of equipment, it was also evaluated the standard deviation of the friction coefficient. The total error considered was the sum of resolution error and standard deviation at equation 39.

$$
\begin{gathered}
S=\sqrt{\left(\frac{1}{n-1}\right) \sum_{i=1}^{n}\left(x_{i-} \bar{x}\right)^{2}} \\
\text { Total error }= \pm \text { Error }+S
\end{gathered}
$$

After the experiments, files recorded during the experiments were analyzed. The data were imported for Matlab software, which was used to evaluate the friction coefficient for each test condition, and made it possible the following analysis:

- Average speed (Spd 1) friction coefficient (Starved and Fully flooded test);

- Average speed (Spd 2) friction coefficient (Starved and Fully flooded test);

- Average speed (Spd 3) friction coefficient (Starved and Fully flooded test);

- Average speed (Spd 4) friction coefficient (Fully flooded test);

- Average speed (Spd 5) friction coefficient (Fully flooded test);

- Values of average and total error for Spd 1, Spd 2, Spd 3, Spd 4 and Spd 5 were recorded in the txt file extension; 


\subsubsection{Topography characterization}

In order to evaluate the topography a surface profilometer Taylor-Hobson CCI-MP (Figure 30) was used. This equipment uses an interferometer method of measurement by using surfaces with reflectivity between $0.3 \%$ and $100 \%$. In the present study it was measured the Sq so that the specific oil film could be predicted considering the roughness parameter.

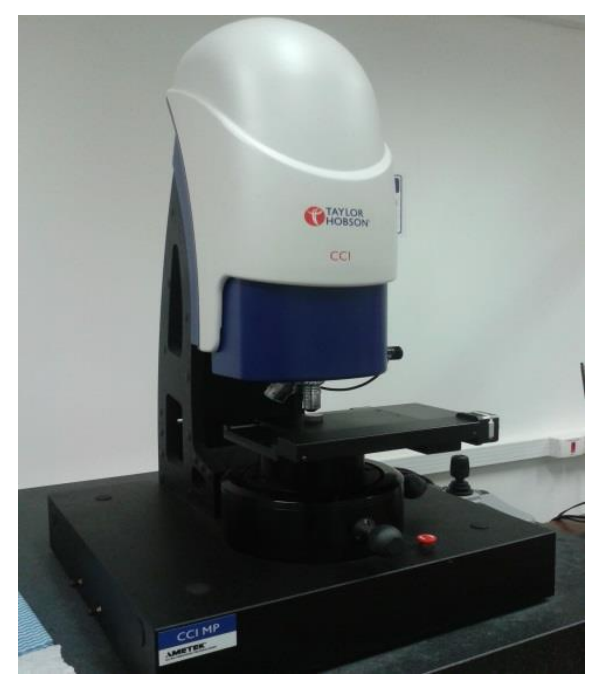

Figure 30 - Surface profilometer Taylor - Hobson CCl, author.

Also an optical microscope (NIKON SMZ800) was used (Figure 31) in order to evaluate the wear scars on the disc surface after tribological tests under starved condition.

As well complementary characterization was performed by a scanning electron microscope (SEM) JEOL JSM - 6010LA (Figure 32) in order to analyze the chemical elements presents on a disc or ball surface after tribological tests. 


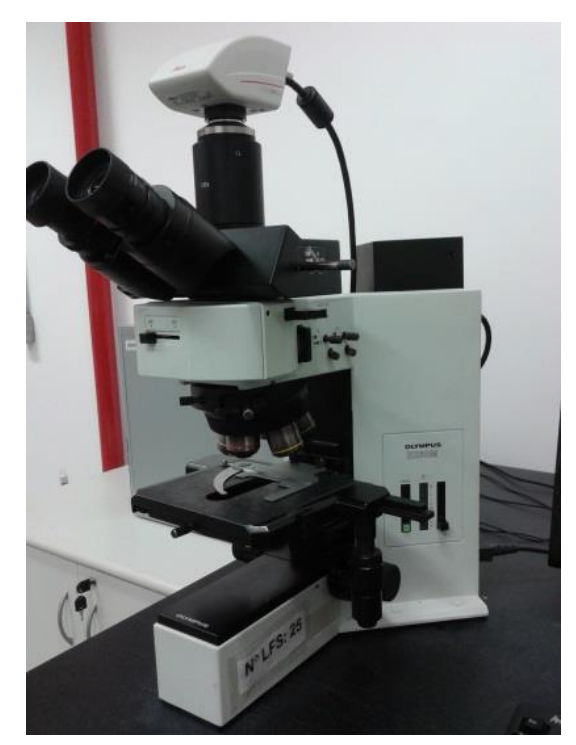

Figure 31 - Optical microscopy at LFS laboratory, author.

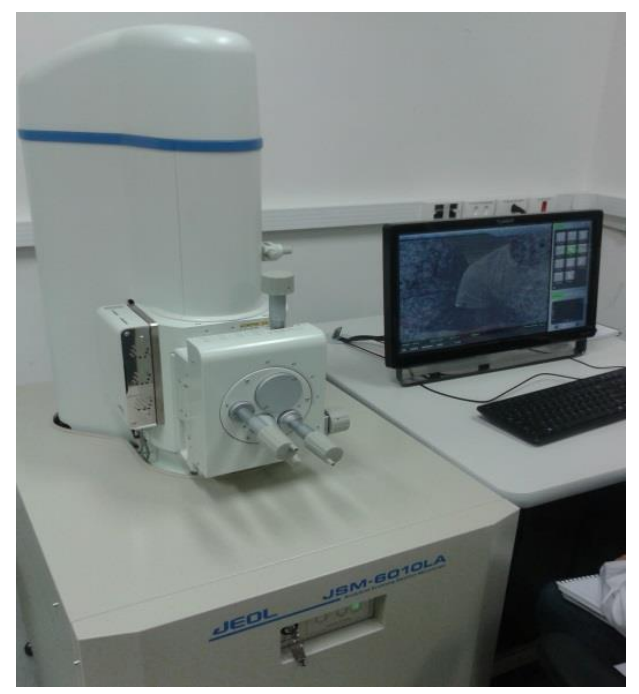

Figure 32 - Scanning electron microscopy (SEM) - JEOL JSM-6010LA, author.

\subsubsection{Lubricant characterization}

In order to evaluate the oil spectrum and understand the behavior of additives present in the lubricants studied, it was used an Energy Dispersive X-ray Spectrometer (EDS) displayed in Figure 33. To identify some components of the lubricant and evaluate changes due to lubricant oxidation, consumption of additives and, water adsorption. 


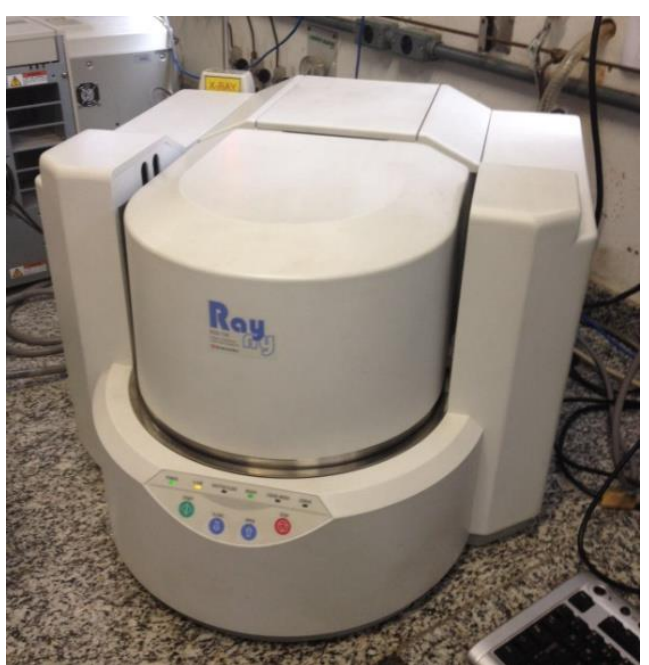

Figure 33 - EDX-720 Energy dispersive X-ray spectrometer, author.

Another way to evaluate the lubricant is by means of the Fourier Transform Infrared Spectroscopy (FTIR). FTIR analyzes made it possible to identify components of lubricants to assessing changes in lubricant oxidation, consumption of additives, water adsorption and it is a nondestructive technique. 


\section{RESULTS AND DISCUSSION}

This chapter will present the roughness parameter, the calculation made to determine $\Lambda$ and results and discussion of tribological experiments performed as described in the item 3.2 .

\subsection{CHARACTERIZATION OF THE SURFACE TOPOGRAPHY}

Prior test, the roughness parameter $(\mathrm{Sq})$ was measured in some discs. Since the manufacturing process was controlled, although slight differences can be found and it would not be significantly influence the results.

Figure 34 shows a surface topography map. Table 8 displays the roughness parameters of five discs. Results of Sq are nearly to $0.8 \mu \mathrm{m}$.

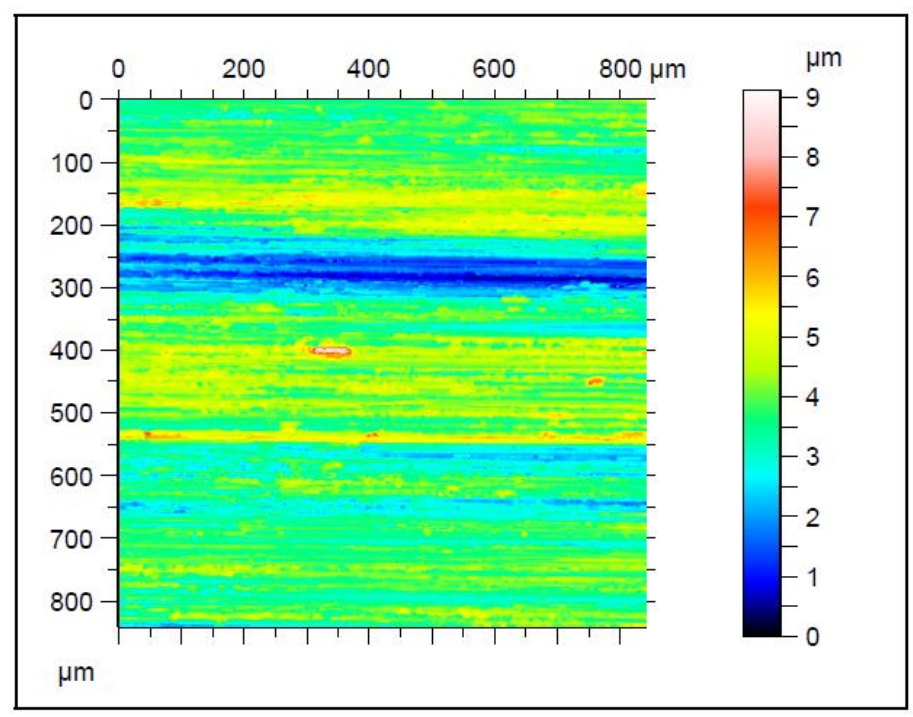

Figure 34 - Example topography measurement of roughness surface

Table 8 - Roughness parameters of a disc evaluated before tribological test

\begin{tabular}{ccc}
\hline Disc & Sq & Sa \\
\hline 1 & 0.723 & 0.562 \\
2 & 0.791 & 0.614 \\
3 & 0.865 & 0.666 \\
4 & 0.733 & 0.576 \\
5 & 0.846 & 0.684 \\
\hline Mean & 0.792 & 0.620 \\
\hline Std Dev. & 0.064 & 0.054 \\
\hline
\end{tabular}




\subsection{DISC HARDNESS}

The disc hardness was measured in the transverse section from the surface to the inner region (Figure 35 and Figure 36). The value near to the surface is about $800 \mathrm{HV}$, that is a higher than the $750 \mathrm{HV}$ of the sphere. The hardness profile of discs was almost the same found in regular gears after the manufacturing process (grinding and heat treatment).

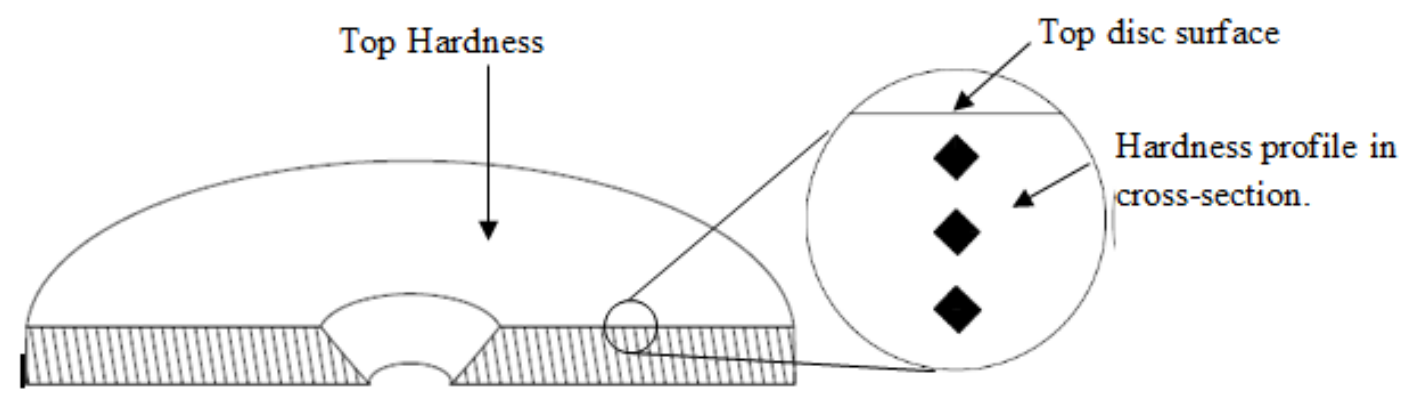

Figure 35 - Schematic view of transverse, indicating the direction of measurements.

The values near to the surface is about $750 \mathrm{HV}_{50}$ (macro hardness) on top configuration and $800 \mathrm{HV}_{2}$ (micro hardness) on cross-section, that is a little higher than the sphere $(750 \mathrm{HV})$.

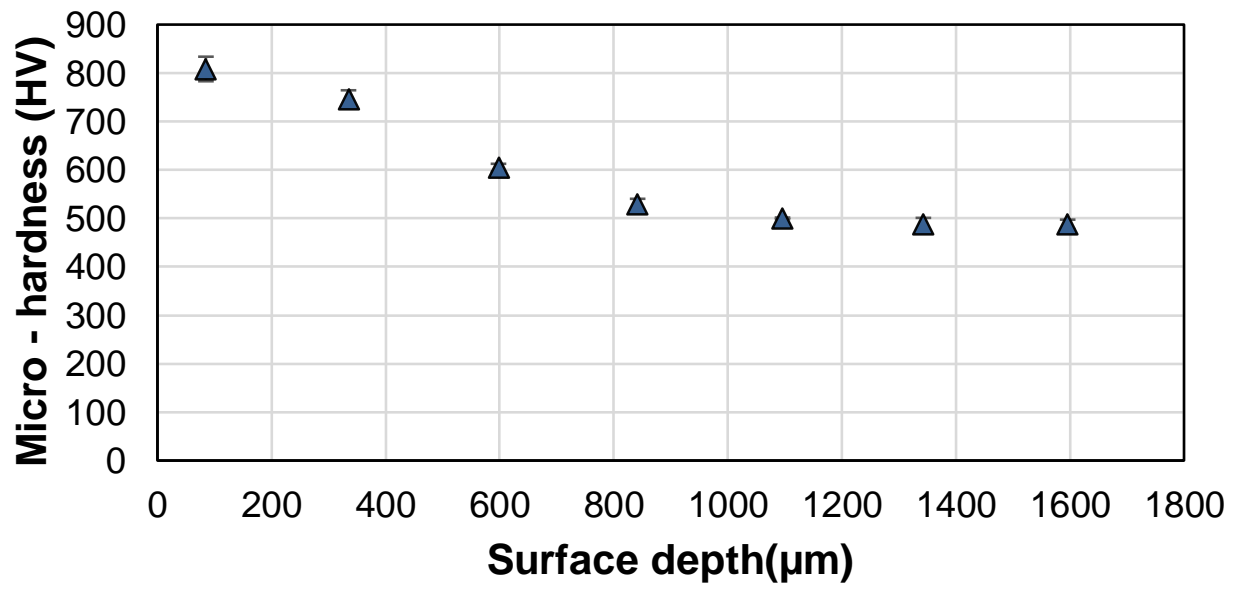

$\Delta$ Ground

Figure 36 - Microhardness profile X surface depth for a disc. 


\subsection{SPECIFIC FILM THICKNESS $(\Lambda)$}

The specific film thickness is an important parameter, since it will establish the lubrication regime. All tests were carried out in the EHD conditions. Therefore, the results of oil film thickness will be used further on.

As presented in the literature review (chapter 02) the calculation of $\Lambda$ parameter is based on equations 07-24:

Where:

$U$ is the tangential speed in $\mathrm{m} / \mathrm{s}$ shown in table 07 ;

$\eta$ is dynamical viscosity shown in table 06;

$\alpha$ is Piezoviscosity coefficients shown in table 06 and equation 04 ;

$\mathrm{R}_{x}$ is the equivalent radius shown in equation 13;

Fn is the normal load shown in table 07;

$v$ is the Poisson coefficient for the steel, which is approximately 0.29 ;

$\mathrm{E}^{*}$ is the elasticity coefficient and for steel material is approximately $213 \mathrm{GPa}$;

$\bar{\sigma}$ is dimensionless surface roughness;

Figure 37 displays the difference between Hamrock and Dowson (1981) and Khonsari e Masjedi (2014) formulation. In the present study it was considered Khonsari e Masjedi (2014) formulation. 


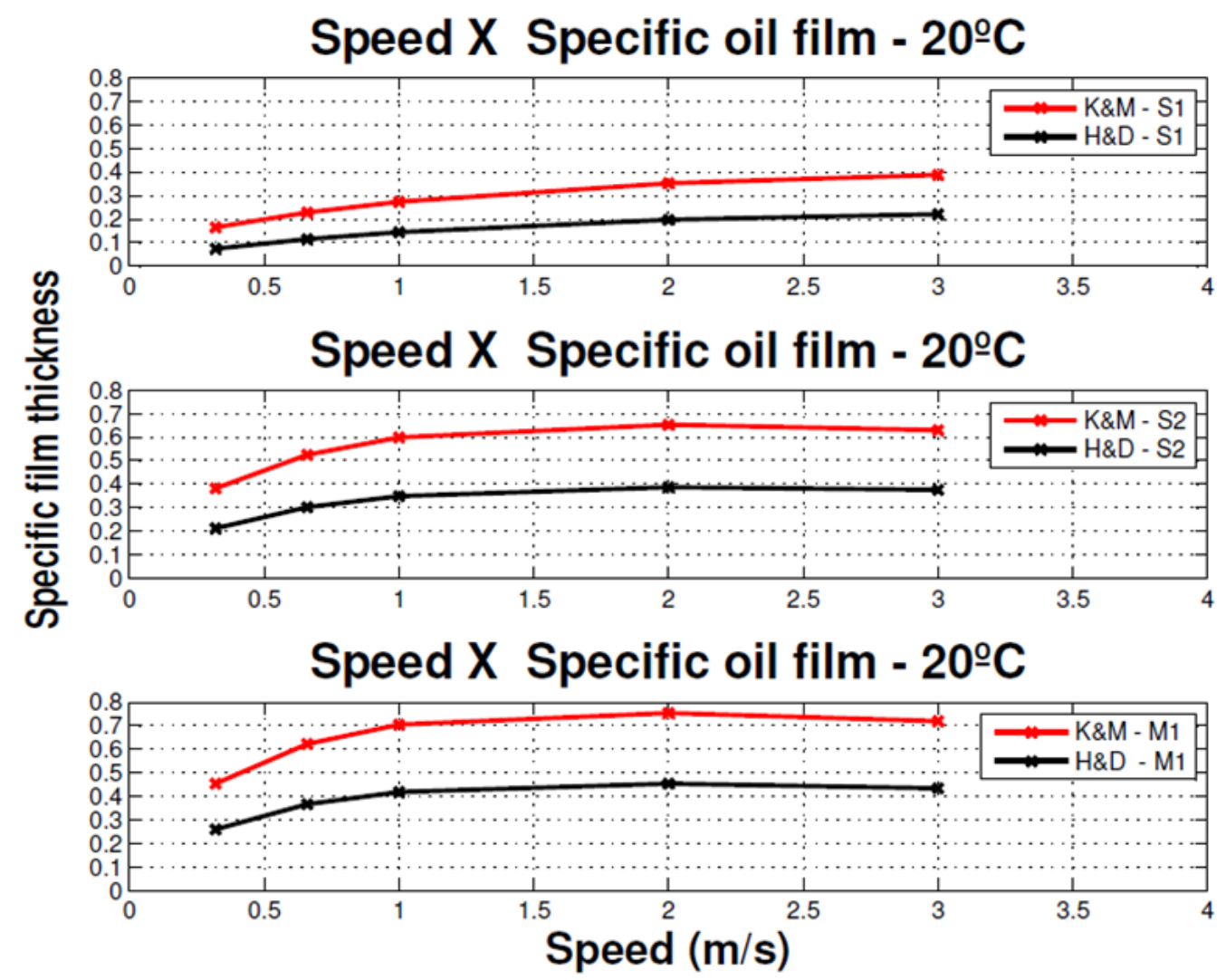

Figure 37 - Difference between Hamrock and Dowson (1981) (black line) formulation and Khonsari e Masjedi (2014) (red line) formulation for the $20^{\circ} \mathrm{C}$ temperature condition.

Based on the parameters presented, it was calculated, the thickness of the oil film for the three lubricants studied. These results are displayed in Figure 38, in which can observe variation of the thickness of the oil film with the speed $(\mathrm{m} / \mathrm{s})$ and the temperature ${ }^{\circ} \mathrm{C}$.

Figure 38 also displays the difference between the lubricants. One can observe the $\mathrm{S} 1$ oil has the lowest value of $\Lambda$. S1 oil also presents lowest viscosity at temperature of $20^{\circ} \mathrm{C}$ and the difference is remarkable.

The $\Lambda$ variation in all conditions tested (temperatures, speeds and loads) is between 0.10 and 0.75 (Table 9), and these results are a function of roughness. 
Speed X Specific film thickness - 20ㅇ C

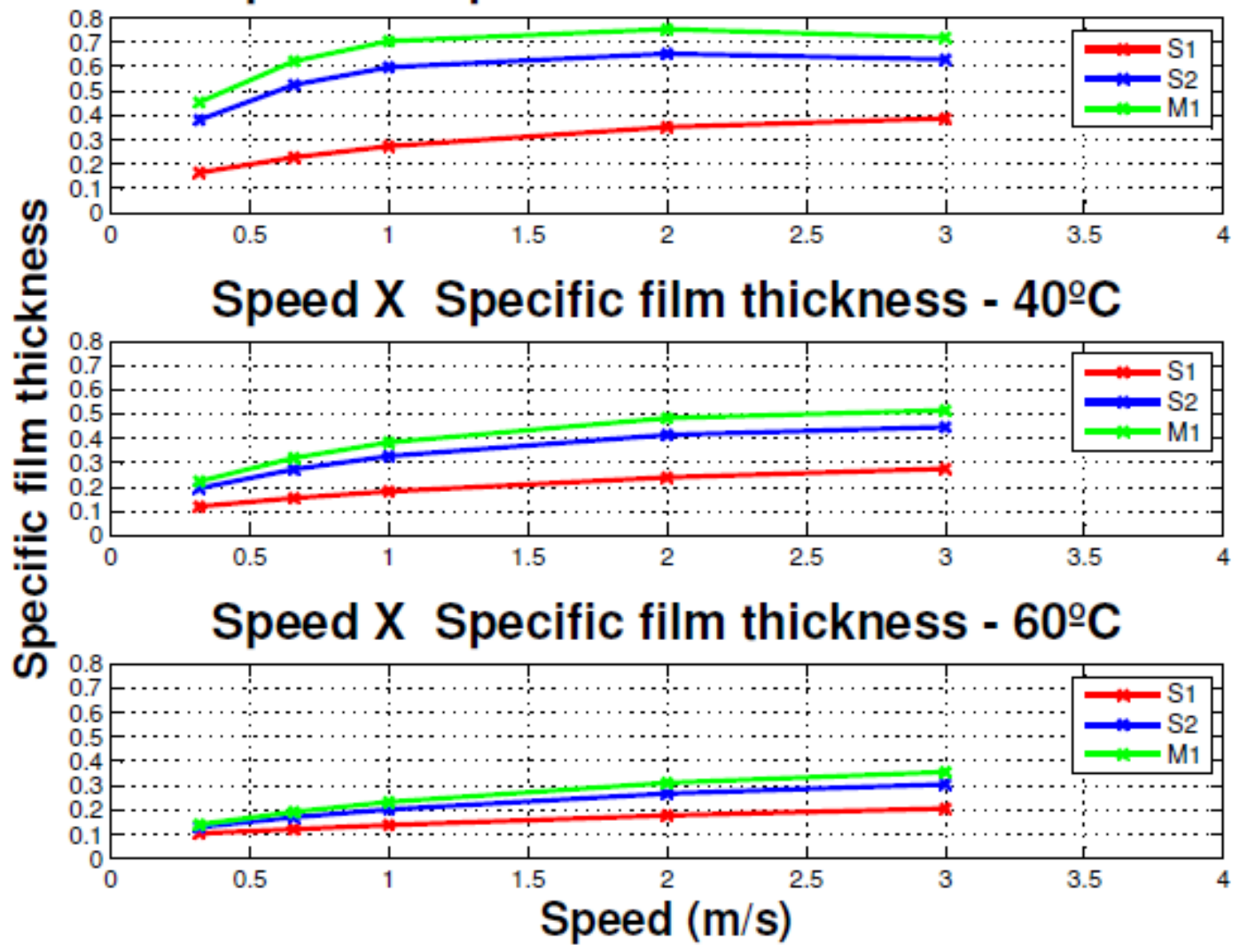

Figure 38 - Specific film thickness $(\Lambda)$ resultsa functionee lubricants as a function of speed $(0.32-3 \mathrm{~m} / \mathrm{s})$.

Table 9 - Specific film thickness calculated based on Khonsari and Masjedi (2014) formulation

\begin{tabular}{|c|c|c|c|c|c|c|c|}
\hline $\mathrm{T}(\mathrm{o} C)$ & $\mathrm{Speed}(\mathrm{m} / \mathrm{s})$ & $\mathrm{S} 1-(\Lambda)$ & $\mathrm{S} 1\left(\emptyset_{t}\right)$ & $\mathrm{S} 2-(\Lambda)$ & $\mathrm{S} 2\left(\emptyset_{t}\right)$ & $\mathrm{M} 1-(\Lambda)$ & $\mathrm{M} 1\left(\emptyset_{t}\right)$ \\
\hline \multirow{4}{*}{20} & 3 & 0.39 & 0.64 & 0.63 & 0.35 & 0.72 & 0.33 \\
\cline { 2 - 8 } & 2 & 0.35 & 0.75 & 0.65 & 0.48 & 0.75 & 0.45 \\
\cline { 2 - 8 } & 1 & 0.27 & 0.88 & 0.60 & 0.69 & 0.70 & 0.67 \\
\cline { 2 - 8 } & 0.66 & 0.23 & 0.92 & 0.52 & 0.79 & 0.62 & 0.77 \\
\cline { 2 - 8 } & 0.32 & 0.17 & 0.97 & 0.38 & 0.90 & 0.45 & 0.89 \\
\hline \multirow{4}{*}{40} & 3 & 0.28 & 0.78 & 0.45 & 0.58 & 0.52 & 0.56 \\
\cline { 2 - 8 } & 2 & 0.24 & 0.85 & 0.41 & 0.70 & 0.48 & 0.68 \\
\cline { 2 - 8 } & 1 & 0.18 & 0.93 & 0.33 & 0.85 & 0.38 & 0.84 \\
\cline { 2 - 8 } & 0.66 & 0.15 & 0.96 & 0.27 & 0.90 & 0.32 & 0.89 \\
\cline { 2 - 8 } & 0.32 & 0.12 & 0.98 & 0.20 & 0.96 & 0.22 & 0.95 \\
\hline \multirow{4}{*}{60} & 3 & 0.21 & 0.86 & 0.31 & 0.75 & 0.36 & 0.73 \\
\cline { 2 - 8 } & 2 & 0.18 & 0.91 & 0.27 & 0.83 & 0.31 & 0.82 \\
\cline { 2 - 8 } & 1 & 0.14 & 0.96 & 0.20 & 0.92 & 0.23 & 0.91 \\
\cline { 2 - 8 } & 0.66 & 0.12 & 0.97 & 0.17 & 0.95 & 0.19 & 0.94 \\
\cline { 2 - 8 } & 0.32 & 0.10 & 0.99 & 0.13 & 0.98 & 0.14 & 0.98 \\
\hline
\end{tabular}




\subsection{RESULTS OF CHEMICAL ANALYSIS OF LUBRICANTS}

Table 10 shows chemical analysis of the lubricants evaluated in this study. It was found Zinc, Calcium, Sulfur and Phosphorus. S1 and S2 lubricants have very similar chemical composition. Comparing $\mathrm{S} 1$ and $\mathrm{S} 2$ oils with $\mathrm{M} 1$ it can be noted that the lubricant M1 has no Zinc and a lower value of Calcium. Phosphorus contents in the M1 oil are lower than S1, while the Sulfur percentage is much higher in M1 than in the S1 and S2 oils.

\begin{tabular}{ccccc} 
Table 10 - Chemical composition in gear oils by using XRS ana \\
\cline { 2 - 5 } Gear Oils & \multicolumn{4}{c}{ XRS analysis } \\
\cline { 2 - 5 } & $\begin{array}{c}\text { Zn } \\
(\mathrm{ppm})\end{array}$ & $\begin{array}{c}\mathrm{P} \\
(\mathrm{ppm})\end{array}$ & $\begin{array}{c}\mathrm{S} \\
(\mathrm{ppm})\end{array}$ & $\begin{array}{c}\mathrm{Ca} \\
(\mathrm{ppm})\end{array}$ \\
\hline $\mathrm{S} 1$ & 2423 & 1951 & 5028 & 3301 \\
$\mathrm{~S} 2$ & 2373 & 1793 & 4991 & 3234 \\
M1 & 0 & 337 & 22108 & 14 \\
\hline
\end{tabular}

The results obtained from FTIR, showed in Figure 39, indicate differences among the evaluated lubricants. The $\mathbf{S} 2$ oil presented two distinct peaks in relation to the other lubricants:

- The peak at $\sim 1730 \mathrm{~cm}^{-1}$, can related be to carbonil $(C=O)$ of ester group and often used in anti-wear (AW) additives as reported by M. Diaby et al (2008);

- The peak at $\sim 1160 \mathrm{~cm}^{-1}$ which is common in viscosity improvers as reported by M. Diaby et al (2008);

Moreover, Figure 39. (b) provides the FTIR spectrum of synthetic base oil and synthetic base oil with $\mathrm{Zn}$ additives (AW). The main difference between these two spectrums is the peak at $\sim 975 \mathrm{~cm}^{-1}$ that indicates the presence $\mathrm{Zn}$, similarly to reported by Diaby et al. (2008). This peak was also observed in S1 and S2 oils (Figure 399.(a)), confirming the presence of the AW additives on these oils. 


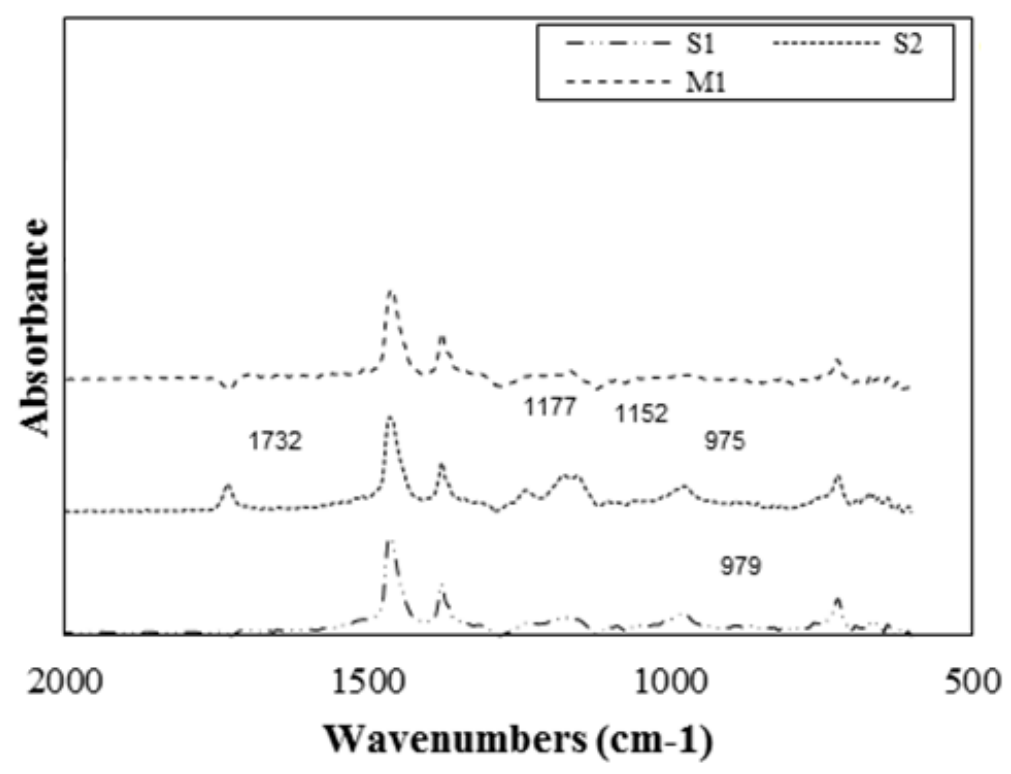

(a)

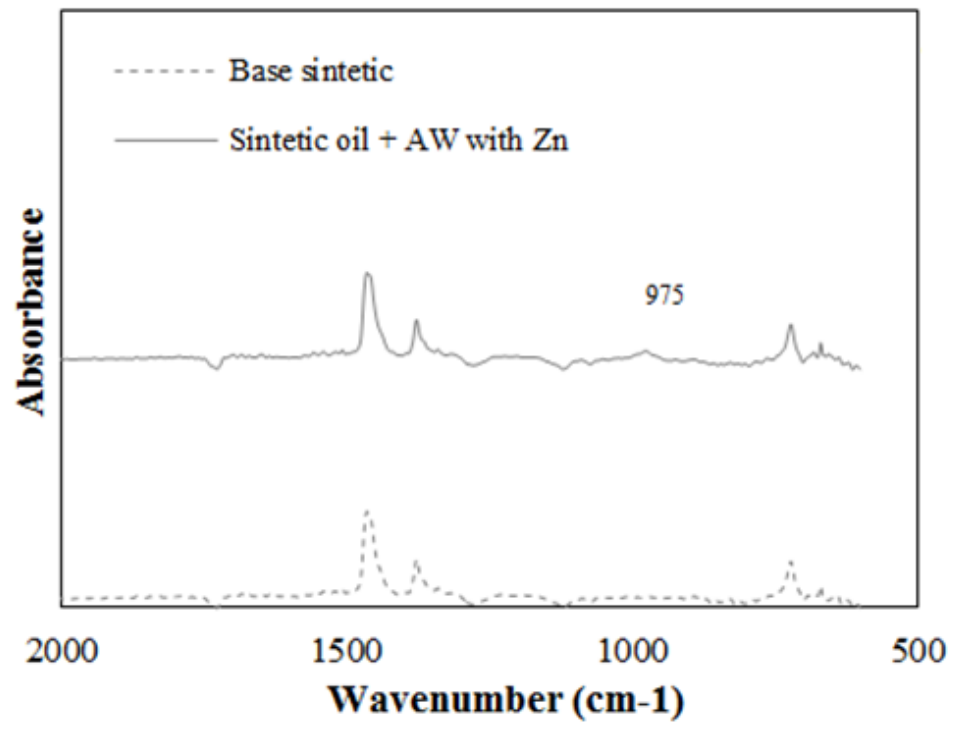

(b)

Figure 39 - Fourier Transformed Infra-Red spectrums (FTIR) of: (a) S1, S2 and M1 oil (b) comparative oils. 


\subsection{TRIOBOLOGICAL RESULTS - STARVED CONDITION}

This topic will present results of the tribological tests by using PLINT equipment (ball-on-disc). First of all, it will be shown the results for starved condition lubrication. Parameters were displayed in Table 7:

\subsubsection{Coefficient of friction (COF)}

Figure 40 shows an example of COF variation during the tests (parameters: S2 oil, $20^{\circ} \mathrm{C}$ and $30 \mathrm{~N}$ of applied load). The stabilization of the disc speed occurs in the first 30 seconds, thereon is applied the load (first regime). Then, the COF increased and became nearly constant (second regime). Hence, the test was set to be performed for $300 \mathrm{~s}$ in each speed evaluated. It is worth mentioning, the speed was decreased step by step from 1 to 0.66 and $0.32 \mathrm{~m} / \mathrm{s}$, respectively, without stopping the test.

During all tests the stationary regime occurred after the load was applied and Figures from all tests in Starved condition are presented in the Appendix B. In the next topics the results will be displayed taking into account the mean value of friction coefficient in a stationary regime, and therefore, the running-in was not evaluated. 


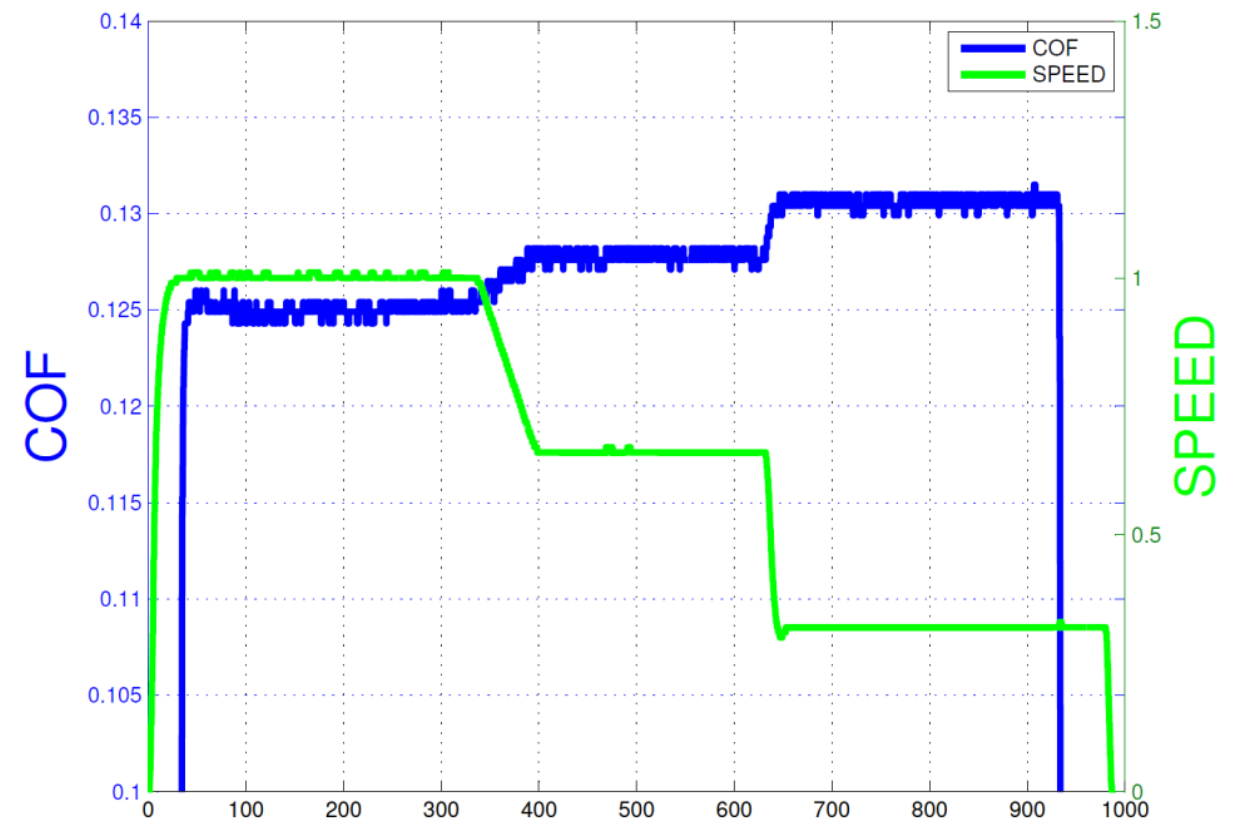

Figure 40 - Coefficient of Friction and Speed X Time - S2 oil at $20^{\circ} \mathrm{C}$ and $30 \mathrm{~N}$ of applied load.

\subsubsection{Coefficient of friction $x$ Speed}

This topic will show results of the average coefficient of friction versus speed for each tested condition (Figures 41 to 46 ).

Results of average friction coefficient are similar regarding the two synthetic lubricants, within the margin of error. At $20^{\circ} \mathrm{C}, 30 \mathrm{~N}$ and $50 \mathrm{~N}$ load, the lubricant S1 and S2 have a lower average coefficient of friction than lubricant M1, for all tested speeds. However, at $40^{\circ} \mathrm{C}$ and $60^{\circ} \mathrm{C}$ and $50 \mathrm{~N}$ load, it was observed that the lubricant $\mathrm{S} 1$ has an average friction coefficient lower than the lubricant S2, but the results are within the margin of error. M1 presents higher friction coefficient than both synthetic oils. For the conditions carried out at $40^{\circ} \mathrm{C}, 30 \mathrm{~N}$ and $50 \mathrm{~N}$ load, the $\mathrm{M} 1$ oil has a significant increase COF. These results can be related to the absence of $\mathrm{Zn}$ and $\mathrm{P}$ as antiwear (AW) chemical elements, and it is according to (BRANDÃO et al. 2011).

Summarizing, the conditions tested to make it possible to conclude that lubricant $\mathrm{S} 1$ and $\mathrm{S} 2$ has similar friction and, $\mathrm{M} 1$ has a little higher friction coefficient, considering speed variation. 
The graphics of speed $x$ COF are not generally presented, typically these results are presented by the Modified Stribeck or by means of the specific oil film thickness. However, Figures 41 to 46 give a good illustration about each condition tested and the error analysis.

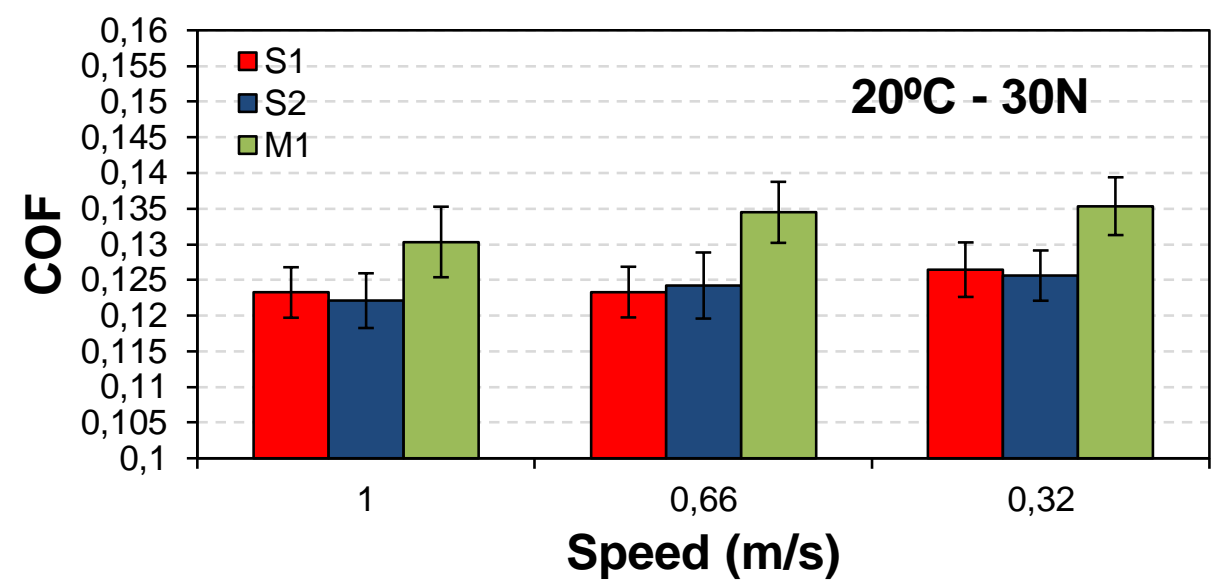

Figure 41 - Average coefficient of friction as a function of speed at $20^{\circ} \mathrm{C}$ and $30 \mathrm{~N}$ normal load.

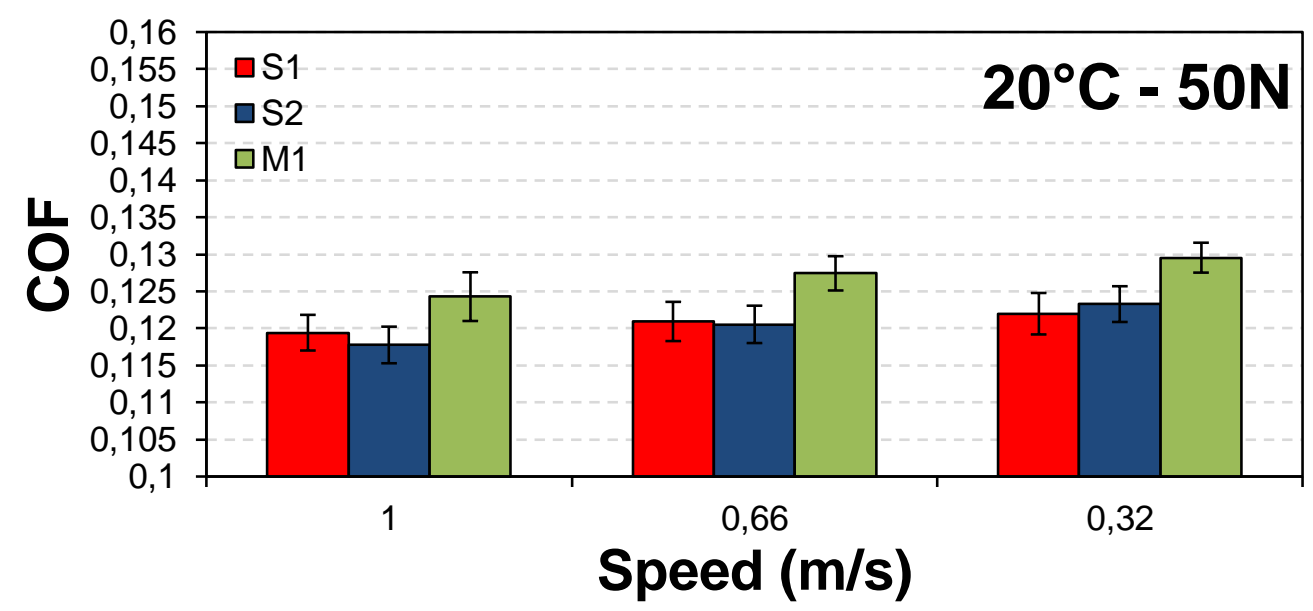

Figure 42 - Average coefficient of friction as a function of speed at $20^{\circ} \mathrm{C}$ and $50 \mathrm{~N}$ normal load.

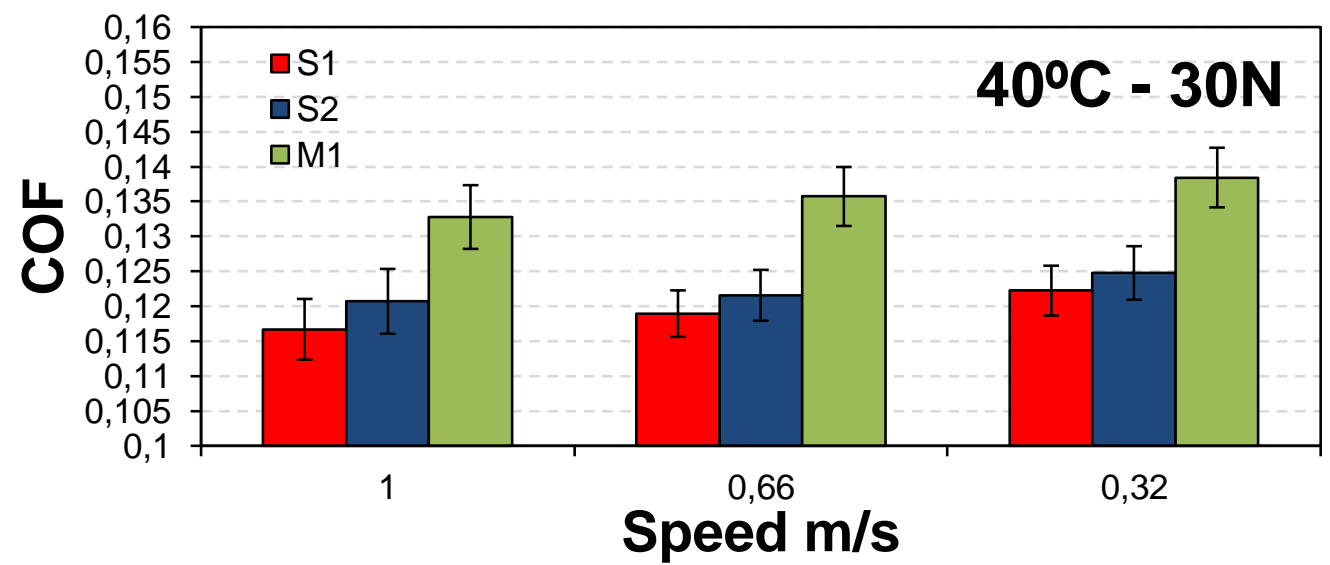

Figure 43 - Average coefficient of friction as a function of speed at $40^{\circ} \mathrm{C}$ and $30 \mathrm{~N}$ normal load 


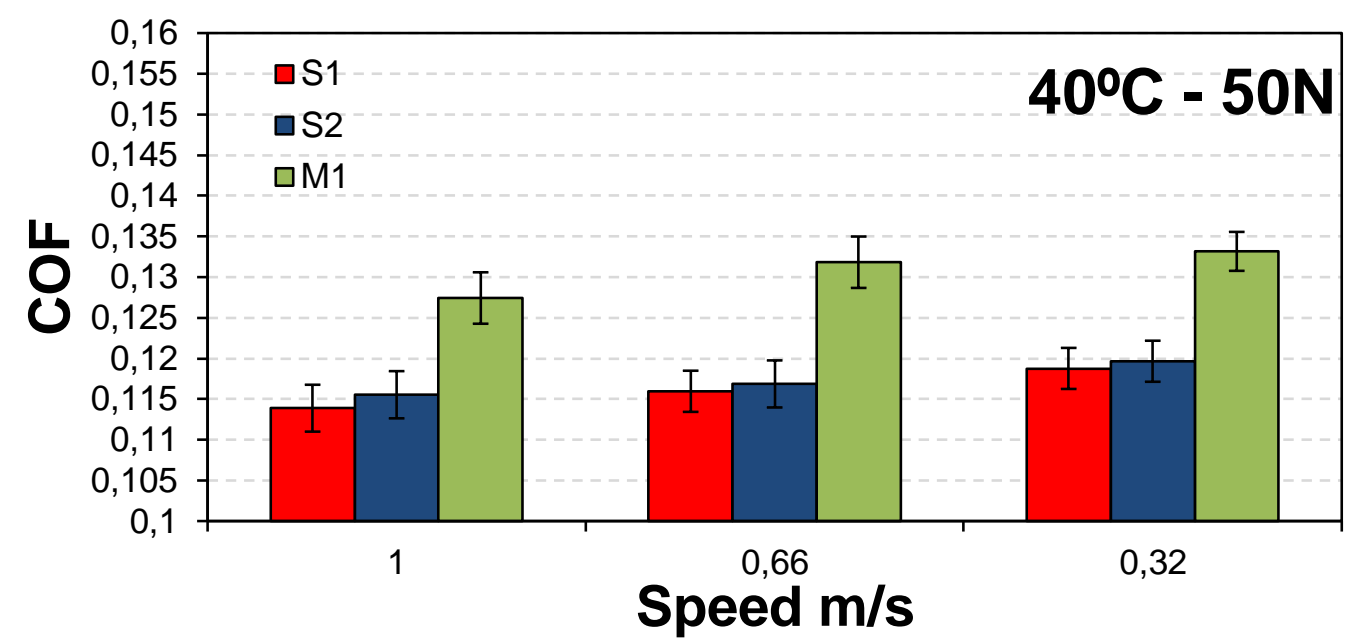

Figure 44 - Average coefficient of friction as a function of speed at $40^{\circ} \mathrm{C}$ and $50 \mathrm{~N}$ normal load

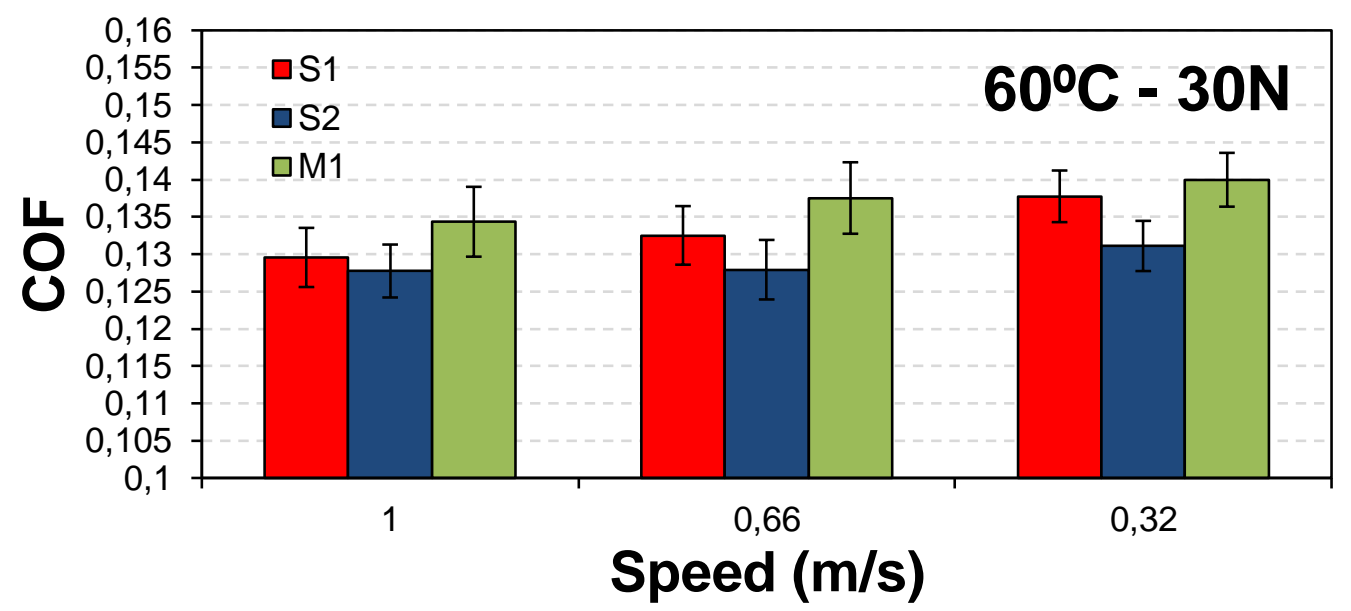

Figure 45 - Average coefficient of friction as a function of speed at $60^{\circ} \mathrm{C}$ and $30 \mathrm{~N}$ normal load

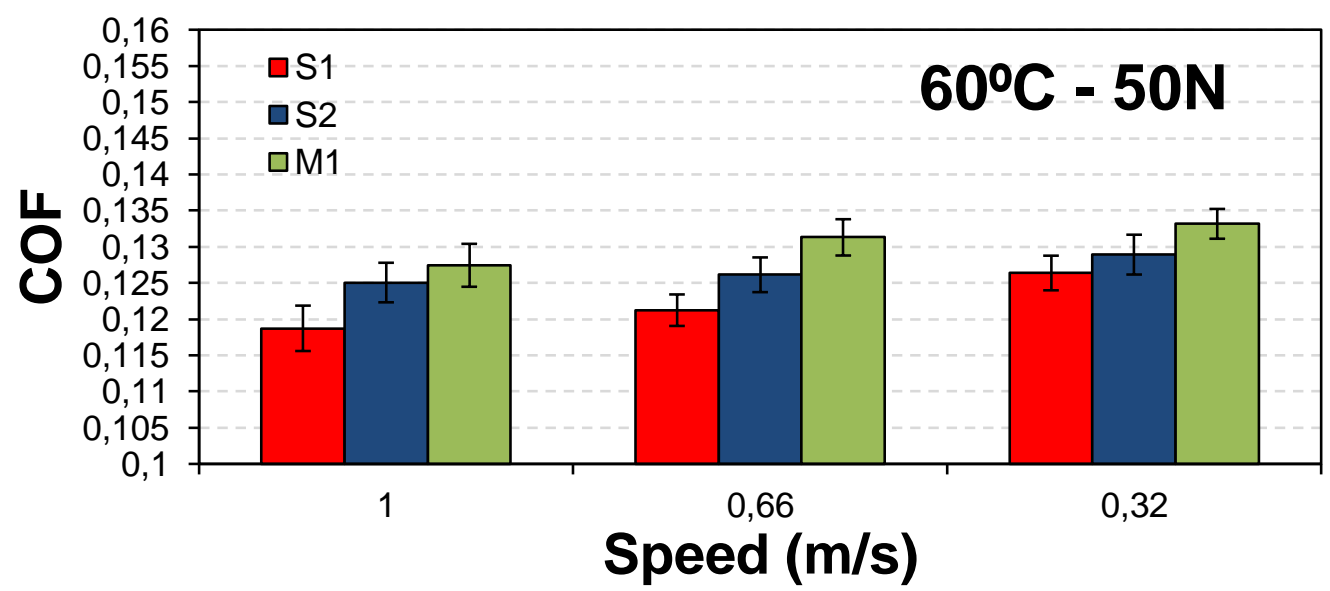

Figure 46 - Average coefficient of friction as a function of speed at $60^{\circ} \mathrm{C}$ and $50 \mathrm{~N}$ normal load. 


\subsubsection{Coefficient of friction $\times$ Specific film thickness}

Each chart (Figure 47) shows the average coefficient of friction values for the three different types of lubricants, which have been tested in conditions of loads, speeds and temperatures presented in Table 7. The first line indicates the S1 oil, the second line indicates S2 oil and the third one indicates M1 oil behavior. The left side shows the load condition of $30 \mathrm{~N}$ and the right side shows $50 \mathrm{~N}$ load condition. The red line indicates the results at $20^{\circ} \mathrm{C}$, the blue line indicates results at $40^{\circ} \mathrm{C}$ and the black line indicates results at $60^{\circ} \mathrm{C}$, by using the specific film thickness parameter. Each chart below is presented in Appendix D separately.

The specific film thickness for S2 and M1 is higher than for S1 oil, due to the viscosity and the Piezoviscosity value. In addition, it was observed the specific oil film thickness is lower than 0.7 for oils $\mathrm{S} 2$ and $\mathrm{M} 1$ and, for $\mathrm{S} 1$ it was lower than 0.27 .

Based on Table 4 (topic 2.2.2) S1 and S2 oil reach only boundary lubrication regime $(0.1<\Lambda<0.7)$ for all temperature conditions. $M 1$ at highest speed $(1 \mathrm{~m} / \mathrm{s})$ and at $20^{\circ} \mathrm{C}$ condition reach a mixed lubrication regime $(\Lambda>0.7)$. However, for all speeds the boundary lubrication regime was achieved $(0.14<\Lambda<0.62)$ considering specific film thickness, considering synthetic oils. The specific film thickness of $\mathrm{S} 1$ oil at $20^{\circ} \mathrm{C}$ and $40^{\circ} \mathrm{C}$ is similar to at $40^{\circ} \mathrm{C}$ and $60^{\circ} \mathrm{C}$ of $\mathrm{S} 2$ and $\mathrm{M} 1$ oil.

Analyzing the Figure 47 is possible to conclude that at $20^{\circ} \mathrm{C}$ and $40^{\circ} \mathrm{C}$ the regime found is mixed lubrication, at $60^{\circ} \mathrm{C}$ there is a transient phase between mixed and boundary lubrication, achieving boundary in a lower speed tested. The values defined on a Table 4 should be improved for these lubrication conditions and test parameters. 


\section{Starved}

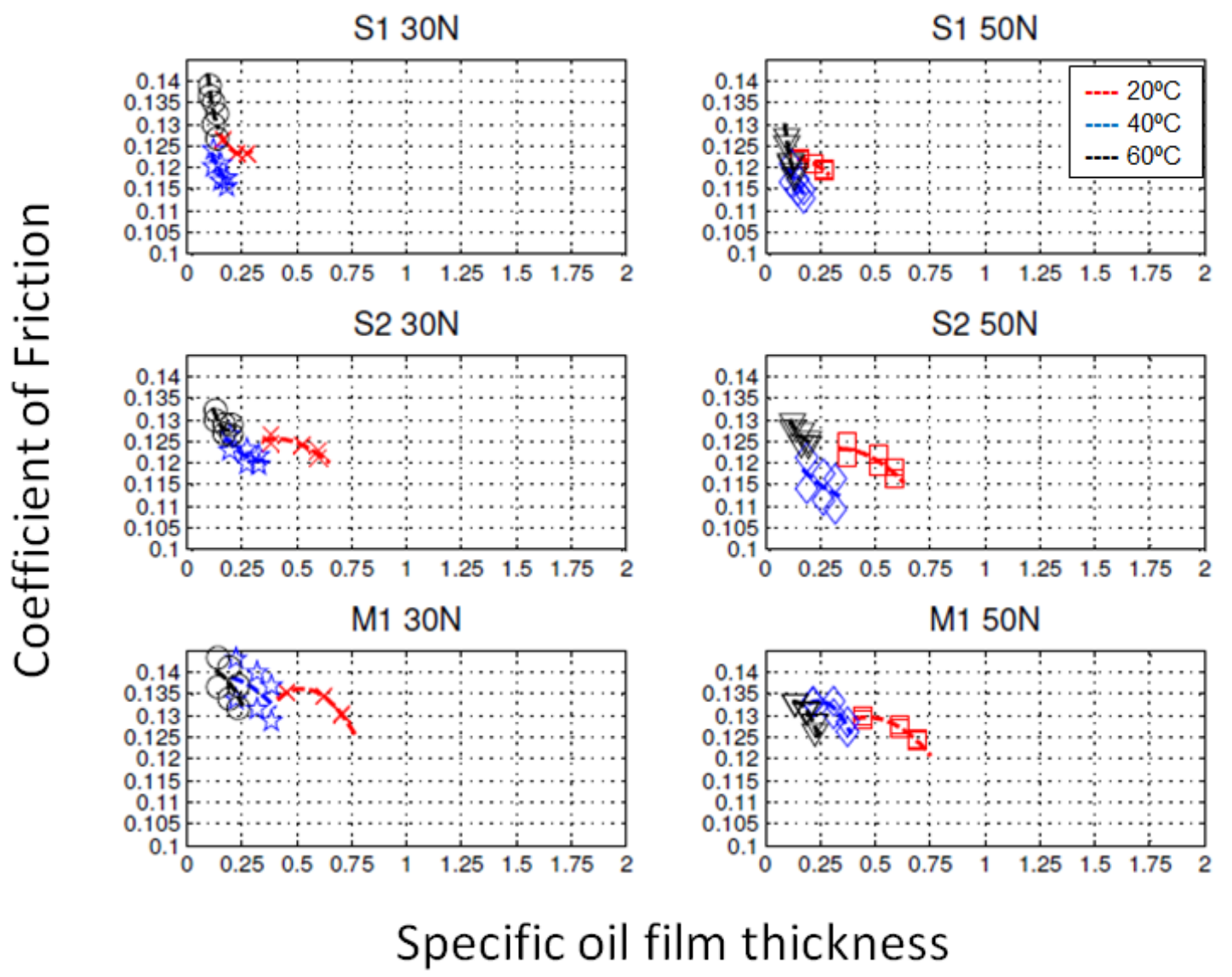

Figure 47 - Average coefficient of friction as a function of $\Lambda$ for all conditions tested in the starved condition - S1, S2 and M1 oil.

Figure 47 shows that S1 oil has a higher decrease of COF than S2 and M1 oil. The S1 oil has also lower piezo-viscosity coefficient ( $\alpha$ ) as compared as S2 and M1 oil. Table 6 emphasizes these results.

\section{Coefficient of friction $x$ Loads}

In Figure 47, in which can be compared the behavior of coefficient of friction by applying $30 \mathrm{~N}$ load with $50 \mathrm{~N}$ load, it is possible to observe a decrease of the coefficient of friction is more pronounced on $\mathrm{S} 1$ oil on the $60^{\circ} \mathrm{C}$ test condition. This decrease is observed in the most of conditions and it should be explained by the EP additives presence. 


\section{Coefficient of friction $\mathrm{x}$ Temperatures}

For $\mathrm{S} 1$ and $\mathrm{S} 2$ oil It is clearly observed that at $40^{\circ} \mathrm{C}$ conditions the lowest COF is obtained and, this result may be related to the AW additive packages. This result is important for transmission efficiency cycle, once the temperatures between $31^{\circ} \mathrm{C}$ to $40^{\circ} \mathrm{C}$ represents almost $30 \%$ of the test time as demonstrated in topic 3.2 .

M1 oil has higher COF than $\mathrm{S} 1$ and $\mathrm{S} 2$ oil mainly at $40^{\circ} \mathrm{C}$ and $60^{\circ} \mathrm{C}$ due to the $\mathrm{M} 1$ oil has not $\mathrm{Zn}$ and $\mathrm{P}$ as $\mathrm{AW}$ chemical elements.

Additives present in M1 lubricant seems not to be stable at $40^{\circ} \mathrm{C}$ and $60^{\circ} \mathrm{C}$, since COF values are with dispersion in two replicas.

\section{Coefficient of friction $x$ Speeds}

It is worth noting that with the decrease of speed there is an increase of the average coefficient of friction for all lubricants and, by increasing the load will result in a decrease of the average friction coefficient, Thurston apud Woydt and Wäsche (2010), reported the same behavior between COF and speed.

Figure 48 shows all the conditions tested, in a different point of view, instead of showing the oil test condition are shown the different temperatures for all lubricants in different applied loads.

Even the specific oil film thickness is lower for S1 in relation to S2 and M1. The COF for $\mathrm{S} 1$ at $20^{\circ} \mathrm{C}$ is in an error margin for $\mathrm{S} 2$ and lower than the M1, and it should be due M1 does not content AW chemical elements.

At $40^{\circ} \mathrm{C}$ and $60^{\circ} \mathrm{C}$ results are close as a function of the viscosity and piezoviscosity presents lower differences as compared as at $20^{\circ} \mathrm{C}$.

For the highest speeds, where there is a tendency to move from boundary lubrication to mixed lubrication, the COF values of $\mathrm{S} 2$ and M1 oil tends to be lower than $\mathrm{S} 1$ oil. It can be explained by the higher piezo-viscosity at $20^{\circ} \mathrm{C}$ and $50 \mathrm{~N}$ of load, Brandão et al. (2011) and Vengudusamy et al. (2013) related to the same behavior described above. 


\section{Starved}

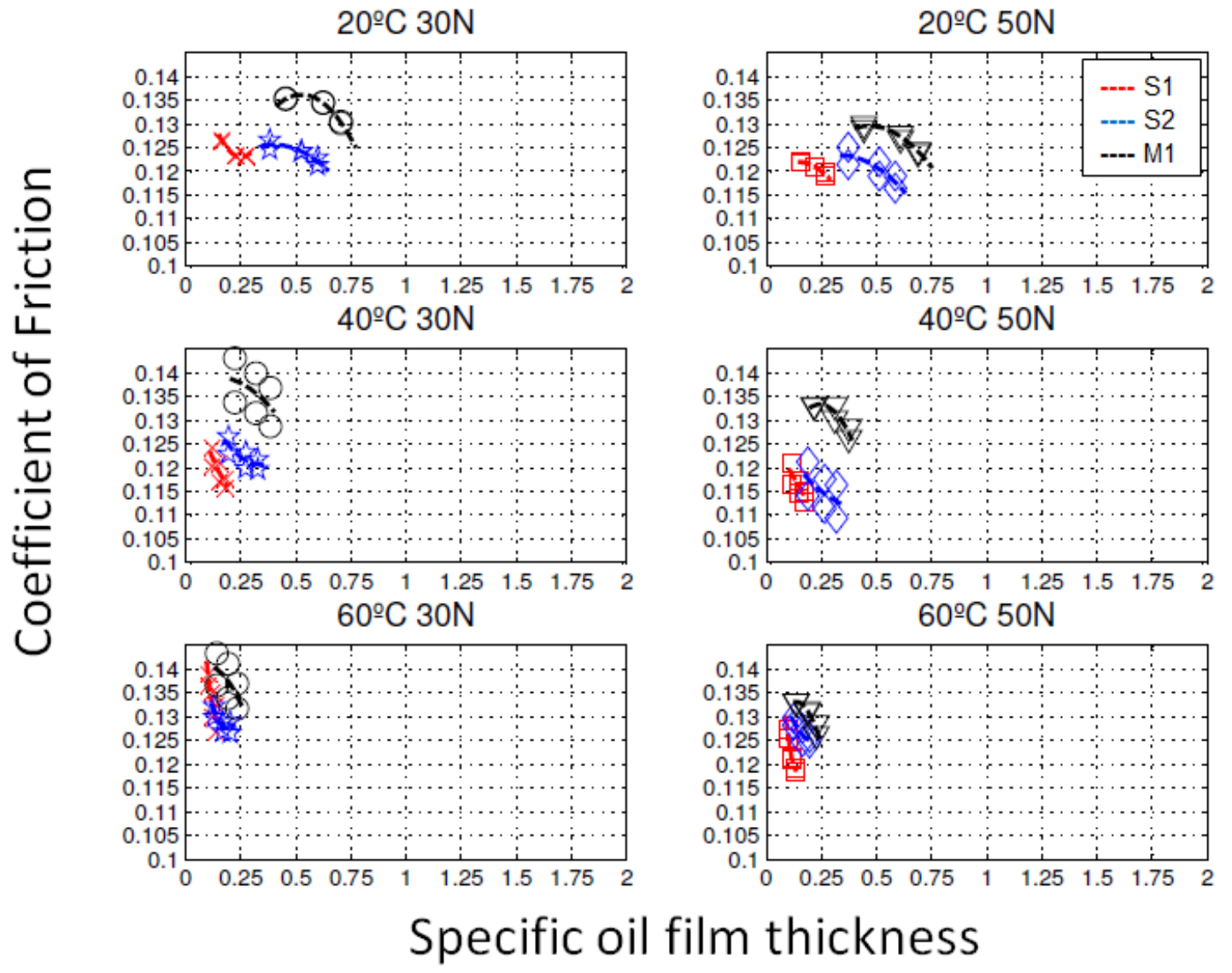

Figure 48 - Average coefficient of friction in function of $\Lambda$ for all conditions tested in the starved condition for S1, S2 and M1 oil in terms of temperatures and loads.

\subsection{BOUNDARY LUBRICATION TESTS}

Figure 49(a) and (b) present, respectively, a comparison of the different oils tested under two normal loads in terms of friction coefficient and wear. The wear was calculated as the volume removed from the balls after test, since the discs barely worn out. In terms of wear, no differences were observed whatever is the load applied or the used lubricant, while slight differences were observed in terms of friction. The highest friction values were obtained with the synthetic lubricants (S1 and S2) and the lower ones with the mineral lubricants during the low load test $(50 \mathrm{~N})$. At the higher load test $(100 \mathrm{~N})$ all the lubricants presented similar friction values. It is also observed a slight reduction of friction coefficient 
with the increase of normal load for the synthetic oils S1 and S2, but not for the mineral M1.

The highest friction values of the synthetic lubricants were obtained at $50 \mathrm{~N}$ load, and they are most likely related to the formation of ZDDP tribofilm. It is worth mentioning that the synthetic oils studied contain dispersants and detergents, which might change the tribological response of the ZDDP films, as shown by Spikes et al. The ZDDP films are easily removed by rubbing in dispersantcontaining-oil.

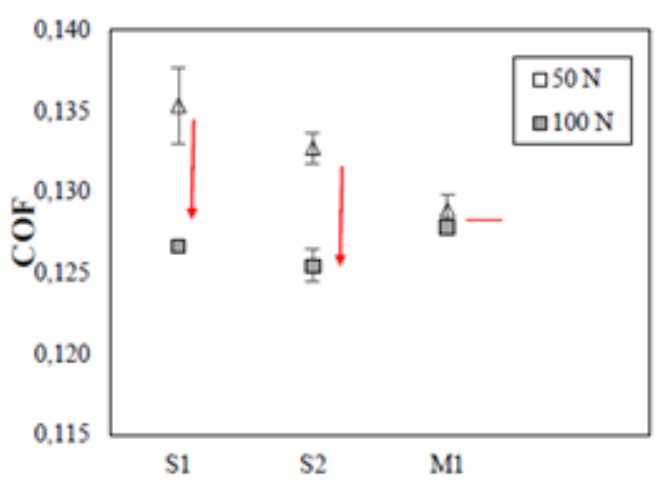

(a)

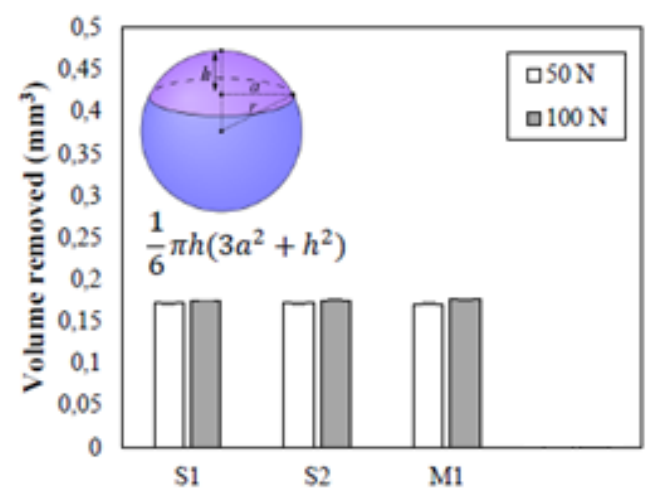

(b)

Figure 49 - (a) Average COF and (b) volume removed, considering all the lubricant oils tested at 50 and $100 \mathrm{~N}$ of normal lo, d, Tertuliano I.S et al., 2016.

Figure 50 shows only images of the worn surface of balls and discs tested with $100 \mathrm{~N}$ load, since the $50 \mathrm{~N}$ images provide similar insights. As can be seen, oxidative wear was present not only on the worn ball's surface, but also on the asperities of the discs.

EDS analysis by SEM (Figure 51) confirms the presence of $Z n$ and $P$ on the ball's surface tested with the lubricants with a zinc based AW additives (S1 and S2), and only S and P on the surfaces tested with M1 and SS2 lubricants, as expected. However, only $\mathrm{O}$ and $\mathrm{S}$ elements were found on the wear track on all discs (Figure 52). The formation of some tribochemical films requires oxide removal during the rubbing process, which in this case occurred only in the softest material (balls). This explains the absence of Zn from ZDDP tribofilm on the discs' surface and its presence on the ball's surface. 

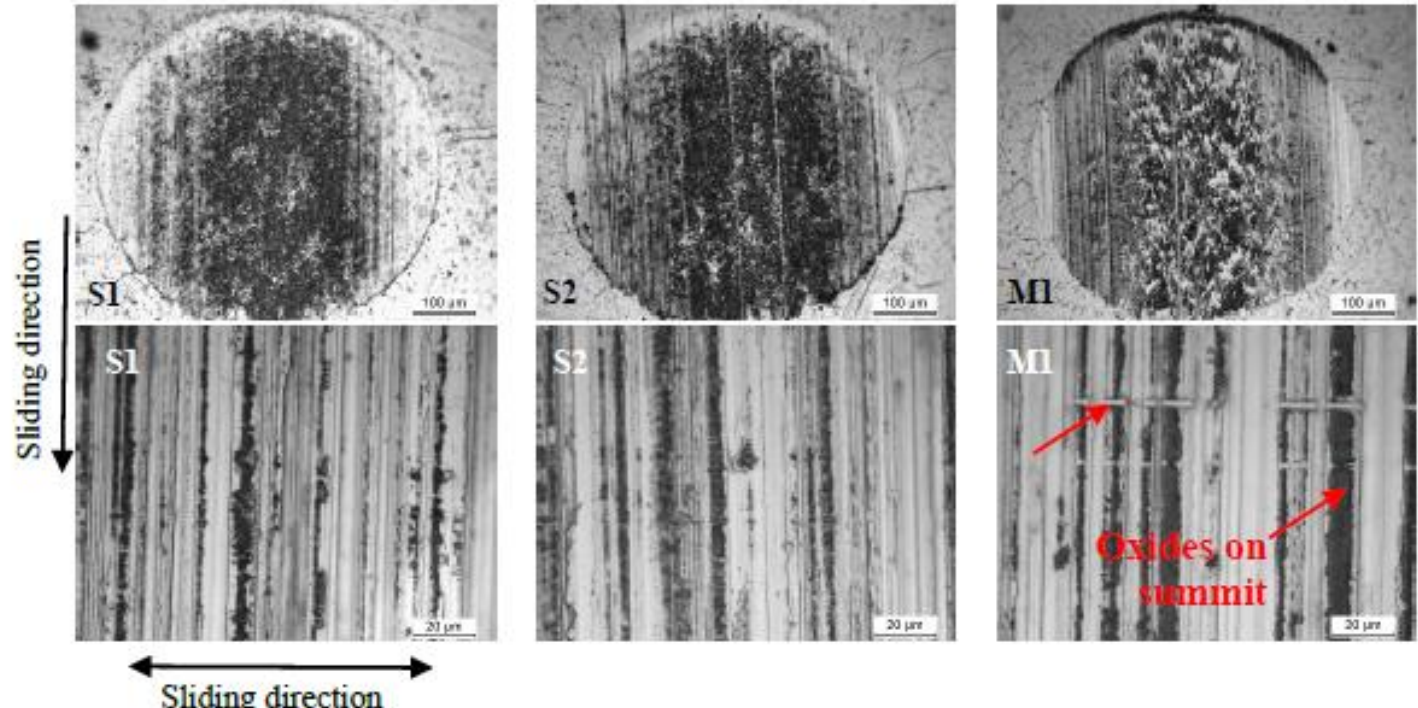

Figure 50 - Features on the wear scars on the steel balls (top) and discs. Surfaces (bottom) by optical microscopy, showing oxides (dark patches) and abrasion scratches, Tertuliano I.S et al., 2016.
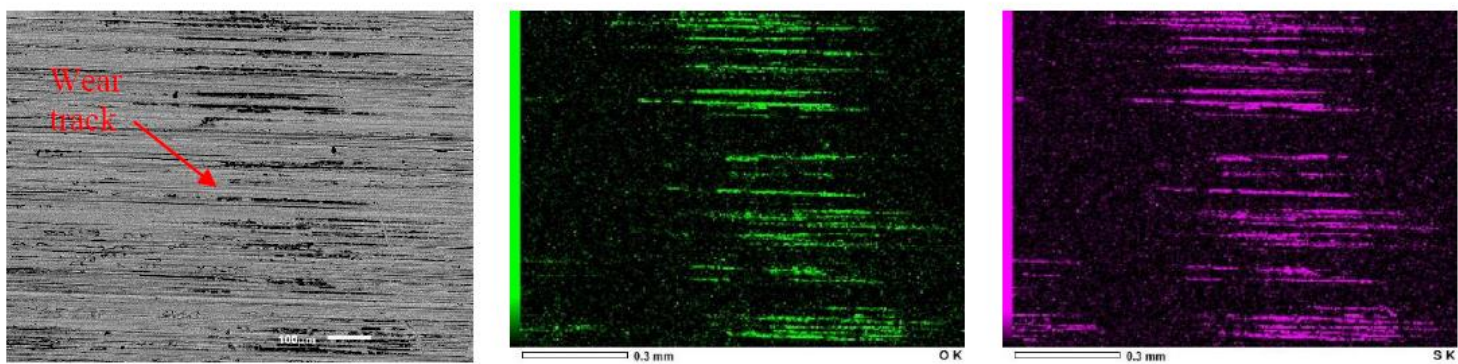

Figure 51 - SEM images of wear track, tested with S1 oil and 100N, present S and O in EDS map, Tertuliano I.S et al., 2016. 

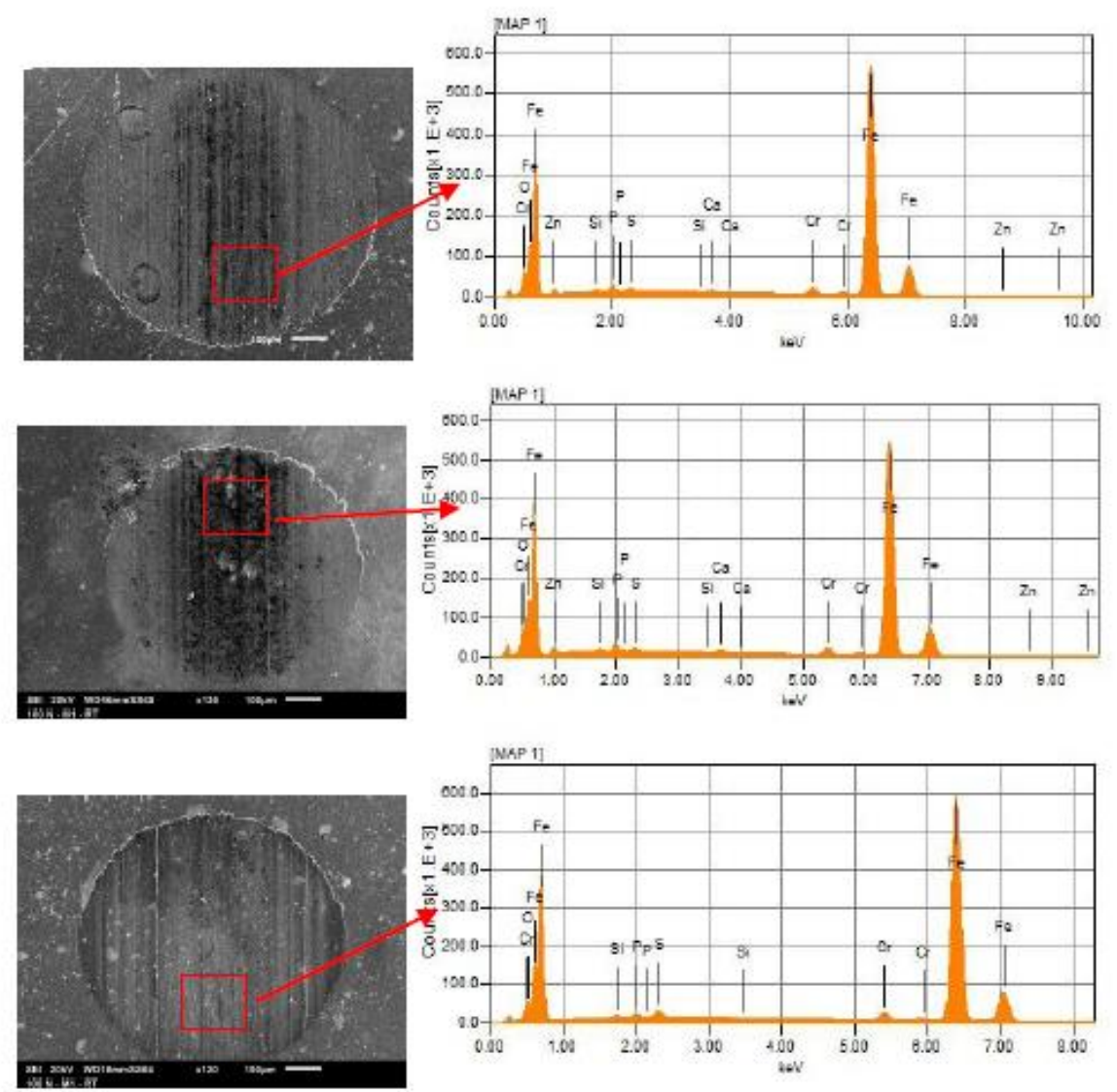

Figure 52 - SEM images of ball worn scar with corresponding chemical analysis by means of EDS. Oil S1, S2 and M1, respectively, Tertuliano I.S et al., 2016.

\subsection{TRIOBOLGICAL RESULTS - FULLY FLOODED CONDITIONS}

In this topic the results obtained through the triboligical testing are shown, according to Table 6 and Table 7 for each condition already mentioned. Two replicas were used for each test, a system that provides the oil supply to guarantee the minimum oil film thickness, in case the tangential velocity is high enough to eject the oil from the disc surface.

\subsubsection{Coefficient of friction X Speed}

The results of the average friction coefficient versus speed for each condition tested will be demonstrated on this topic. Figures related to COF $\mathrm{x}$ time 
are displayed in Appendix C. COF $\mathrm{x}$ time presented the same behavior demonstrated in the item 4.5.

Figures 53 to 58 demonstrate that the results of average friction coefficient are similar for the three lubricants; differences are within the margin of error. At $20^{\circ} \mathrm{C}$, lubricant $\mathrm{S} 1$ has the lowest average friction coefficient when compared with lubricant S2 for all tested velocities, even S1 oil presents lower oil film thickness than $\mathrm{S2}$, and it is due to viscosity and piezoviscosity values.

For the conditions of the tests conducted at $40^{\circ} \mathrm{C}$ and $60^{\circ} \mathrm{C}$, it was observed that the lubricant $\mathrm{S} 1$ has a higher average friction coefficient than the $\mathrm{S} 2$ and M1 lubricants. The exception is the condition conducted at $60^{\circ} \mathrm{C}$ and $30 \mathrm{~N}$ normal load and speed at $3 \mathrm{~m} / \mathrm{s}$. In all tests oil $\mathrm{S} 1$ and $\mathrm{S} 2$ have the COF value under error measurement. In topic 4.4 the FTIR results for S1 and S2 showed that they have a fit Wavenumber close, then for boundary condition the results of COF are expected to be similar, once S1 and S2 have a similar AW additive package.

It can be observed that the decrease in the speed will result in an increase of the average coefficient of friction for all lubricants. On the other hand, the increase in the contact pressure will result in a decrease of the average friction coefficient for mixed and boundary regimes. Brandão et al (2011) reported that the contact pressure affects mixed lubrication, since an increase in the contact pressure decreases the friction due to activating the AW additive packages.

By comparing tests without and with oil supply, the results of friction for M1 oil are totally different. For oils S1 and S2, the results showed the same behavior. 


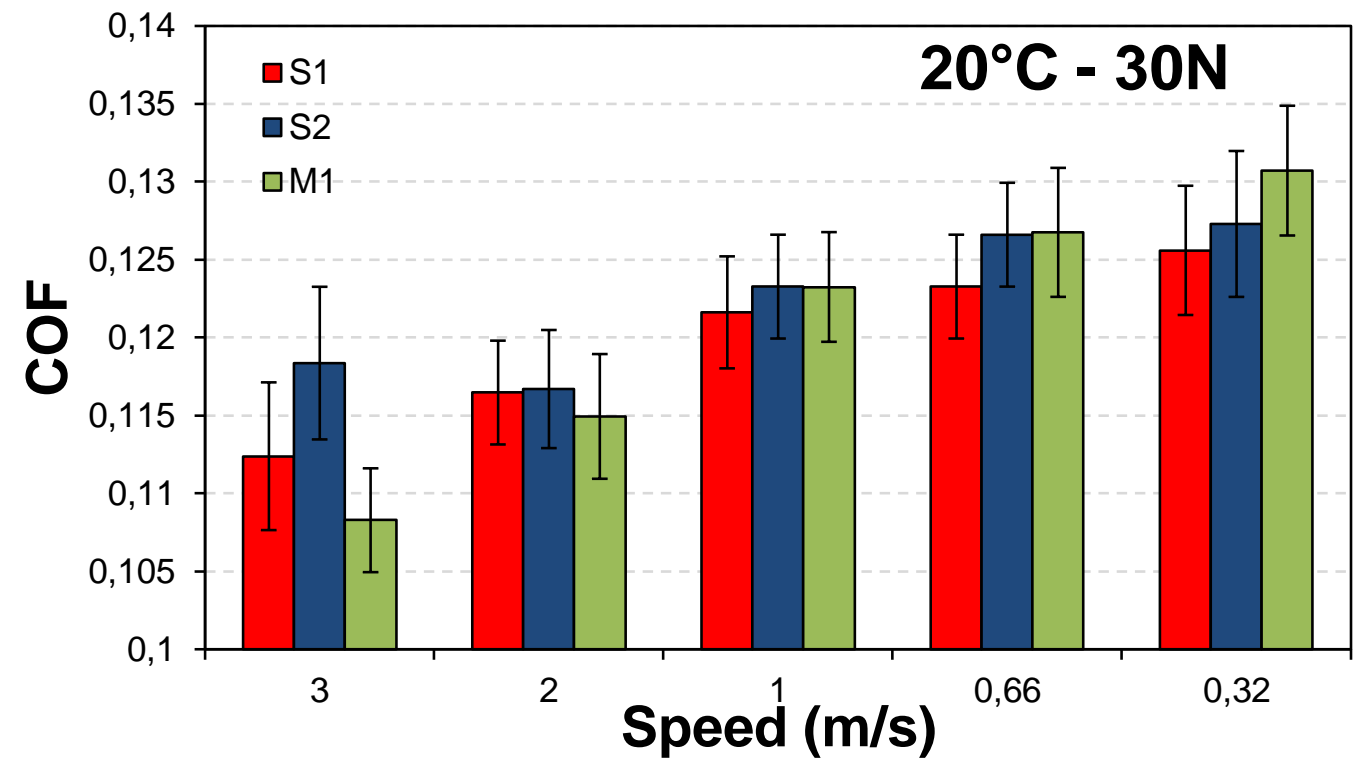

Figure 53 - Average coefficient of friction in function of velocity for $20^{\circ} \mathrm{C}$ temperature, $30 \mathrm{~N}$ normal load.

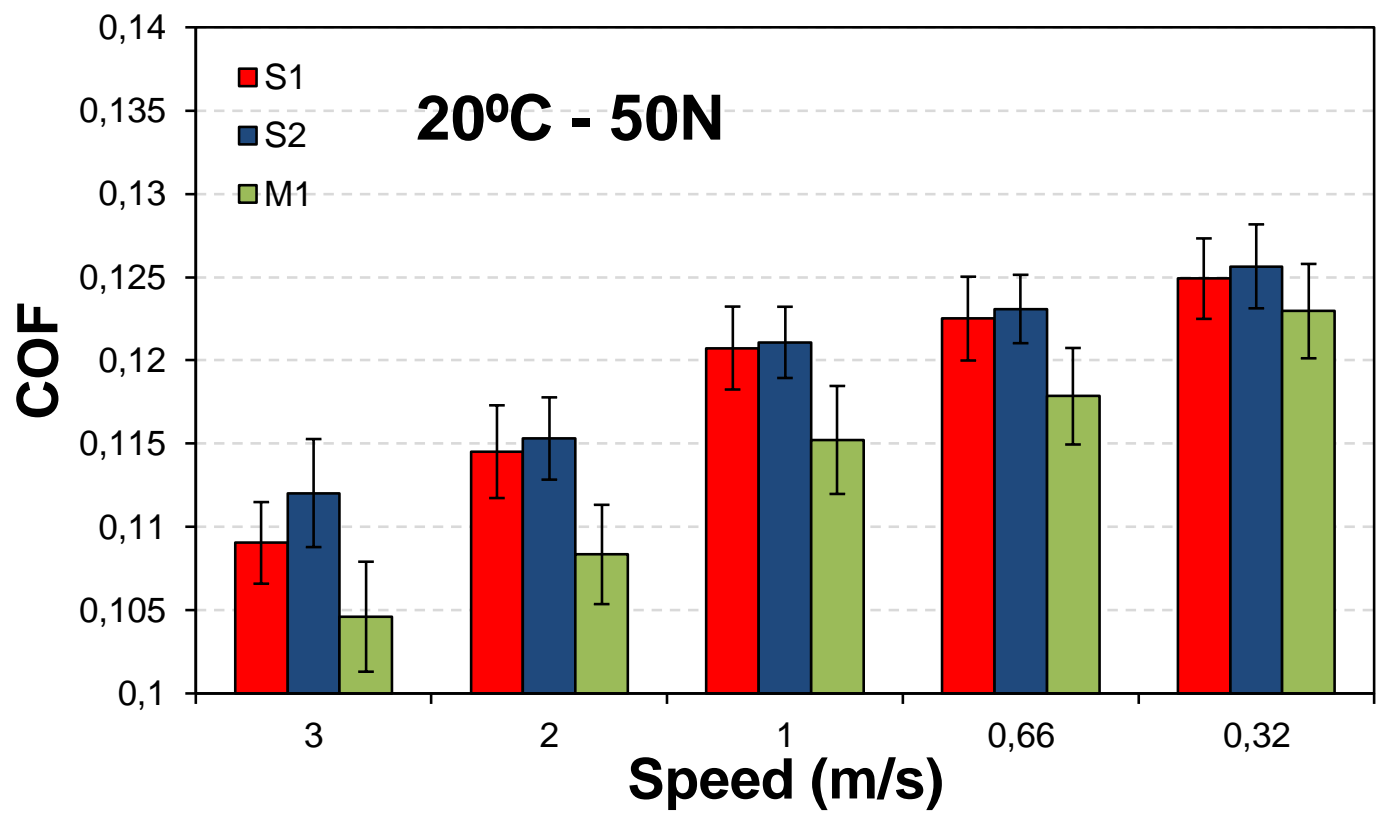

Figure 54 - Average coefficient of friction in function of velocity for $20^{\circ} \mathrm{C}$ temperature, $50 \mathrm{~N}$ normal load. 


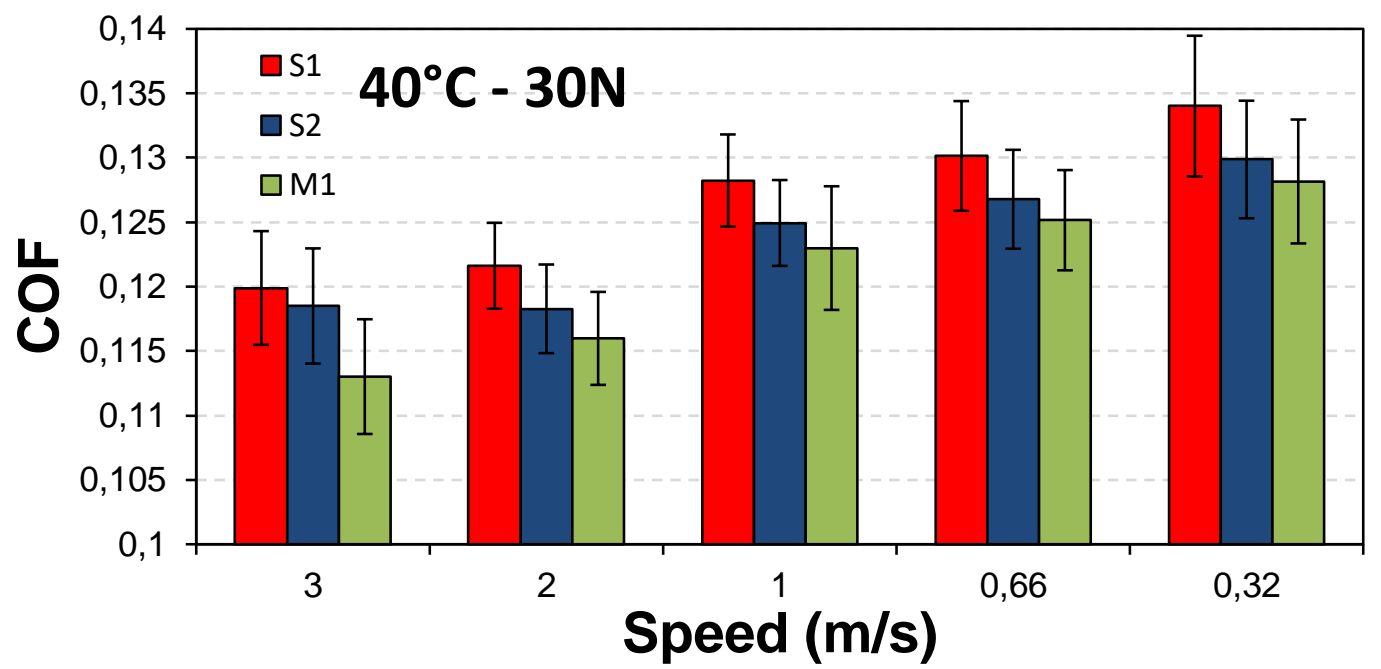

Figure 55 - Average coefficient of friction in function of velocity for $40^{\circ} \mathrm{C}$ temperature, $30 \mathrm{~N}$ normal load.

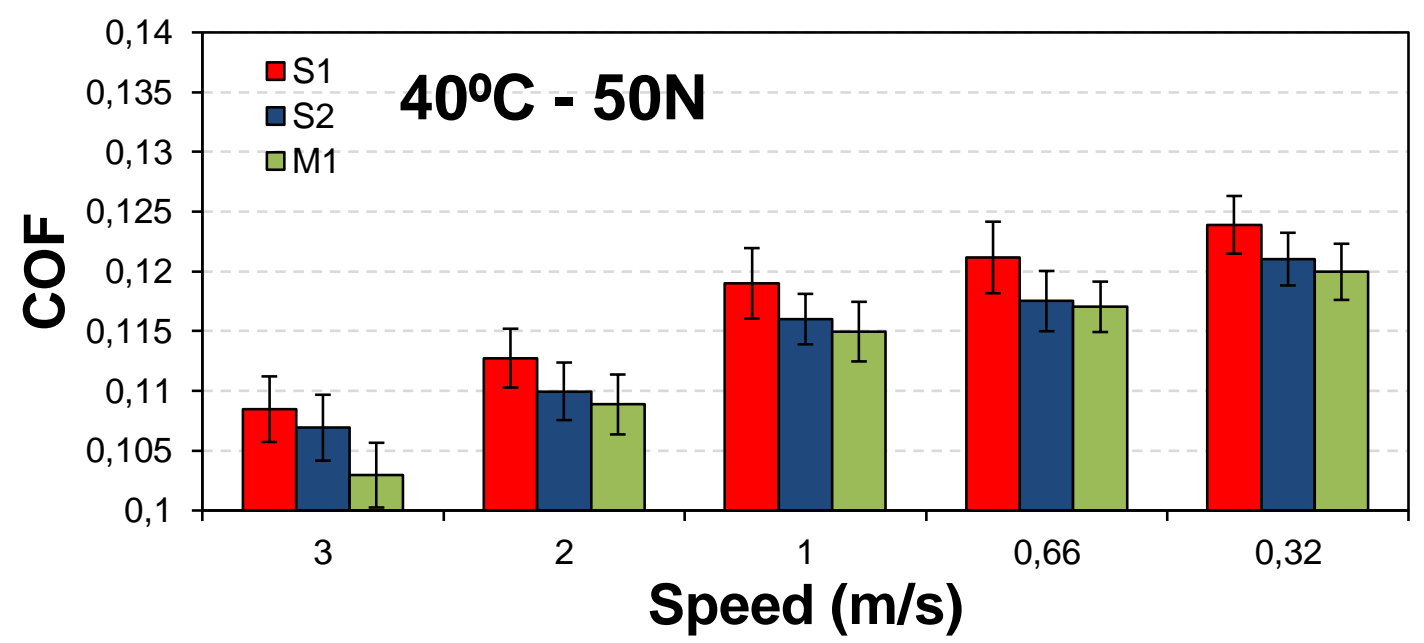

Figure 56 - Average coefficient of friction in function of velocity for $40^{\circ} \mathrm{C}$ temperature, $50 \mathrm{~N}$ normal load.

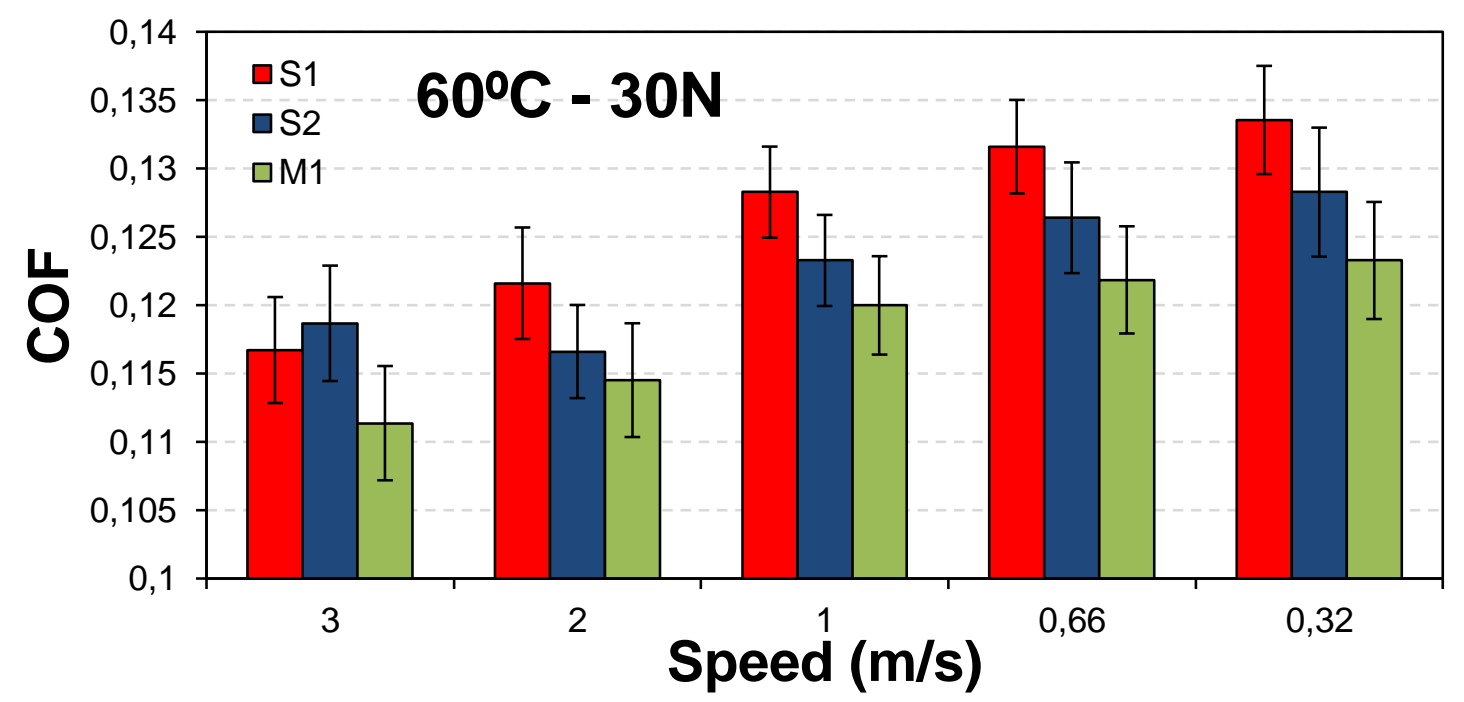

Figure 57 - Average coefficient of friction in function of velocity for $60^{\circ} \mathrm{C}$ temperature, $30 \mathrm{~N}$ normal load. 


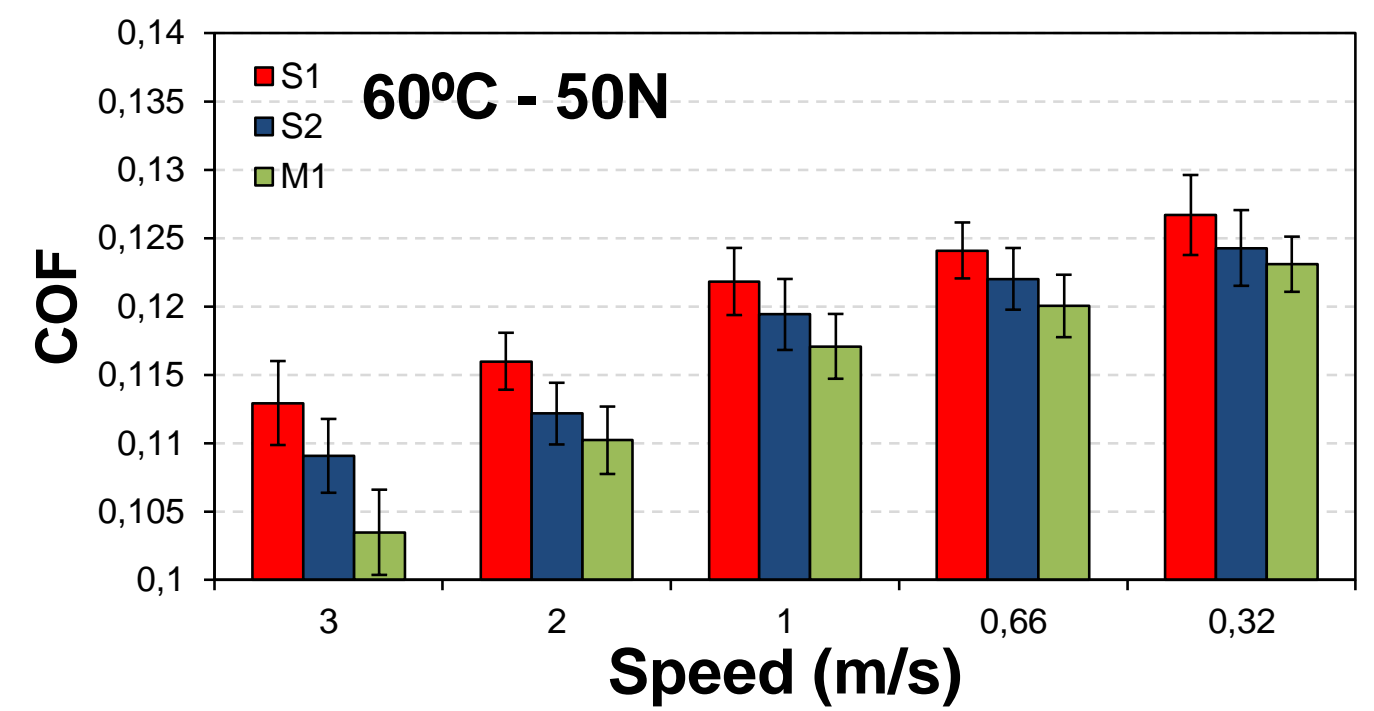

Figure 58 - Average coefficient of friction in function of velocity at $60^{\circ} \mathrm{C}$ temperature, $50 \mathrm{~N}$ normal load.

\subsubsection{Coefficient of friction $X$ Specific film thickness}

Figure 59 displays the average friction coefficient values for the five (05) speeds tested, two replicas were evaluated, and three different types of lubricants, which have been tested in conditions of loads, speeds and temperatures as displayed in Table 06 and 07.

Figure 59 shows all the conditions tested for the fully flooded condition, in the first line the $\mathrm{S} 1$ oil is displayed, in the second line, the S2 oil and the third one M1 oil are also displayed. The left side of the figure shows the load condition of $30 \mathrm{~N}$ and the right side is the load condition of $50 \mathrm{~N}$. The red line indicates the results at $20^{\circ} \mathrm{C}$, the blue line presented the results at $40^{\circ} \mathrm{C}$ and the black line represents the $60^{\circ} \mathrm{C}$ results. Each chart is presented in Appendix $\mathrm{D}$ separately.

The specific oil film thickness in the fully flooded condition is a little bit higher than the starved one due to the higher velocity tested ( 2 and $3 \mathrm{~m} / \mathrm{s}$ ).

The behavior observed in Figure 59 shows that $\mathrm{S} 1$ oil has a higher decrease of COF than S2 and M1 oil (the same behavior found in the starved condition). The S1 oil has a lower piezo-viscosity coefficient ( $\alpha$ ) as demonstrated in Table 06. 
As discussed for results under Starved condition, based on Table 3 (topic 2.2.2), $S 1$ and $S 2$ oil reach only boundary lubrication regime $(0.1<\Lambda<0.65)$ for all temperature conditions. M1 at speeds higher than $1 \mathrm{~m} / \mathrm{s}$ at $20^{\circ} \mathrm{C}$ condition reach a mixed lubrication regime $(\Lambda>0.7)$, however, for all speeds below $1 \mathrm{~m} / \mathrm{s}$ the boundary lubrication regime was achieved $(\Lambda<0.62)$ considering specific film thickness. The specific film thickness of $\mathrm{S} 1$ oil at $20^{\circ} \mathrm{C}$ and $40^{\circ} \mathrm{C}$ is like at $40^{\circ} \mathrm{C}$ and $60^{\circ} \mathrm{C}$ of $\mathrm{S} 2$ and $\mathrm{M} 1$ oil (same condition as Starved). Analyzing Figure 61 and Figure 62 it is possible to conclude that almost conditions are in mixed or boundary lubrication.

\section{Coefficient of friction $x$ Loads}

Comparing the $30 \mathrm{~N}$ load with $50 \mathrm{~N}$ load it can be observed a decrease of the coefficient of friction for almost all conditions due to EP content in lubricants. S1 lubricant the reduction of friction coefficient is more pronounced at 40 and $60^{\circ} \mathrm{C}$ test conditions.

\section{Coefficient of friction $\mathrm{x}$ Temperatures}

S1 oil at $40^{\circ} \mathrm{C}$ and $60^{\circ} \mathrm{C}$ has similar COF values due to the viscosity close values. The trend line for $\mathrm{S} 1$ oil at $20^{\circ} \mathrm{C}$ and $40^{\circ} \mathrm{C}$ is similar to $40^{\circ} \mathrm{C}$ and $60^{\circ} \mathrm{C}$, respectively, S2 and M1 oil.

S2 and M1 lubricant has similar COF results at $40^{\circ} \Subset$ and $60^{\circ} \mathrm{C}$ and they are in a same lubrication regime at these test conditions.

\section{Coefficient of friction $x$ Speeds}

It was found the same behavior on COF results as compared to Starved condition, where the decrease of speed causes an increase of the average coefficient of friction for all lubricants and, by increasing the load there is a decrease of the average friction coefficient, Thurston apud Woydt and Wäsche (2010) reported the same behavior between COF and speed. 


\section{Fully Flooded}

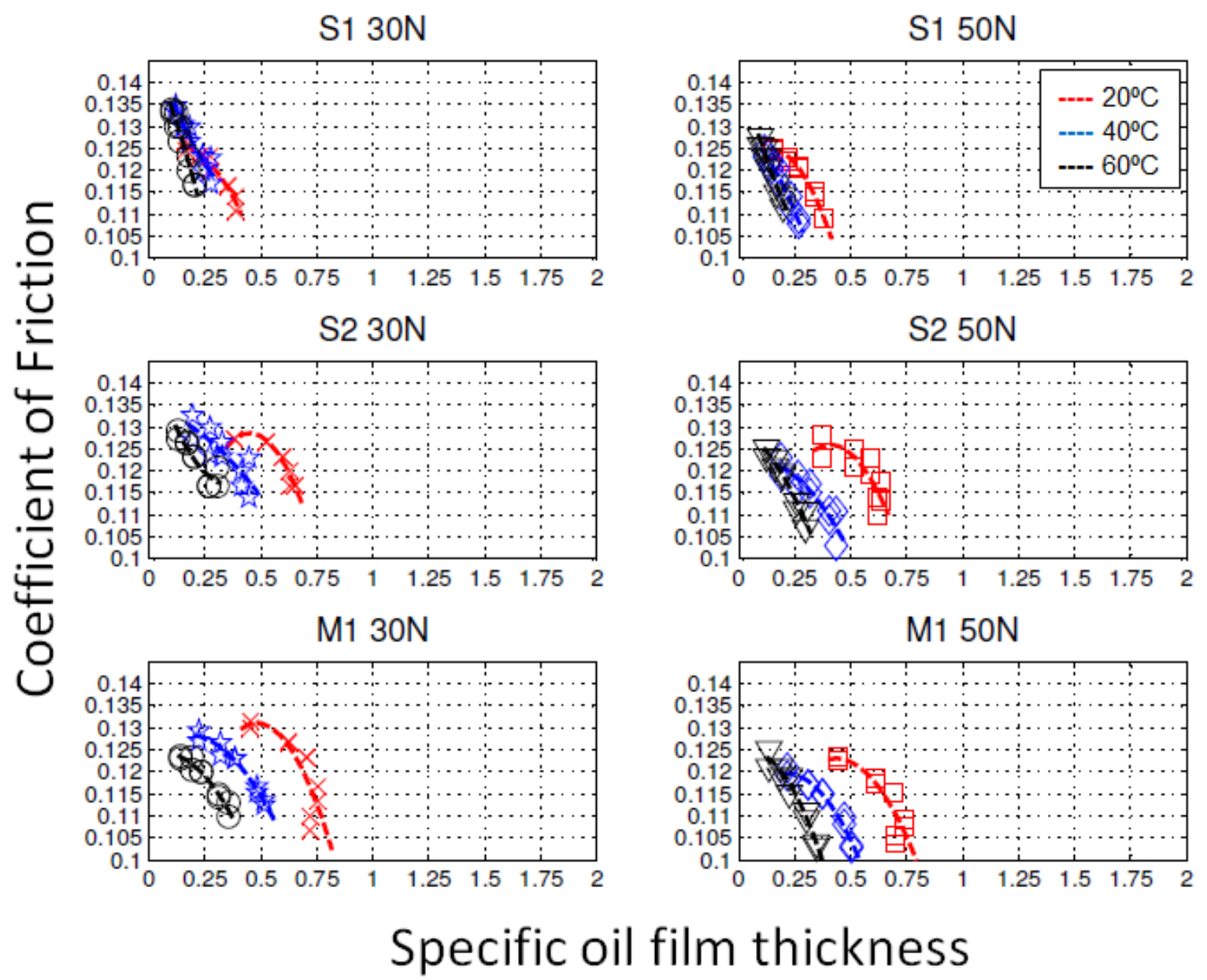

Figure 59 - Average coefficient of friction in function of $\Lambda$ for all conditions tested in a fully flooded test.

Figure 60 shows all the conditions tested, in a different point of view, instead of using each figure for each oil test condition, it is used each figure to present different temperatures for all lubricants in different loads.

For higher speeds, in the mixed lubrication there is a tendency of COF values from $\mathrm{S} 2$ and $\mathrm{M} 1$ oil to be lower than $\mathrm{S} 1$ oil. This result is due to the higher piezo-viscosity and it can be observed at $20^{\circ} \mathrm{C}$ and $40^{\circ} \mathrm{C}$ and, $50 \mathrm{~N}$ of load. 
Vengudusamy et al (2012) reported a similar study using fully formulated gear oils and had concluded that mixed friction is primarily controlled by oil type, viscosity and piezoviscosity coefficient.

\section{Fully Flooded}

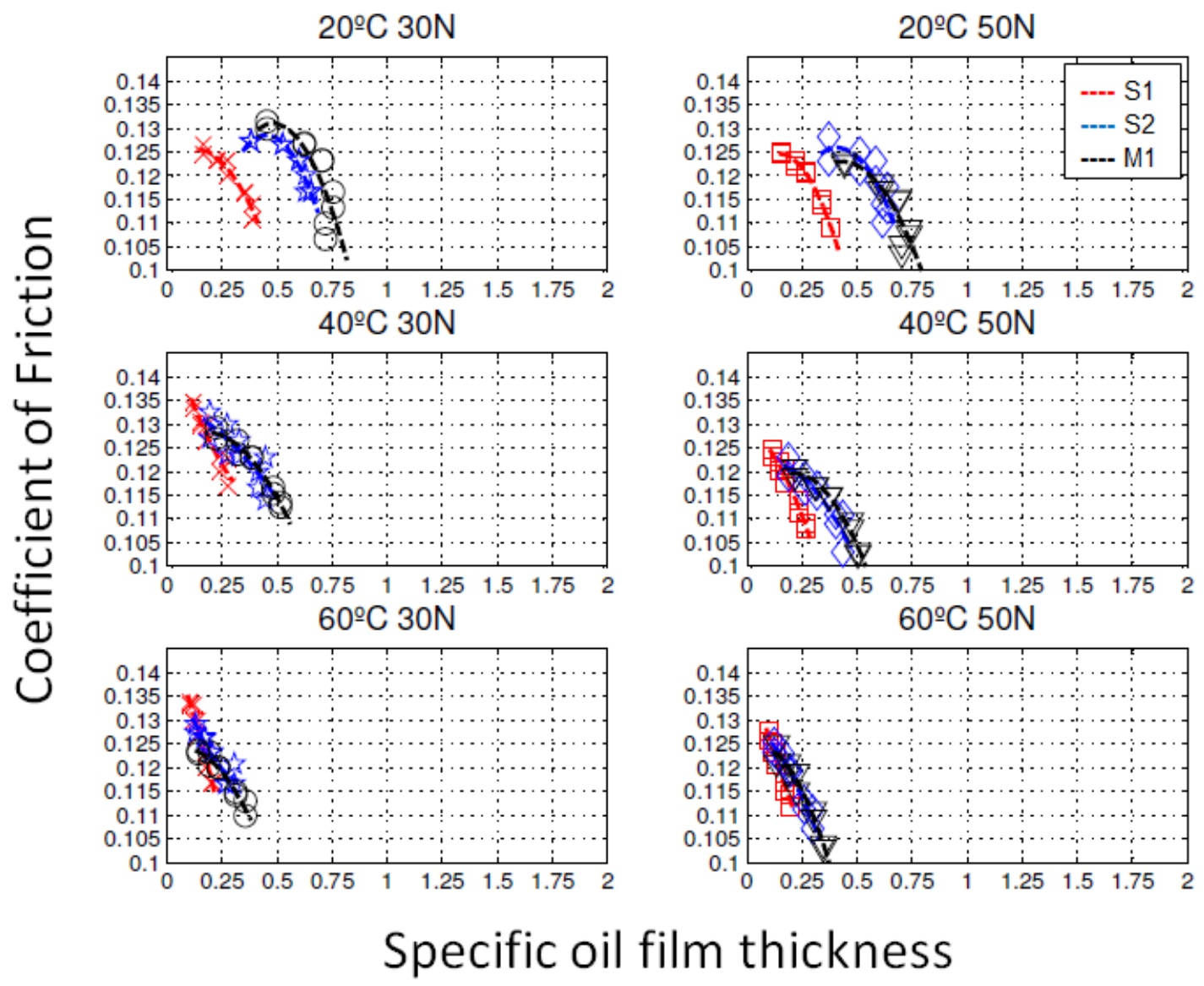

Figure 60 - Average coefficient of friction in function of $\Lambda$ for all conditions tested in a starved condition for S1, S2 and M1 oil in terms of temperatures and loads. 


\section{CONCLUSION}

The present study is focused on understanding the coefficient of friction behavior considering three different lubricants formulated for automotive transmission gears. The mainly conclusions are described below:

1. Starved Condition:

- Results from tribological tests in the starved lubrication showed the lubrication reaches the mixed regime at the highest speed $(1 \mathrm{~m} / \mathrm{s})$ at $20^{\circ} \mathrm{C}$ for M1 lubricant;

- The lowest COFs were obtained at the highest loads and speeds. These results can be related to the presence of $\mathrm{Zn}$ (additives) in the synthetic lubricant as shown by FTIR results;

- The $\mathrm{S} 1$ and $\mathrm{S} 2$ oils presented the lowest value of COF at $40{ }^{\circ} \mathrm{C}$ test conditions, due the presence of the additives.

- Specific oil film thickness presented the lowest values for S1 lubricant;

2. Boundary Condition:

- Oils (S1 and S2), which contain anti-wear additives were more effective under high load conditions;

- In boundary regime, the ZDDP film roughness may control the friction;

- EDS analysis confirms presence of $Z n$ and $P$ on sphere surfaces, using oils containing AW additives ( $\mathrm{S} 1$ and $\mathrm{S} 2$ respectively), and $\mathrm{S}$ and $\mathrm{P}$ were found using $\mathrm{M} 1$ oil.

- EDS analysis confirms the presence of $O$ and $S$ elements on the wear track of all discs. Adsorbed AW film reacted mostly on the worn ball surface, while adsorbed sulfur film reacted with oxidized surfaces of the hardest bodies (discs); 
3. Fully Flooded Condition;

- Results from tribological tests in the fully flooded condition made it possible to verify the tests, in which S2 and M1 oils were used at $20^{\circ} \mathrm{C}$, are in the mixed lubrication and, at $40^{\circ} \mathrm{C}$ and $60^{\circ} \mathrm{C}$ it can be observed a transition between mixed to boundary lubrication. In the case of $\mathrm{S} 1$ oil, at all temperatures, tests are conducted in boundary lubrication;

- The COF evaluation as a function Stribeck modified parameter showed S1 oil has a higher decrease of COF than S2 and M1 oil (the same behavior observed in starved condition);

- Analyzing M1 oil, at the $20^{\circ} \mathrm{C}$ condition at speeds 3,2 and $1 \mathrm{~m} / \mathrm{s}$, the mixed lubrication is achieved. All other conditions the regime lubrication is boundary lubrication, but analyzing Figure 58 we conclude that was reached the mixed lubrication in almost all conditions;

- The behavior of the COF is similar to the starving and fully flooded condition. However, the fully flooded has a COF slightly lower than a starving condition. This result was obtained by using a pump, especially for the test condition conducted at $60^{\circ} \mathrm{C}$;

- Comparing the three lubricants, in terms of COF, it is possible to conclude that they are under error measurement in almost all conditions. The exception was the tests performed at $20^{\circ} \mathrm{C}$ and 30 $\mathrm{N}$ of load, where the average COF of $\mathrm{S} 1$ oil is smaller than $\mathrm{S} 2$ and M1 for speeds below $1 \mathrm{~m} / \mathrm{s}$.

- Regarding the efficiency, the $\mathrm{S} 1$ oil has advantages, since it presents the lowest viscosity and, consequently the lowest churning/pumping losses. 


\section{FUTURE WORKS}

The present study discussed the COF as a function of oil thickness film parameter and Stribeck modified in the automotive transmission gear. In order to improve this study it is proposed the following topics:

- Include rolling in a sliding movement, once the gear engagement presents both movements;

- Perform tests at higher temperatures;

- Perform tests at higher speeds to improve the results of the Stribeck curve;

- Perform ball on disc tests, in which ball and disc were made with the same material;

- Perform tests using a base oil in order to compare the results with the fully formulated lubricants; 


\section{REFERENCES}

"ASSOCIACAO BRASILEIRA DE NORMAS TECNICAS. NBR 6061, Veículos rodoviários automotores leves - Determinação de hidrocarbonetos, monóxido de carbono, óxidos de nitrogênio, dióxido de carbono e material particulado no gás de escapamento".

"ASSOCIACAO BRASILEIRA DE NORMAS TECNICAS. NBR 7024 Veículos rodoviários automotores leves - Medição do consumo de combustível - Método de ensaio".

ASM HANDBOOK. ASM Handbook, Vol. 18. Friction, lubrication and wear technology. [S.I: s.n.], 1992.

AMERICAN GEAR MANUFACTURERS ASSOCIATION. AGMA 2001-B88, Fundamental Rating Factors and Calculation Methods for Involute Spur and Helical Gear Teeth, AGMA Standard, 1988.

AMERICAN SOCIETY FOR TESTING AND MATERIALS. ASTM D5182 - 97: Standard Test Method for Evaluating the Scuffing Load Capacity of Oils (FZG Visual Method). ASTM, 2008.

Beauchamp Tower, First Report on Friction Experiments, Proc. Inst. Mech. Engrs., Nov. 1883

BOWDEN, F.P.; TABOR, D. The Friction and Lubrication of Solids, Part 1, Clarendon Press, Oxford, 1950.

BHUSHAN, B. Principles and Applications of tribology, Second Edition Columbus, 2013.

BLAU, P. J. Friction Science and Technology. [S.I.]: Taylor \& Francis Group, 2009.

BRANDAO J.A.; MEHEUX M.; VILLE F.; SEABRA J.H.O; CASTRO J. Comparative overview of five gear oils in mixed and boundary film lubrication. Tribology International 2012.

COVITCH, J.M.; TRICKETT, K.J. How polymers behave as Viscosity Index Improvers in Lubricating Oils, Advances in Chemical Engineering and Science, 2015.

CAINES, A.J.; HAYCOCK, R.F. Automotive lubricants reference book, SAE International, 2004.

CUI, J.; OBEROI, S.; BRIGGS, S.; GOLDMINTS, I. A viscosity modifier solution to reconcile fuel economy and durability in diesel engines, Elsevier, 2016. 
DIABY, M.; SABLIER, M.; NEGRATE, A.L; FASSI, M.E.; BOCQUET, J. Understanding carbonaceous deposit formation resulting from engine oil degradation, Elsevier, 2008.

FERNANDES, C.MCG; MARTINS, R.C; SEABRA, J.H.O, Coefficient of friction equation for gears based on a modified Hersey parameter, Elsevier, 2016.

FIGUEIREDO, T.P; TERTULIANO, I; SALDARRIAGA, P.A. C; MACHADO, G.A. A; MACHADO, I.Z; 'Comparativo de propriedades de atrito entre dois tipos de lubrificantes em contato de deslizamento, Sae International, 2015.

LECHNER, G; NAUNHEIMER, H. Automotive transmissions. Springer $2^{\mathrm{a}} \mathrm{Ed}$, Stuttgart and Augsburg, 1993.

GOLD P.W.; SCHMIDT A.; DICKE H.; LOOS J.; ASSMANN C.; Viscositypressure- temperature behavior of mineral and synthetic oils. Journal of Synthetic Lubrication 2001.

HOLMBERG, K.; ANDERSSON, P.; ERDEMIR, A. Global energy consumption due to friction in passenger cars. Tribology International, 2011.

HAMROCK, B.; SCHMID, S.; JACOBSON, B. Fundamental of Fluid Film Lubrication. [S.I.]: Marcel Dekker, 2004.

HAMROCK, B, J; DOWSON D. Ball bearing lubrication - the elastohydrodynamics of elliptical contacts. New York: WileyInterscience; 1981.

HUTCHINGS, I. Tribology, Friction and Wear of Engineering Materials. [S.I.]: Butterworth Heinemann, 1992.

KIMURA, Y.; Okabe, H. An Introduction to Tribology, Youkandou Press, Tokyo 1982

KHONSARI, M M; BOOSER, E R. Applied Tribology. Second Edition, John Wiley \& Sons Ltd, 2008.

MANG, T.; DRESEL, W. Fluid film lubrication, Second Edition, Cambridge University Press, 2011.

MARINHO, A. Wear and friction torque in thrust ball and roller bearings lubricated with "Windmill Gear Oils", Universidade do Porto, 2011.

REYNOLDS, O.O. "On the Theory of Lubrication and its Application to Mr. Beauchamp Tower's Experiments," Phil. Trans. R. Soc. Lond, 1886.

TORBACKE, M.; RUDOLPHI, A.K.; KASSFELDT, E. Lubricants - Introduction to Properties and Performance, Wiley, 2014. 
MARTINS, R.; SEABRA, J.; BRITO, A.; SEYFERT, Ch.; LUTHER, R.; IGARTUA, A. Friction coefficient in $F Z G$ gears lubricated with industrial gear oils: Biodegradable ester vs. mineral oil, Tribology International, vol. 39,

NIEMANN, G. Elementos de máquinas. Ed. Edgard Blucher, vol. 3, São Paulo, 1971.

MAZZO, N. "Engrenagens Cilíndricas - Da concepção á fabricação", Editora Blucher, 2013.

NORTON, R. L. Projeto de máquinas: uma abordagem integrada. Ed. Bookman, 20 Ed., 2004.

PIRRO, D.N; WESSOL, A.A. Lubrication Fundamentals. Exxon Mobil Corporation, 2001.

PROFITO, J.F; Modelagem unidimensional do regime misto de lubrificação aplicada a superfícies texturizadas, São Paulo, 2010.

SEABRA, J; CAMPOS, A; SOTTOMAYOR, A. Lubrificação elastohidrodinâmica. Porto, 2002.

SPIKES, H. A. Boundary Lubrication and Boundary Films. Tribology Series, v. 25, 1993.

STACHOWIAK, G.W; BATCHELOR, A.W. Engineering tribology. Elsevier Inc., 2005.

TANG, Z.; LI, S. A review of recent developments of friction modifiers for liquid lubricants, Elsevier, 2014.

TERTULIANO, I.S; FIGUEIREDO, T.P; MACHADO, G.A. A; COUSSEAU, T; SINATORA, A; MACHADO, I.F, Nordtrib, 2016.

VENGUDUSAMY, B., GRAFL A., NOVOTNY-FARKAS F., SCHOFMANN W. "Comparison of frictional properties of gear oils in boundary and mixed lubricated rolling - sliding and pure sliding contacts". Tribology International 2013.

WOYDT, M.; WÄSCHE, R. "The history of the Stribeck curve and ball bearing steels: The role of Adolf Martens. Engineering tribology. Elsevier, 2010. 
Appendix A

\begin{tabular}{|c|c|c|c|c|c|c|c|c|c|c|c|c|c|c|}
\hline$v_{100}$ & $\mathbf{L}$ & H & $v_{190}$ & L. & H & $v_{100}$ & $\mathbf{L}$ & H & $v_{100}$ & $\mathbf{L}$ & $\mathbf{H}$ & $v_{106}$ & L & H \\
\hline 2.00 & 7.994 & 6.394 & 530 & 106.9 & 6505 & 14.6 & 2830 & 143.9 & 21.8 & 573.6 & 261.5 & 41.0 & 1810 & 676.6 \\
\hline 2.10 & 8.660 & 6.894 & 540 & 1092 & 6418 & 16.7 & 2864 & 145.3 & 220 & 585.2 & 2649 & 41.5 & 1851 & 6891 \\
\hline 2.20 & 9.309 & 7410 & R50 & 1115 & 65.32 & 148 & 2897 & 146.8 & 222 & 596.0 & 268.6 & 42.0 & 1892 & 701.9 \\
\hline 2.30 & 10.00 & 7.944 & R.60 & 113.9 & 66.48 & 14.9 & 2930 & 148.2 & 224 & 604.3 & 2723 & 42.5 & 1935 & 714.9 \\
\hline 2.40 & 10.71 & 8.496 & s.7o & 116.2 & 67.64 & 15.0 & 296.5 & 149.7 & 226 & 614.2 & 275.8 & 43.0 & 1978 & 728.2 \\
\hline 2.50 & 11.45 & 9063 & 5.80 & 1153 & 6579 & 15.1 & 3000 & 151.2 & 2218 & 624.1 & 279.6 & 43.5 & 2021 & 741.3 \\
\hline 2.60 & 1221 & 9.647 & 890 & 120.9 & 69.94 & 152 & 303.4 & 1526 & 230 & 6336 & 283.3 & 410 & 2064 & 754.4 \\
\hline 2.70 & 13.00 & 10.25 & 9.00 & 1233 & 71.10 & 15.3 & 306.9 & 154.1 & 232 & 643.4 & 286.8 & 445 & 2106 & 767.6 \\
\hline 2.80 & 1980 & 10.67 & 9.10 & 1257 & 72.27 & 15.4 & 3103 & 1556 & 234 & 653.8 & 290.5 & 450 & 2152 & 7809 \\
\hline 2.90 & 1463 & 11.50 & 9.20 & 128.0 & 73.42 & 15.5 & 3139 & 157.0 & 23.6 & 6653.3 & 254.4 & 45.5 & 2197 & 794.3 \\
\hline 3.00 & 15.49 & 12.15 & 9.30 & 130.4 & 74.57 & 15.6 & 317.5 & 158.6 & 238 & 673.7 & 2979 & i6. 0 & 2243 & 8052 \\
\hline 3.10 & 1636 & 12.82 & 9.40 & 1328 & 75.73 & 15.7 & 321.1 & 160.1 & 240 & $6 \times 3.9$ & 301.8 & 46.5 & 2288 & 821.9 \\
\hline 3.20 & 1726 & 13.51 & 9.50 & 1353 & 7691 & 15.8 & 324.6 & 161.6 & 242 & 694.5 & 305.6 & 47.1 & 2333 & 8.35 .5 \\
\hline 3.30 & 18.18 & 14.21 & 9.60 & 1377 & 7s.os & 15.9 & 3283 & 163.1 & 26.4 & 704.2 & 309.4 & 673 & 2380 & 849.2 \\
\hline 3.60 & 19.12 & 14.93 & 9.70 & 140.1 & 99.27 & 16.0 & 3319 & 164.6 & 246 & 714.9 & 3130 & 480 & 2426 & 8630 \\
\hline 3.50 & 20.09 & 15.66 & 9.80 & 142.7 & 80.46 & 16.1 & 335.5 & 166.1 & 24.8 & 725.7 & 3170 & 48.5 & 2473 & 876.9 \\
\hline 3.60 & 21.08 & 16.42 & 9.90 & 1452 & 81.67 & 16.2 & 339.2 & 167.7 & 250 & 736.5 & 320.9 & $\$ 9.10$ & 2521 & 890.9 \\
\hline 3.70 & 2209 & 17.19 & 10.0 & 1673 & 82.87 & 16.3 & 3429 & 169.2 & 25.2 & 747.2 & 324.9 & 49.5 & 2570 & 905.3 \\
\hline 3.60 & 23.13 & 17.97 & 10.1 & 1503 & 84.06 & 16.4 & 346.6 & 170.7 & 25.4 & 756.2 & 32.8 & 500 & 2618 & 919.6 \\
\hline 3.90 & 24.19 & 18.77 & 10.2 & 152.9 & 85.30 & 16.5 & 3503 & 172.3 & 256 & 769.3 & 332.7 & 50.5 & 2667 & 9336 \\
\hline 4.00 & 2532 & 19.56 & 10.3 & 155.4 & 86.51 & 16.6 & 354.1 & 173.8 & $25 s$ & 779.7 & 336.7 & 510 & 2717 & 9482 \\
\hline 4.10 & 26.50 & 20.37 & 10.4 & 1580 & 87.72 & 16.7 & 3560 & 1754 & 260 & 79014 & 340.5 & 51.5 & 2767 & 9629 \\
\hline 4.20 & 27.75 & 21.21 & 10.5 & 160.6 & 88.95 & 16.8 & 3617 & 177.0 & 26.2 & 601.6 & 344.4 & 520 & 2817 & 97.5 \\
\hline 4.30 & 29.07 & 22.05 & 10.6 & 1632 & 92.19 & 16.9 & 365.6 & 178.6 & 26.4 & 812.8 & 348.4 & 523 & 2867 & 9921 \\
\hline 4.40 & 30.45 & 22.92 & 10.7 & 1658 & 91.40 & 17.0 & 369.4 & 180.2 & 26.6 & 824.1 & 3623 & 530 & 2918 & $100 \%$ \\
\hline 4.50 & 31.96 & 23.81 & 108 & 168.8 & 9265 & 17.1 & 373.3 & 151.7 & 26.8 & 835.5 & $336 \mathrm{~A}$ & 535 & 2969 & 1027 \\
\hline 4.60 & 30.52 & 24.71 & 10.9 & 1712 & 93.92 & 17,2 & 377.1 & 183.3 & 27.0 & 847,0 & 360.5 & 54.0 & 3000 & 1036 \\
\hline 470 & 35.13 & 25.63 & 11.0 & 173.9 & 95.19 & 17.3 & 3810 & 184.9 & 272 & 457.5 & 364.6 & 54.5 & 3003 & 2051 \\
\hline 4.80 & 36.79 & 26.57 & 11.1 & 1766 & 96.45 & 17.4 & 3849 & 186.5 & 27.4 & 869.0 & 3683 & 550 & 3126 & 1066 \\
\hline 4.90 & 38.50 & 27.53 & 11.2 & $179 \mathrm{~A}$ & 9771 & 17.5 & 388.9 & 188.1 & 276 & $8 \times 2.6$ & 372.3 & 55.5 & 3180 & 1062 \\
\hline 5.00 & 40.23 & 28.49 & 13.3 & 182.1 & 96.97 & 17.6 & 3927 & 159.7 & 27.8 & 8923 & 376.4 & 560 & 3233 & 1097 \\
\hline 5.20 & 41.99 & 29.46 & 11.4 & 184.9 & 1002 & 17.7 & 3967 & 191,3 & 28.0 & 904.1 & 380.6 & 56.5 & 3256 & 1112 \\
\hline 5.20 & 43.76 & 30.43 & 11.5 & 1876 & 101.5 & i & 400.7 & 192.9 & 28.2 & 915.8 & 384.6 & 570 & 3340 & 1127 \\
\hline 5.30 & 45.53 & 31.40 & 11.6 & 190.4 & 102.8 & 17.9 & 404.6 & 194.6 & 28.4 & 927.6 & 388.8 & 375 & 3376 & 1143 \\
\hline 5.40 & 47.31 & 32.37 & 11.7 & 1933 & 104.1 & 18.0 & 4066 & 196.2 & 286 & 93 & 393.0 & 58.0 & 3452 & 1159 \\
\hline 5.50 & 49,00 & 33.34 & 11.8 & 2962 & 105.4 & 18.1 & 412.6 & $19 \sigma .8$ & 28.8 & 951.2 & 396.6 & 58.5 & 3500 & 1175 \\
\hline 5.60 & 50.57 & 34.32 & 11.9 & 199.0 & 106.7 & 18.2 & 4167 & 199.4 & 23.0 & 963.4 & 401.1 & 390 & 3563 & 1190 \\
\hline $5 \pi 0$ & 52.64 & 35.29 & 12.0 & 2019 & 108.0 & 18.3 & 4207 & 201.0 & 20.2 & 975.4 & 4053 & 595 & 3619 & 1206 \\
\hline 5.80 & 54.42 & 36.26 & 12.1 & 2048 & 109.4 & 38.4 & 424.9 & 200.6 & 29.4 & 987.1 & 409.5 & 60.9 & 3676 & 1222 \\
\hline 5.90 & $\$ 6.20$ & 37.23 & 122 & 2008 & 110.7 & 28.5 & 4290 & 204.3 & 29.6 & 995.9 & 4135 & 60.5 & 3734 & 1238 \\
\hline 6.00 & 57.97 & 35.19 & 12.3 & 250.7 & 1120 & 18.6 & 4332 & 200.9 & 29.5 & 10ิt & 4176 & 61.0 & 3792 & 1254 \\
\hline 6.10 & 59.74 & 39.17 & 124 & 2136 & 113.3 & 18.7 & 4373 & 200.6 & 30.0 & 1023 & 421.7 & 615 & 3650 & 1270 \\
\hline 6.20 & 61.52 & 40.15 & 125 & 216.6 & 114.7 & 18.8 & 441.5 & 209.3 & 30.5 & 1055 & 432.4 & 620 & 3908 & 1286 \\
\hline 6.30 & 63.32 & 4).13 & 12.6 & 219.6 & 116.0 & 28.9 & 445.7 & 211.0 & 310 & 1086 & 443.2 & 62.5 & 3066 & 1303 \\
\hline 6.40 & $65.1 \mathrm{~s}$ & 4214 & 127 & 222.6 & 117.4 & 19.0 & 419.9 & 212.7 & 31.5 & 1119 & 454.0 & 630 & 4026 & 1319 \\
\hline 6.50 & 67,12 & 43.18 & 12.8 & 225.7 & 118.7 & 19.1 & 4542 & 214.4 & 32.0 & 1151 & 464.9 & 63.5 & 4087 & 1336 \\
\hline 6.60 & 69.16 & 4424 & 129 & 228.8 & 120.1 & 19.2 & 456.4 & 216.1 & 32.5 & 1184 & 475.9 & 640 & 4147 & 1352 \\
\hline 6.70 & 71.29 & 45.33 & 13.0 & 2319 & 121.5 & 19.3 & 4627 & 217.9 & 33.0 & 1217 & 487.0 & 64.3 & $430 \%$ & 1369 \\
\hline 6.80 & 73.48 & 46.44 & 13.1 & 235.0 & 122.9 & 19.4 & 4670 & 219.4 & 33.5 & 1251 & 498.1 & 65.0 & 4268 & 1386 \\
\hline 6.90 & 75.72 & 4751 & 13.2 & 208.1 & 124.2 & 19,5 & 4713 & 221.1 & 34.0 & 1260 & $509 \mathrm{~A}$ & 65.3 & 4329 & 1402 \\
\hline 7.00 & 78.00 & 48.57 & 13.3 & 2412 & 125.6 & 19.6 & 4757 & 222.8 & 34.5 & 1321 & 521.1 & 66.0 & 4392 & 1419 \\
\hline 7.10 & 80.25 & 49.61 & 134 & 2443 & 127.0 & 19.7 & 4797 & 224.5 & 35.0 & 1356 & 532.5 & 66.5 & 4455 & 1496 \\
\hline 7.20 & 82.39 & 50.69 & 13.5 & 247.4 & 128.4 & 29.8 & 483.9 & 226.2 & 35.5 & 1391 & 544.0 & 670 & 4517 & 1454 \\
\hline 7,30 & 8453 & 51.78 & 13.6 & 230.6 & 129.8 & 19.9 & 488.6 & 228,7 & 36.0 & 142 & 535.6 & 675 & 4560 & 1471 \\
\hline 7.40 & 56.66 & 52.88 & 13.7 & 253.8 & 131.2 & 20.0 & 4932 & 229.5 & 36.5 & 1454 & 567.2 & 68.0 & 4645 & 1488 \\
\hline 750 & 55.65 & 5598 & 13.8 & 2470 & 132.6 & 20.2 & 501.5 & 2330 & 390 & 1501 & 579.3 & 68.5 & 4709 & 1506 \\
\hline 760 & 91.04 & 55.09 & 139 & 260.1 & 134.0 & 20.4 & $\sin 8.8$ & 236.4 & 37.5 & 1538 & 591.3 & 690 & 4773 & 1523 \\
\hline 7.70 & 93.20 & 36.20 & 14.0 & 2633 & 135.4 & 20.6 & 519.9 & 240.1 & 38.0 & 1575 & 603.1 & 695 & 4539 & 1541 \\
\hline 780 & 95.43 & 57.31 & 14.1 & 2666 & 136.8 & 20.8 & 528.8 & 243.5 & 38.5 & 1613 & 615.0 & 70.0 & 4966 & 1358 \\
\hline 7.90 & 97.72 & 58.45 & 14.2 & 269.8 & 138.2 & 21.0 & 538.4 & 247.1 & 39.0 & 1651 & 625.1 & & & \\
\hline 800 & 1000 & 59.60 & 14.3 & 273.0 & 139.6 & 21.2 & 547.5 & 250.7 & 39.5 & 1691 & 639.2 & & & \\
\hline 8.10 & 1023 & 60.74 & 14.4 & 276.3 & 141.0 & 21.4 & 566.7 & 254.2 & 40.0 & 1730 & 651.8 & & & \\
\hline 8.20 & 1046 & 61.89 & 14.5 & 2798 & 1624 & 21.6 & $566 A$ & 257,8 & 40.5 & 1770 & 664.2 & & & \\
\hline
\end{tabular}




\section{Appendix B}

\section{Starved Condition}
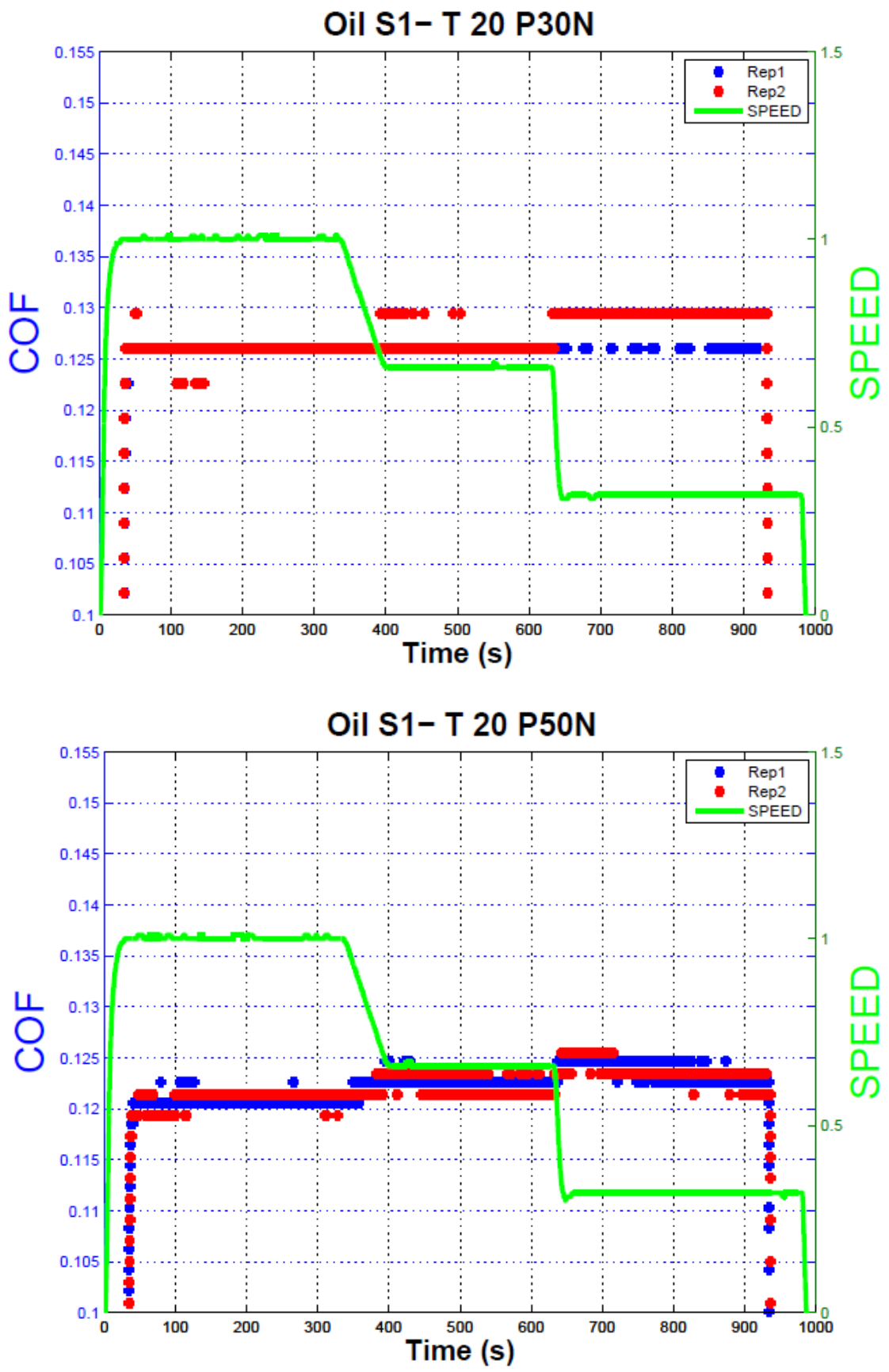

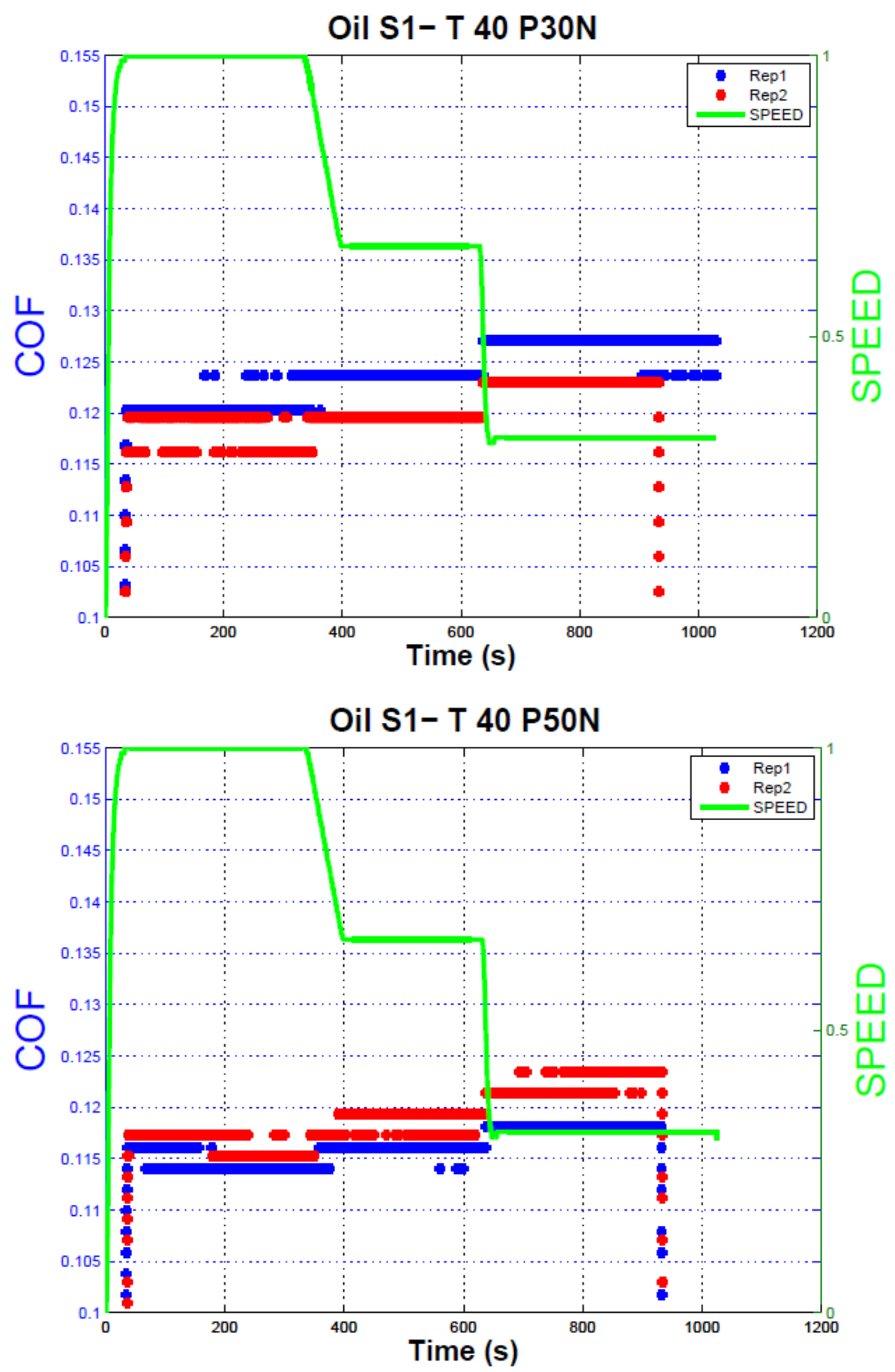

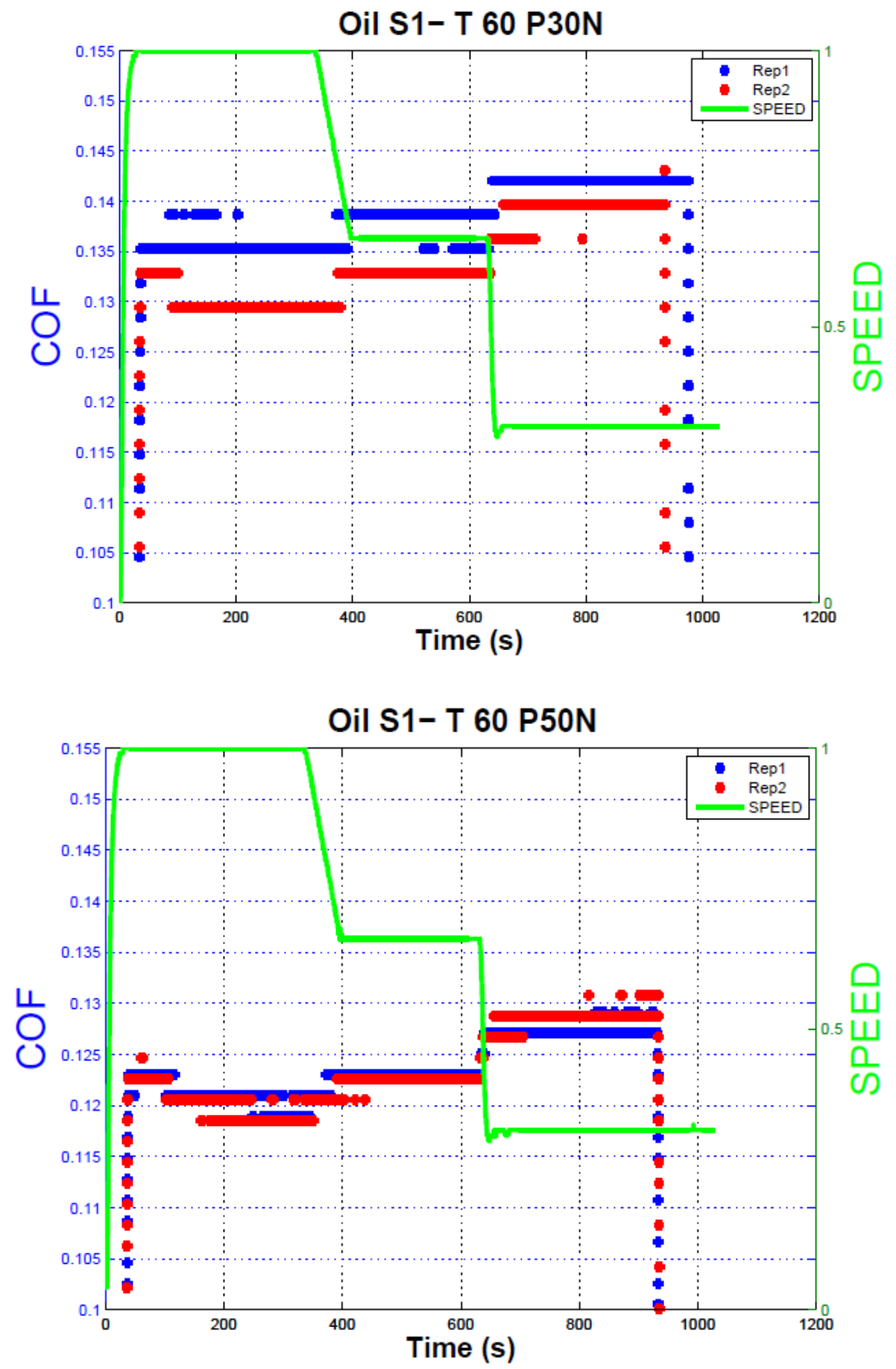

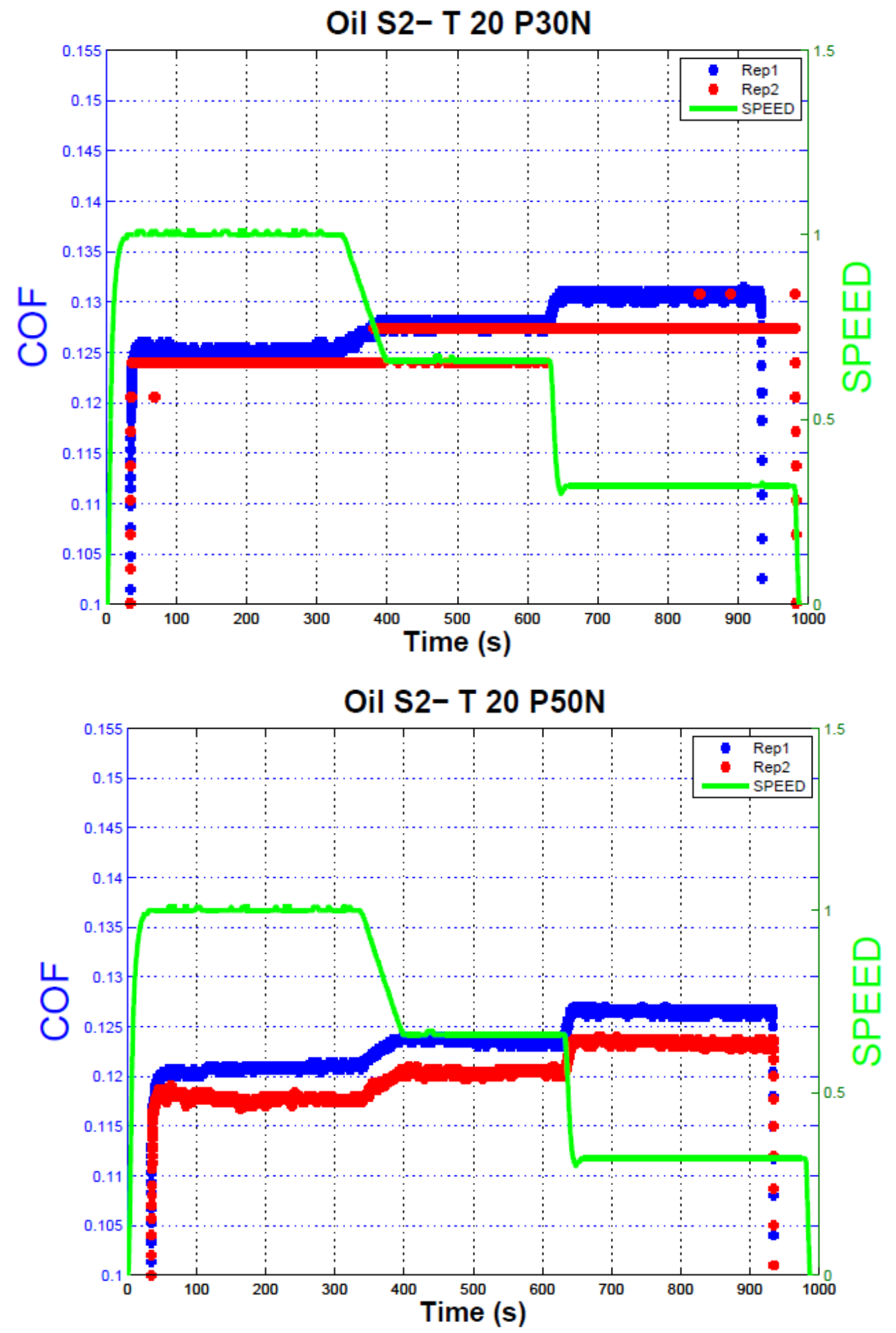

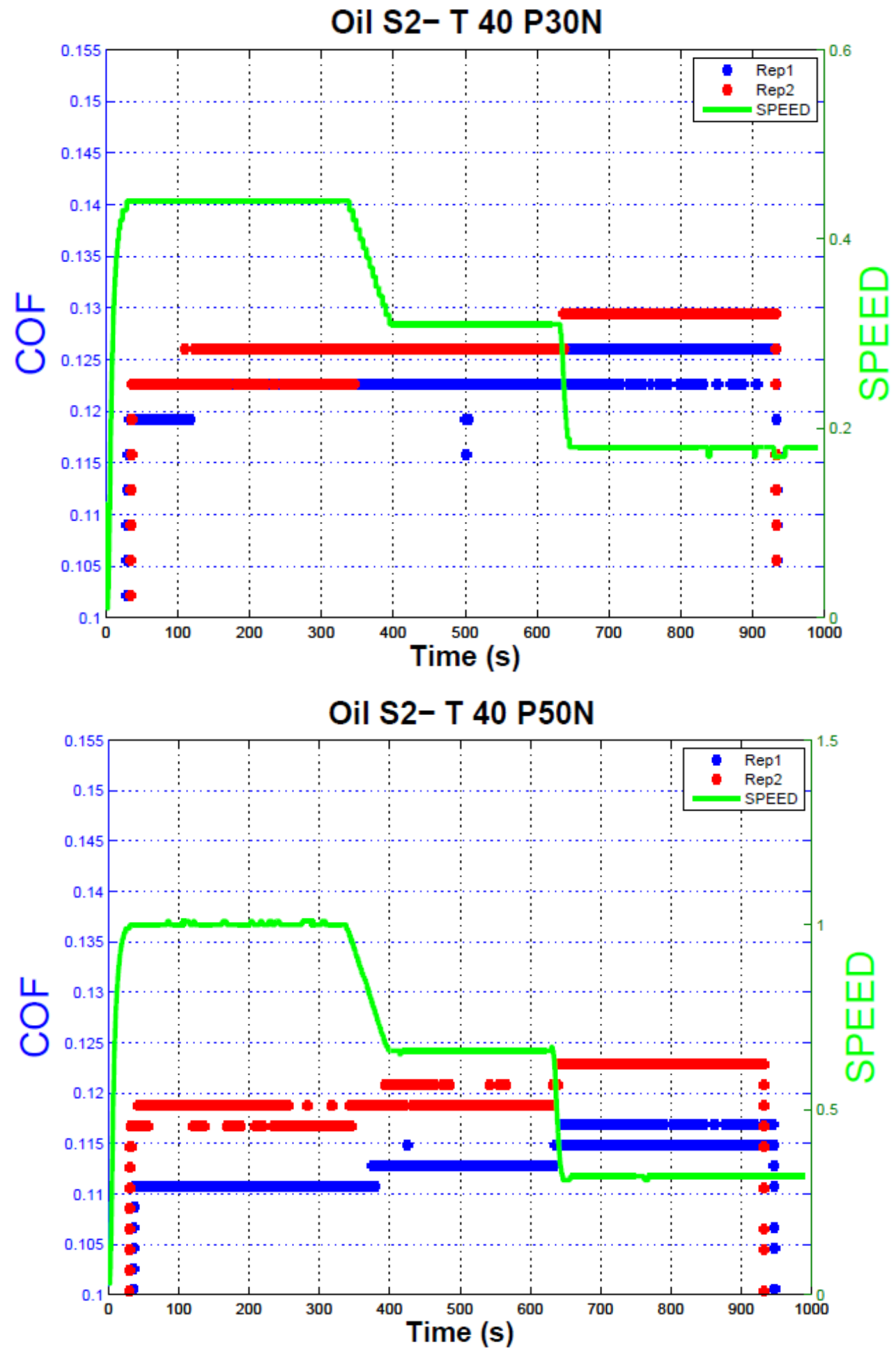

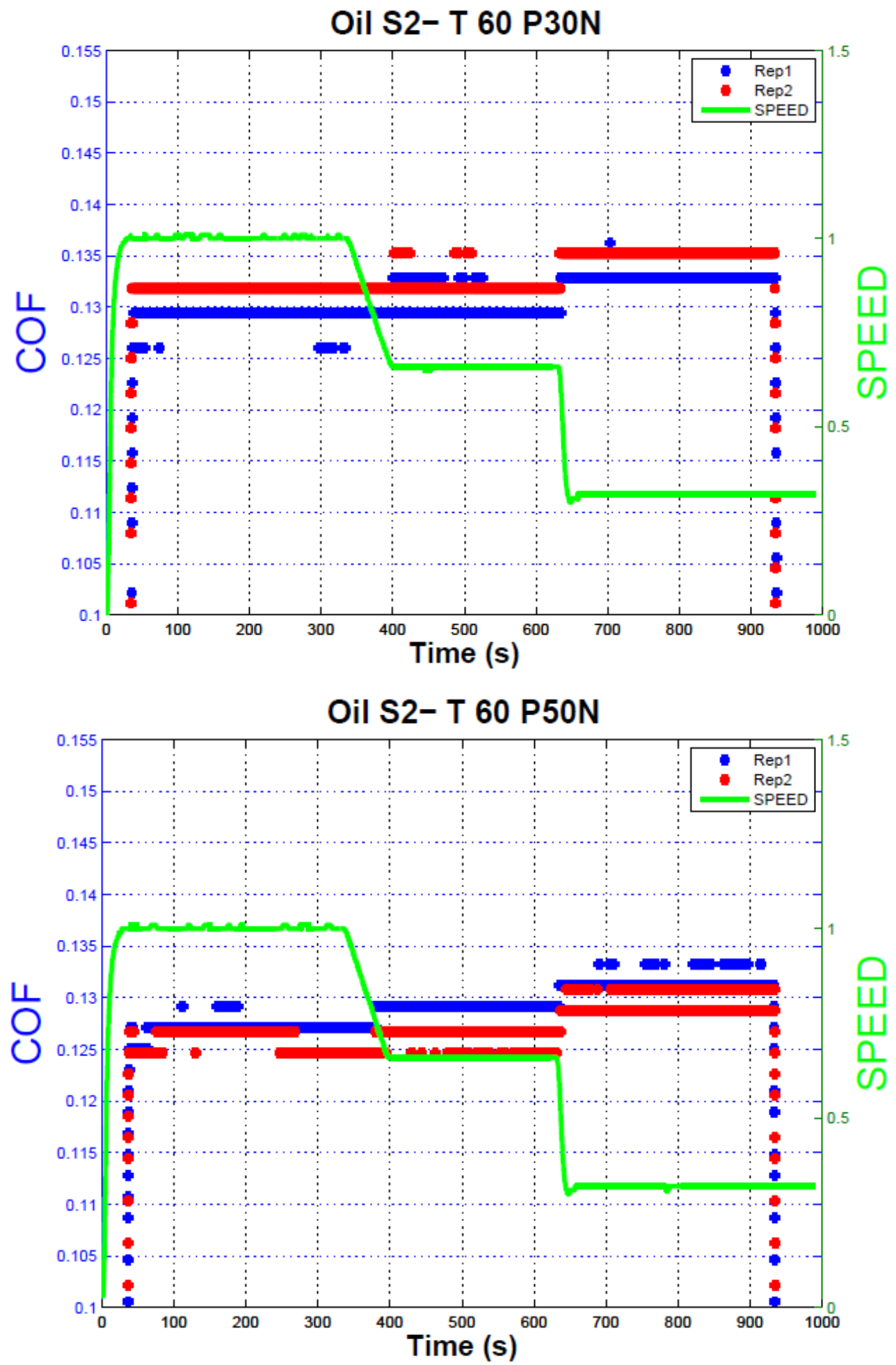

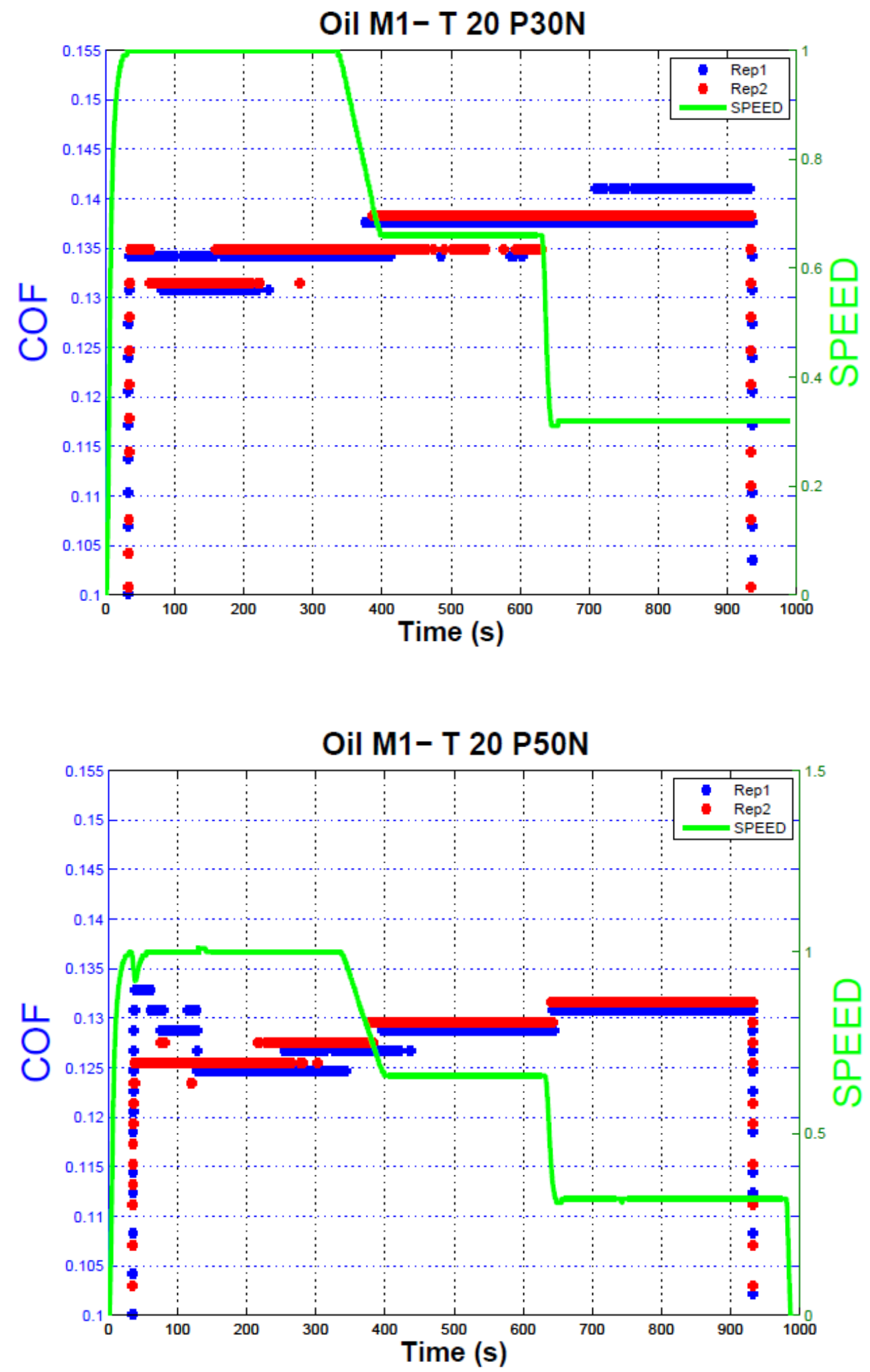

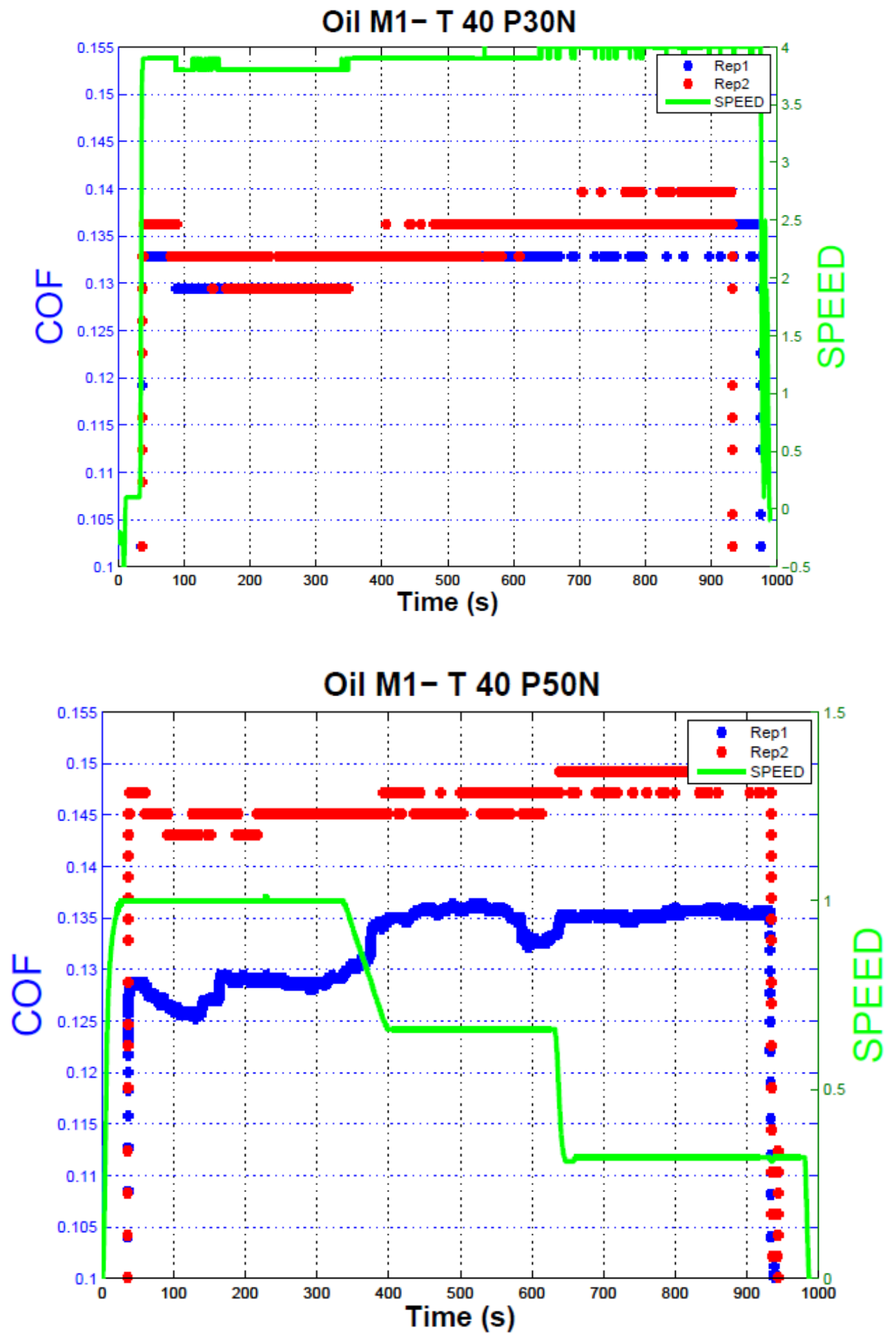

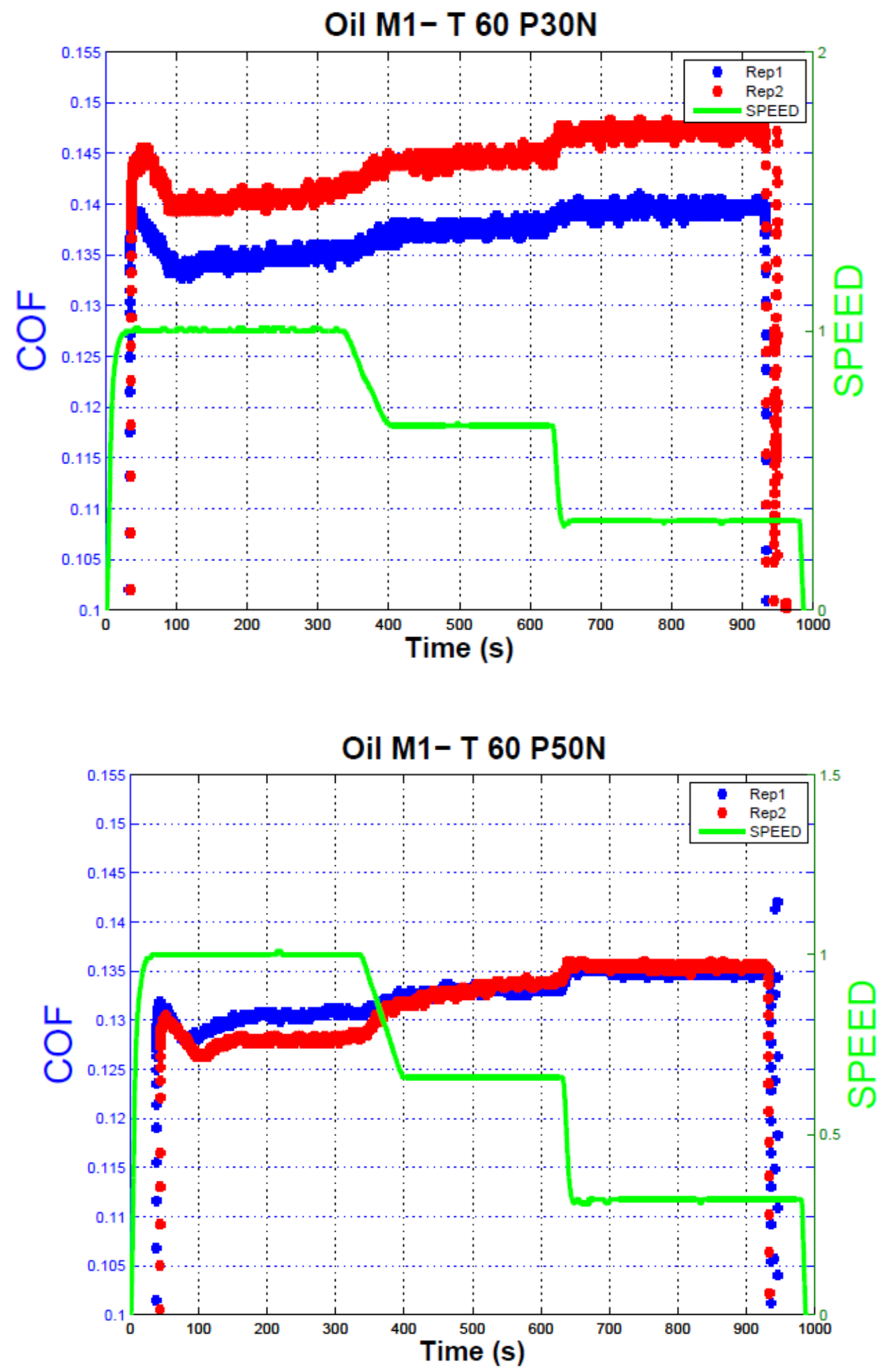


\section{Appendix C}

\section{Fully Flooded Condition}
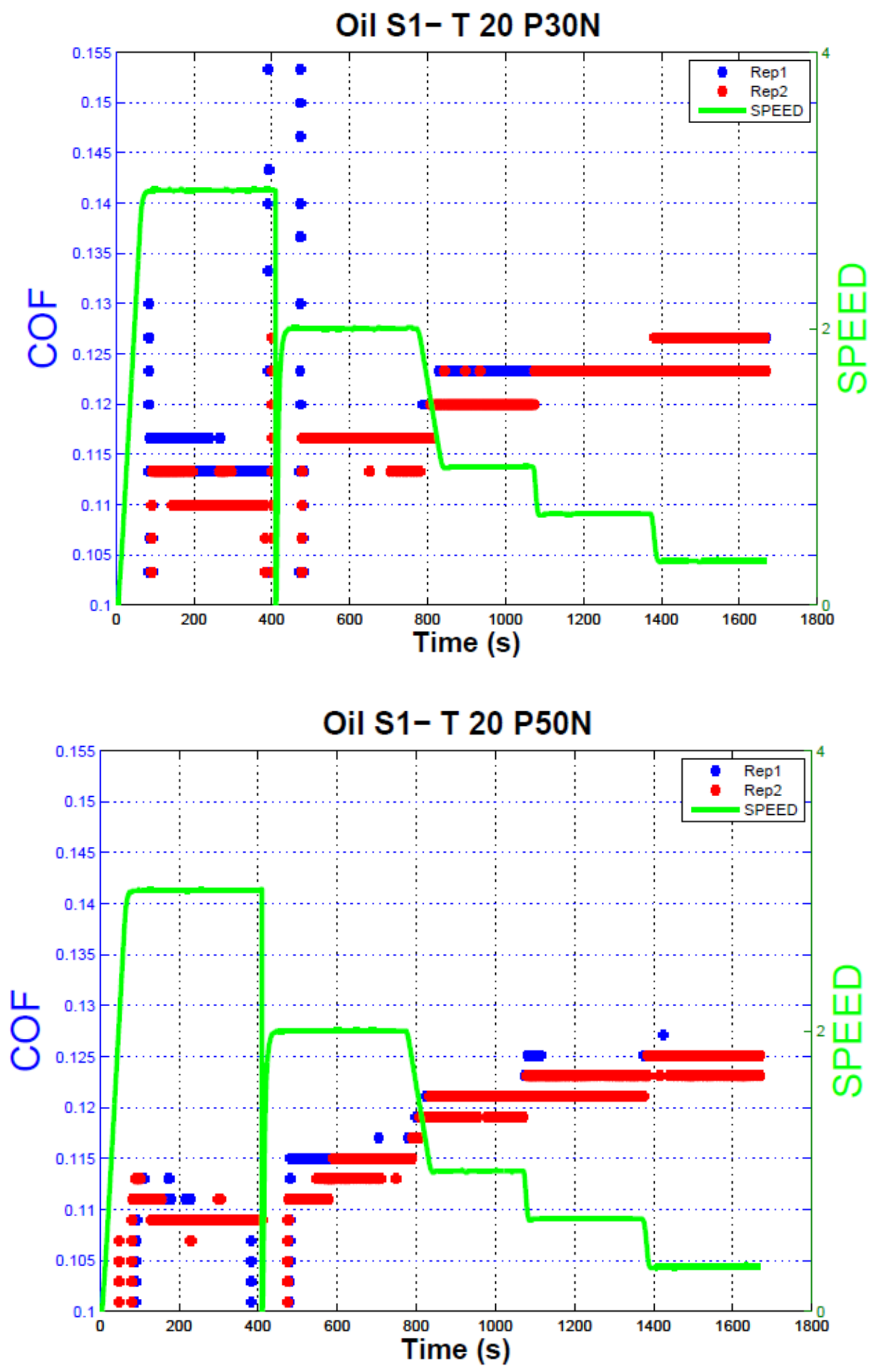

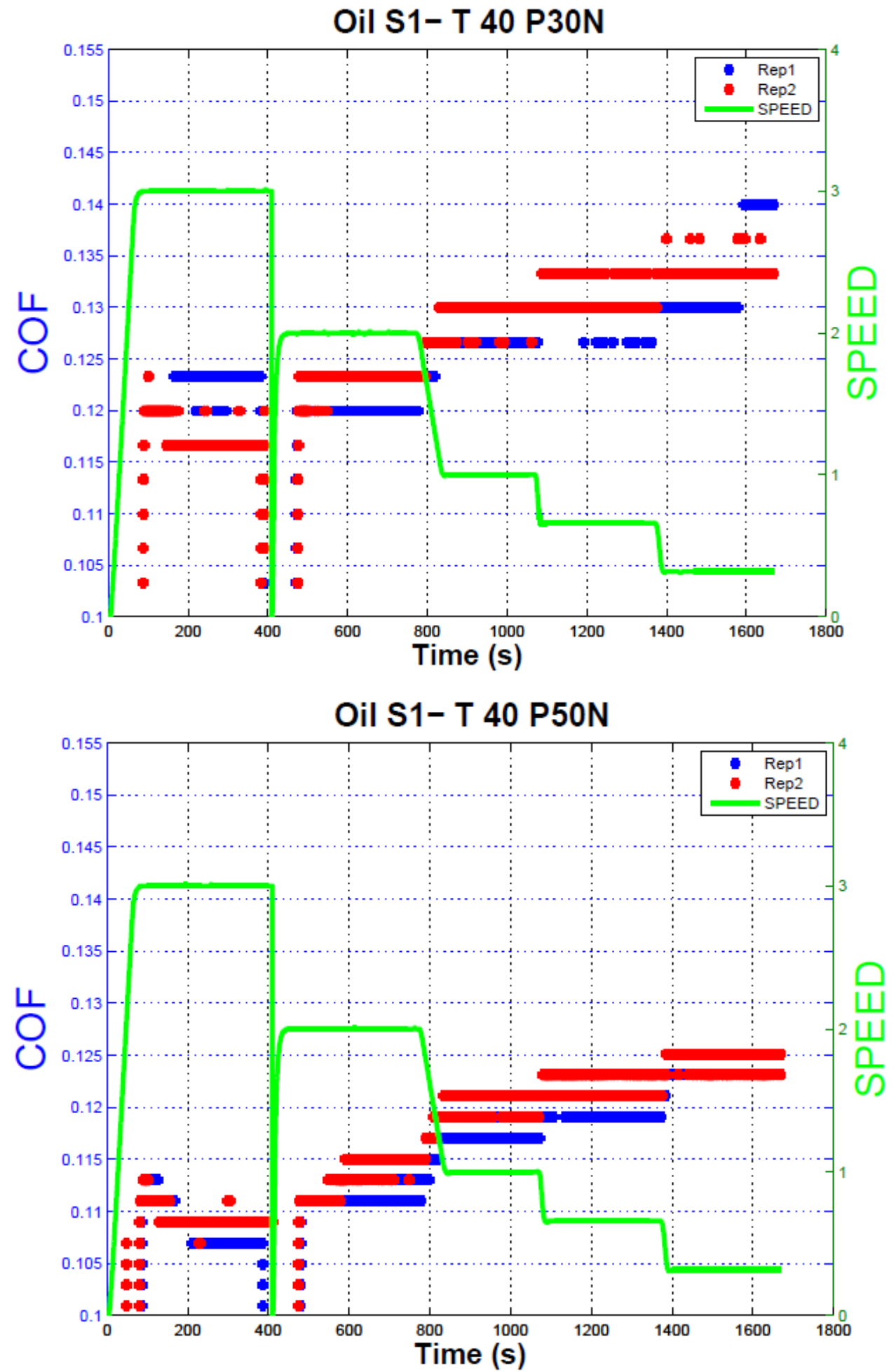

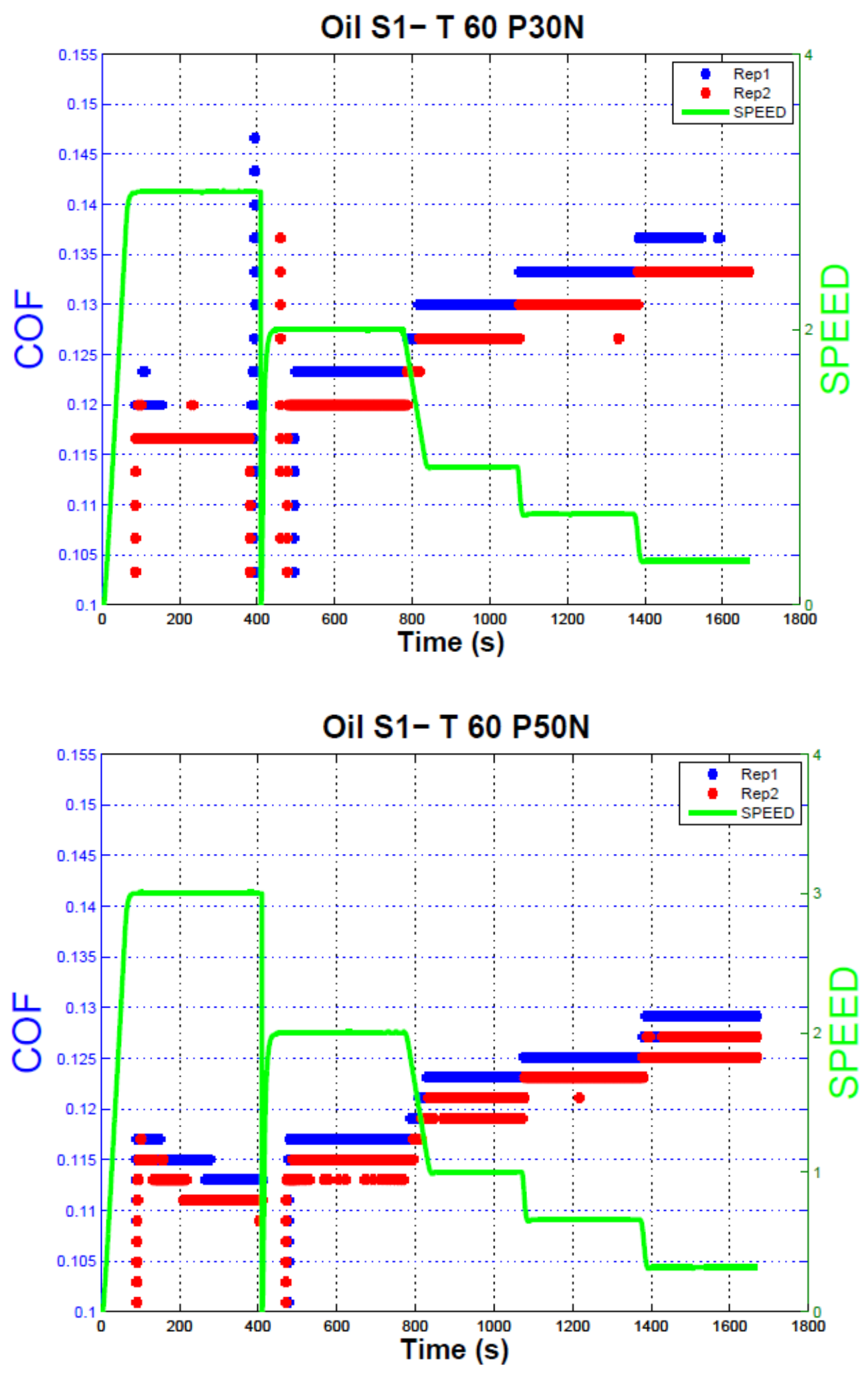

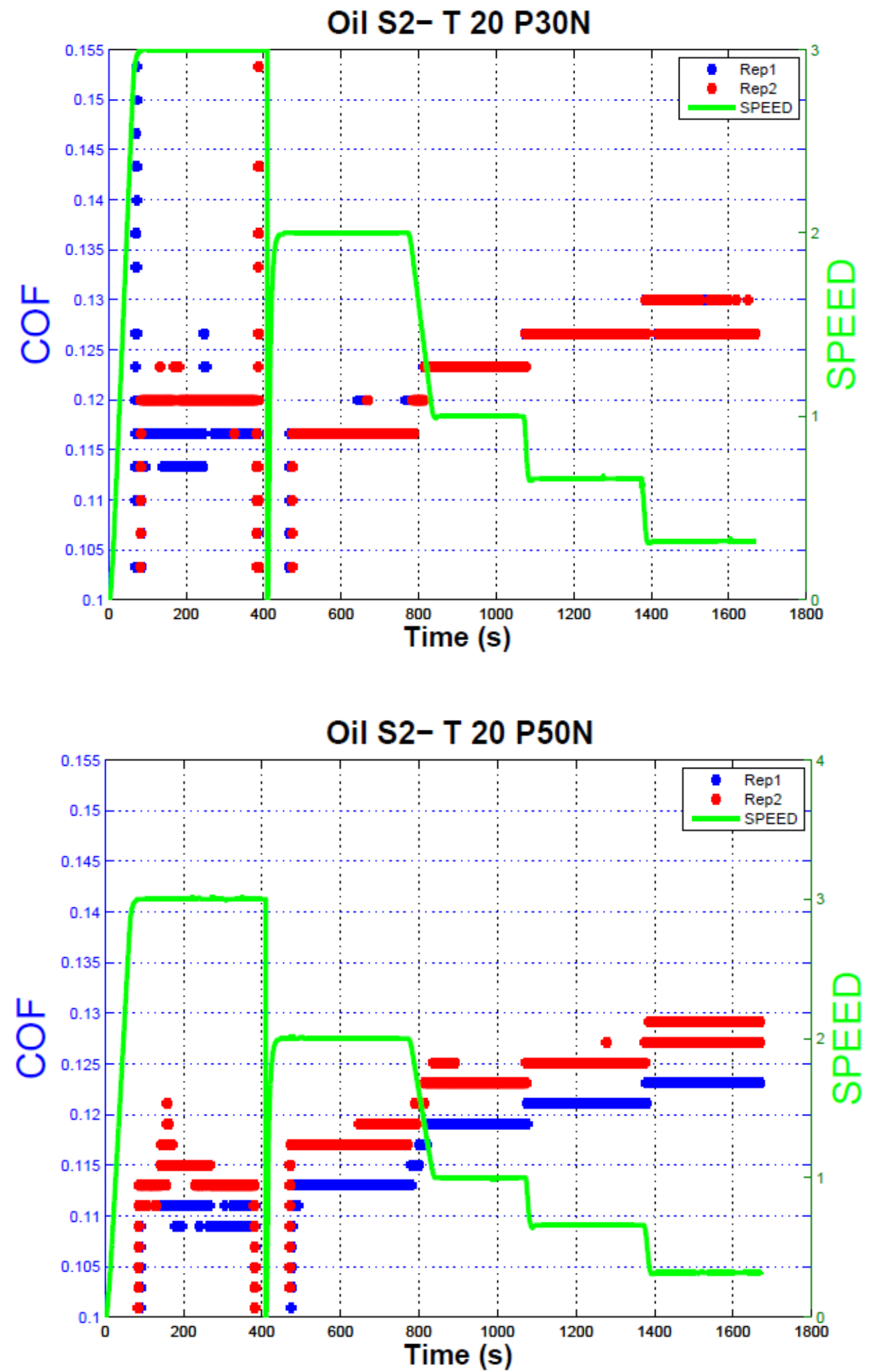

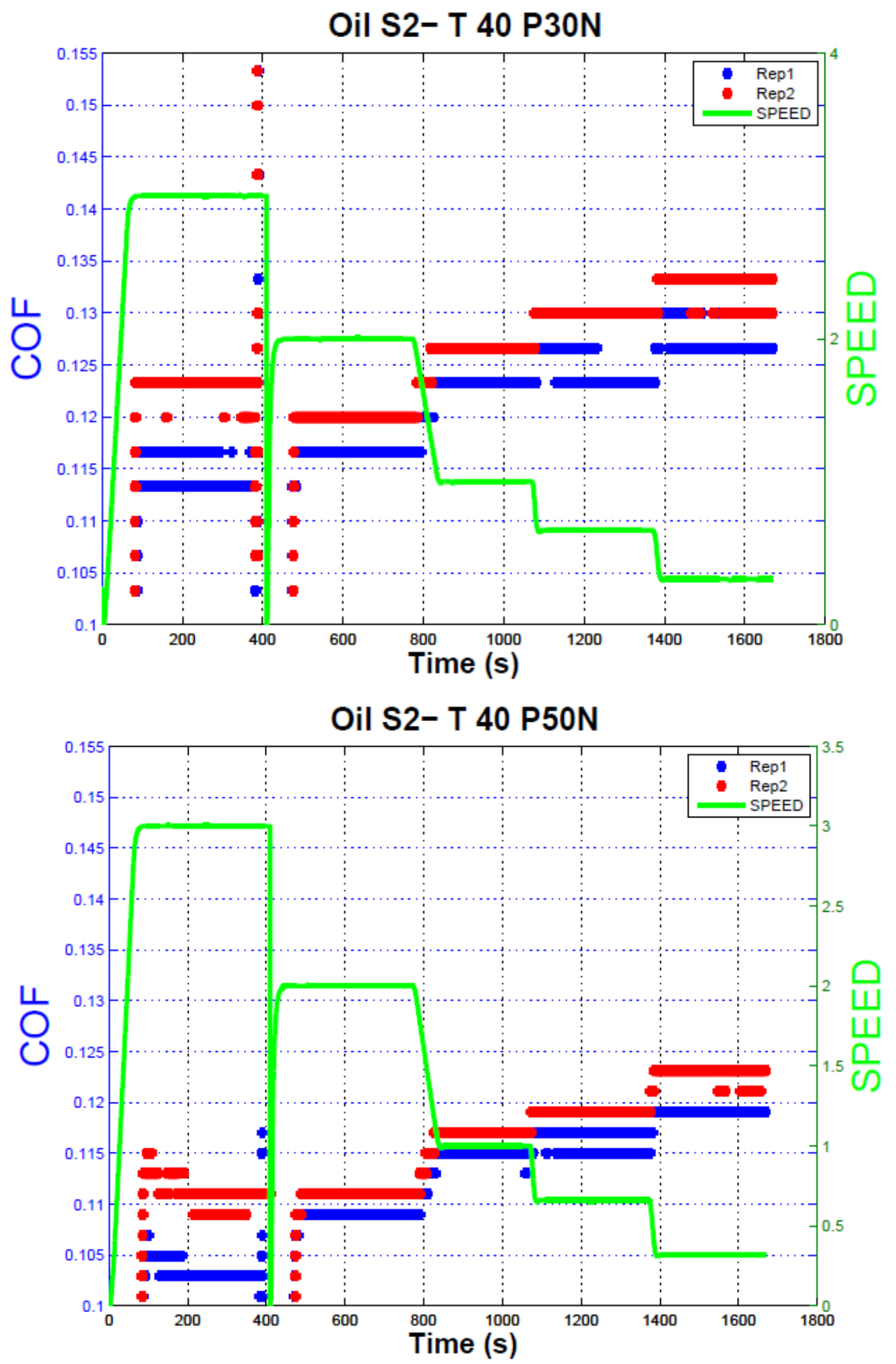

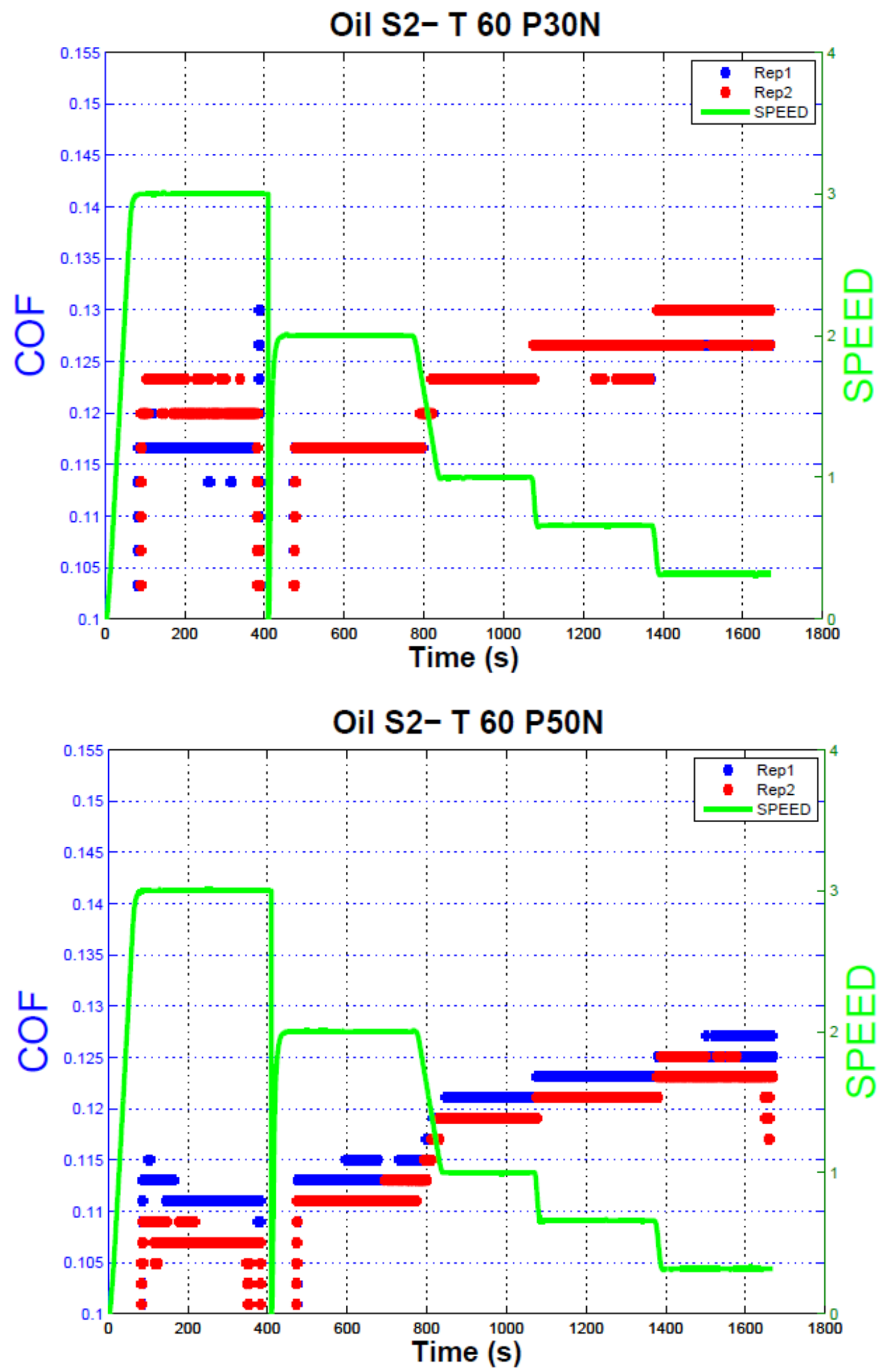

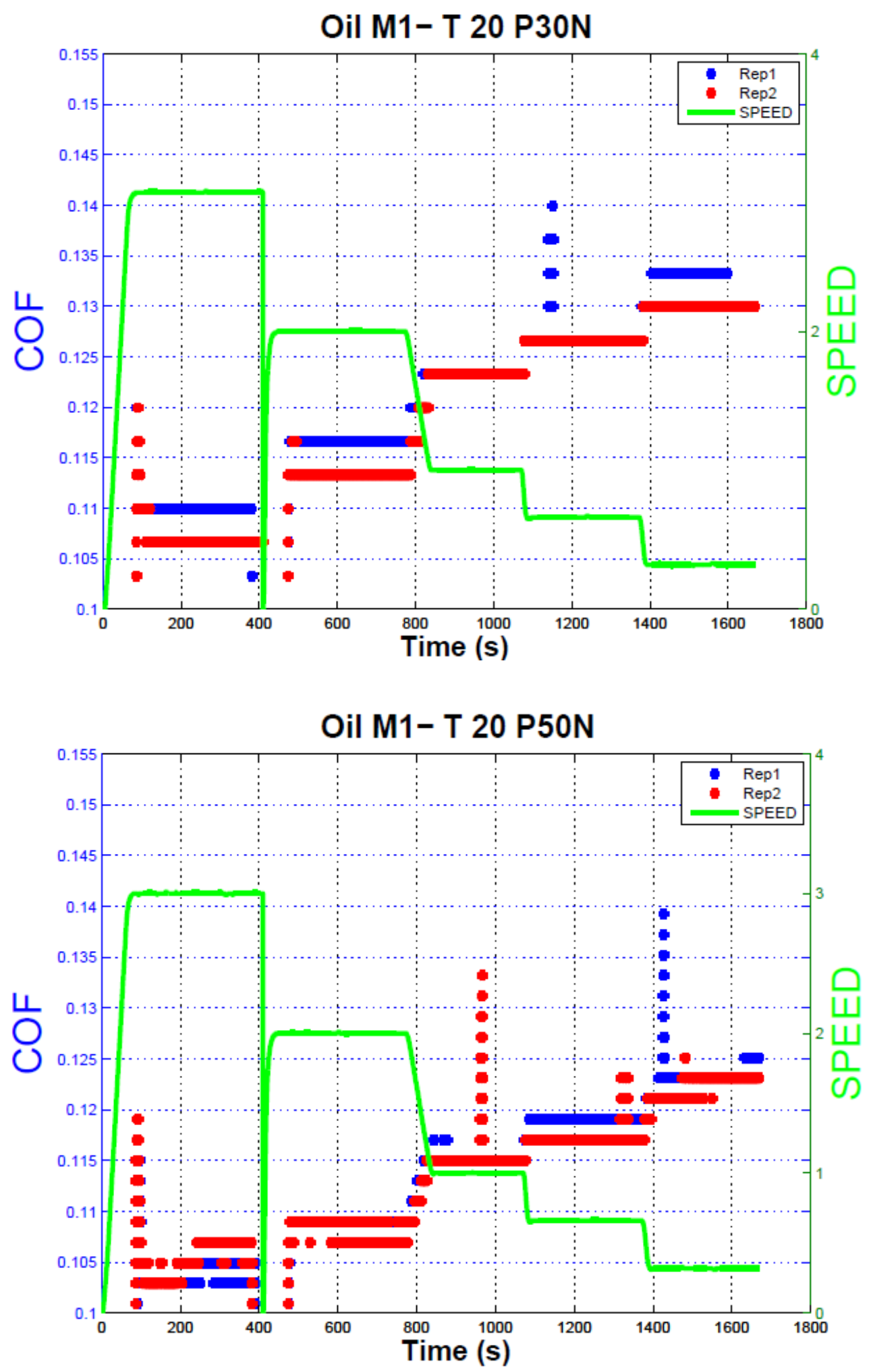

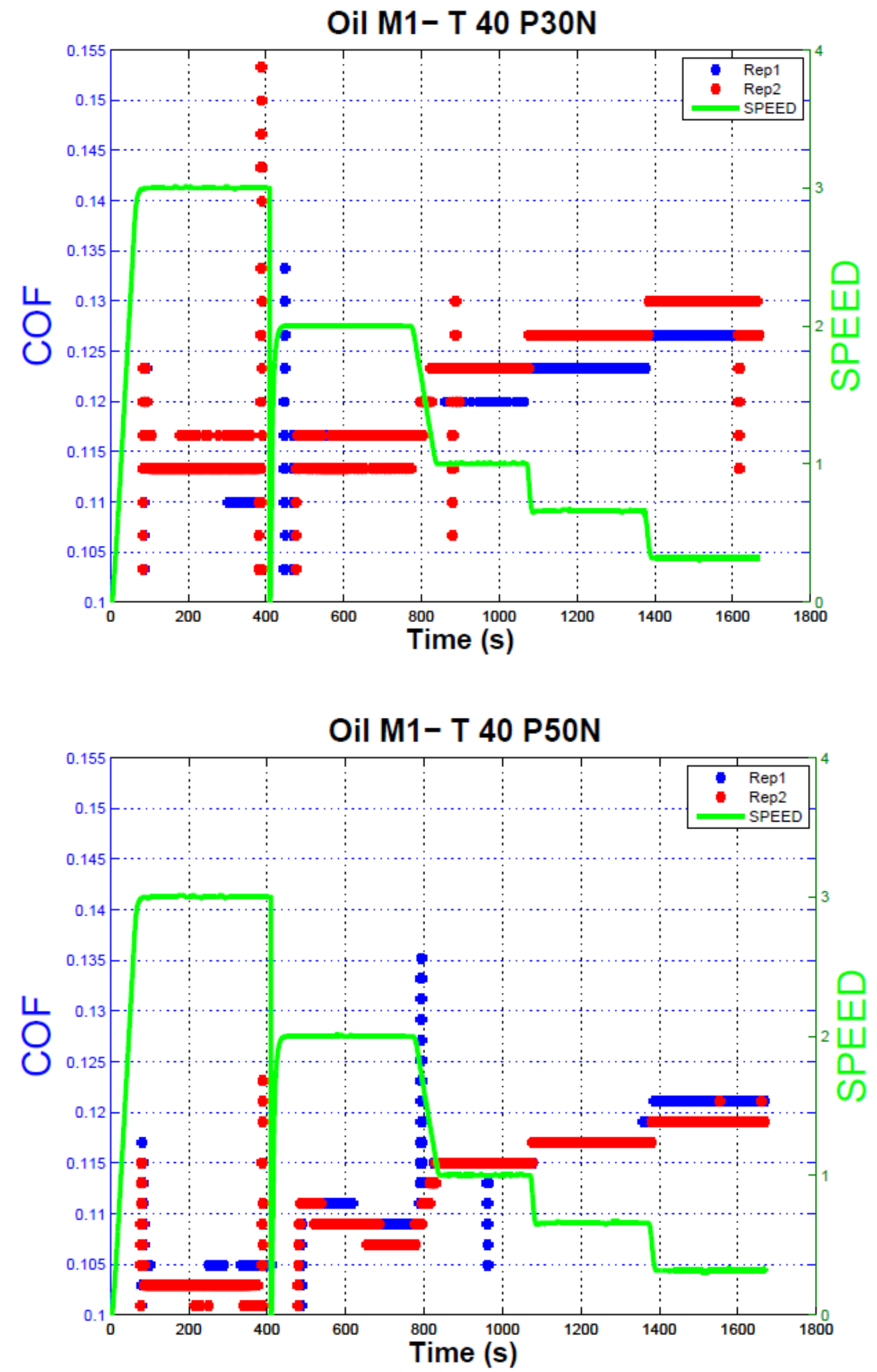

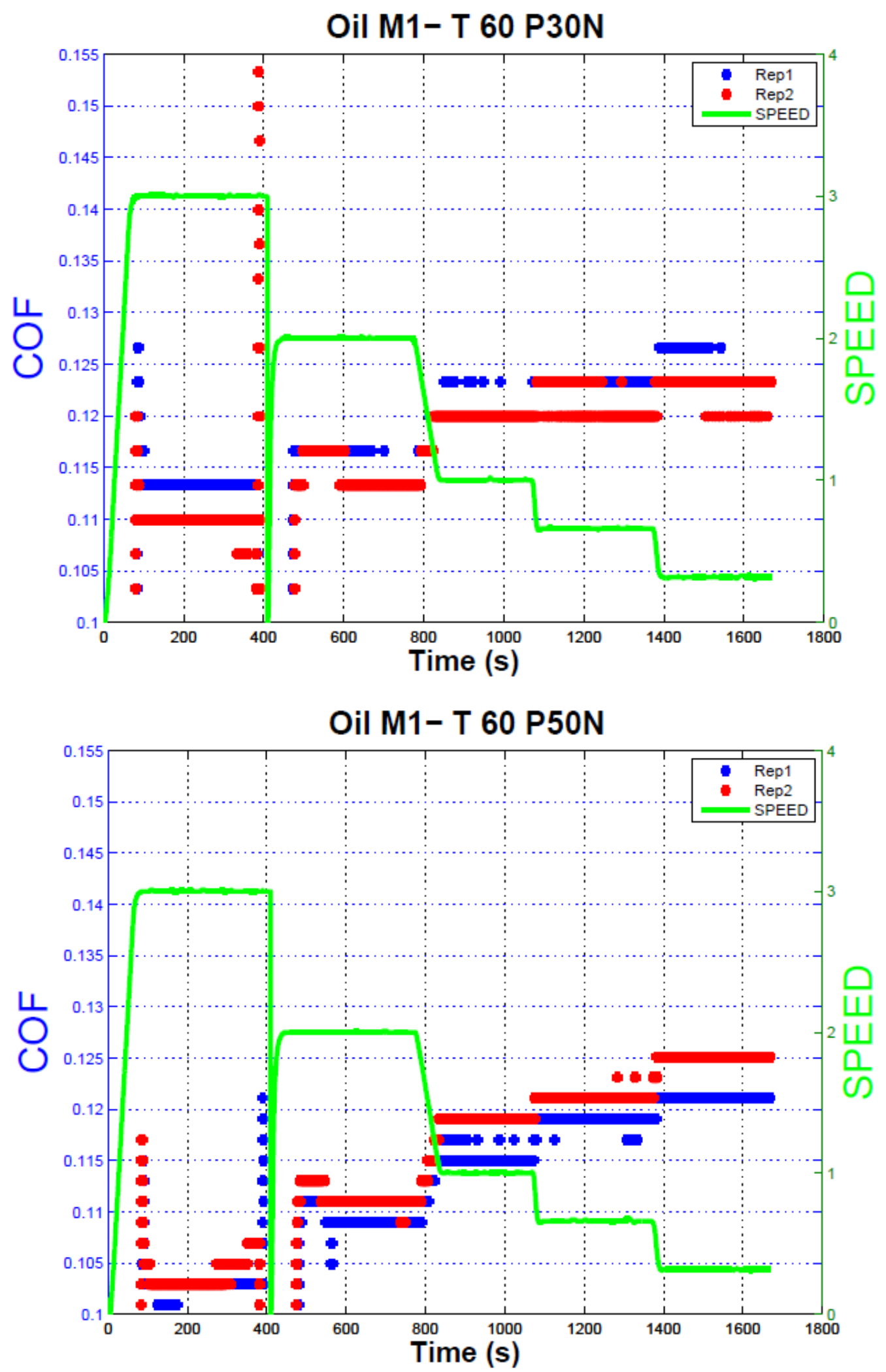


\section{Appendix D}

\section{Starved Condition}
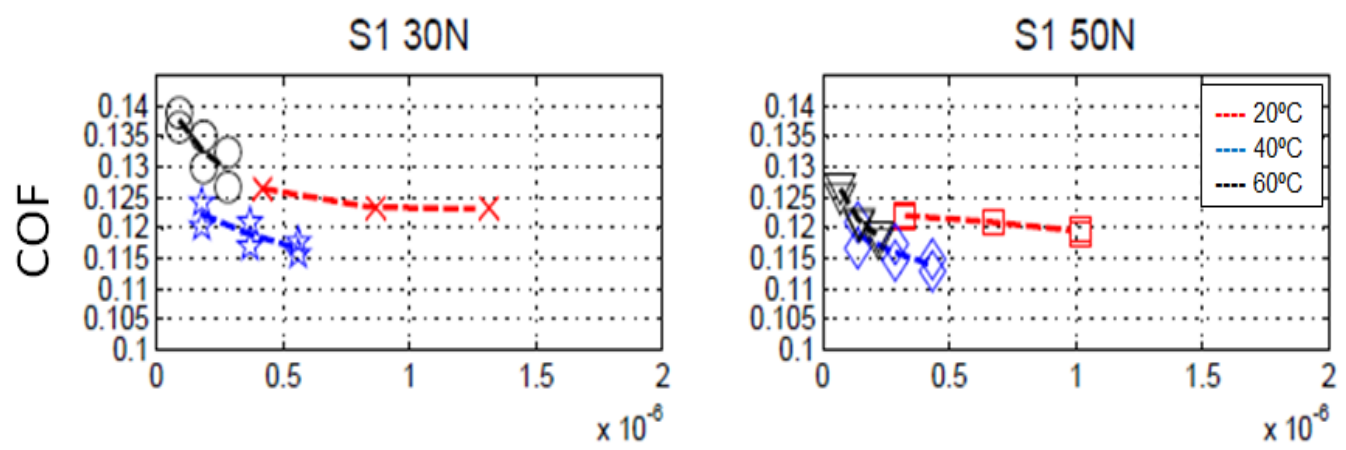

Modified Stribeck
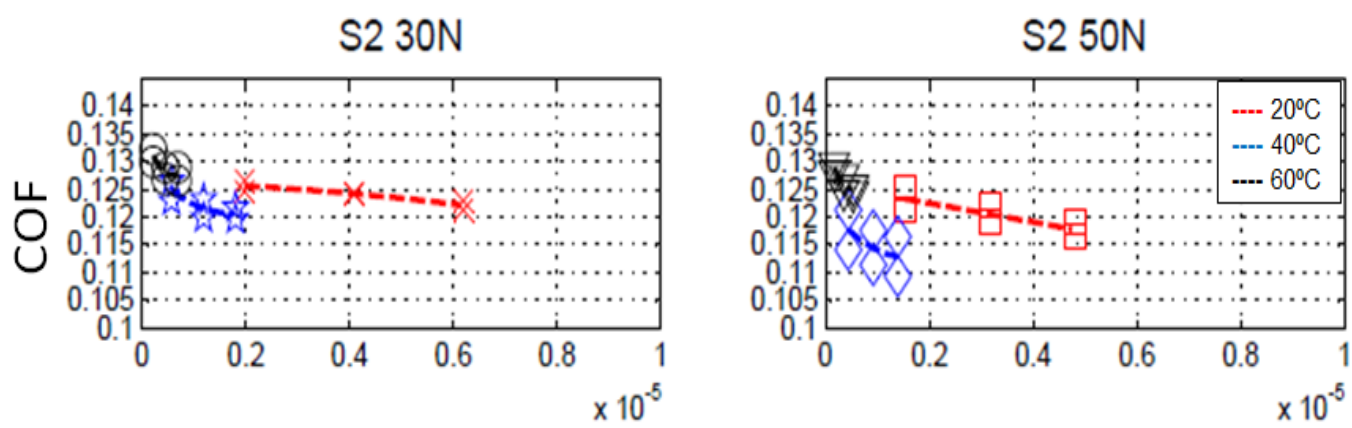

Modified Stribeck
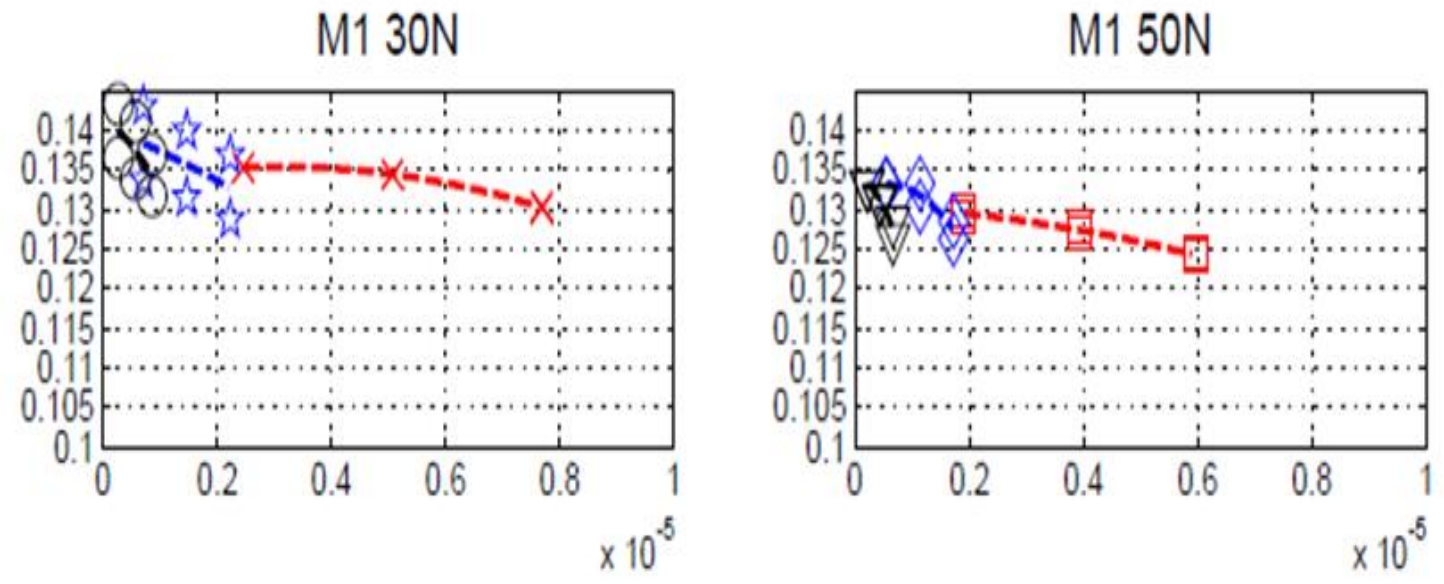
Fully Flooded Condition
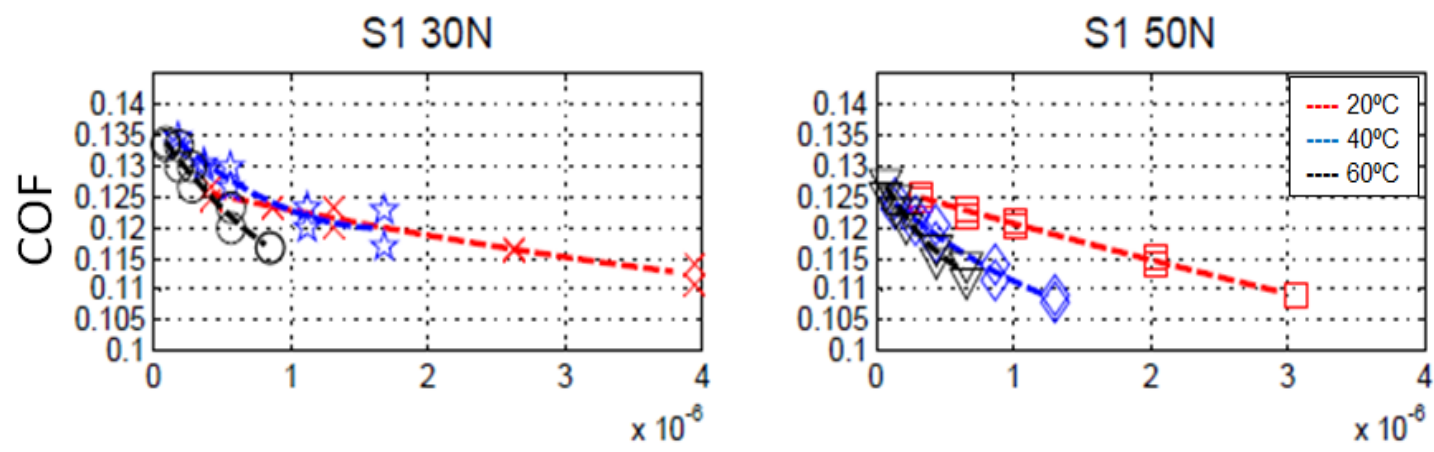

Modified Stribeck
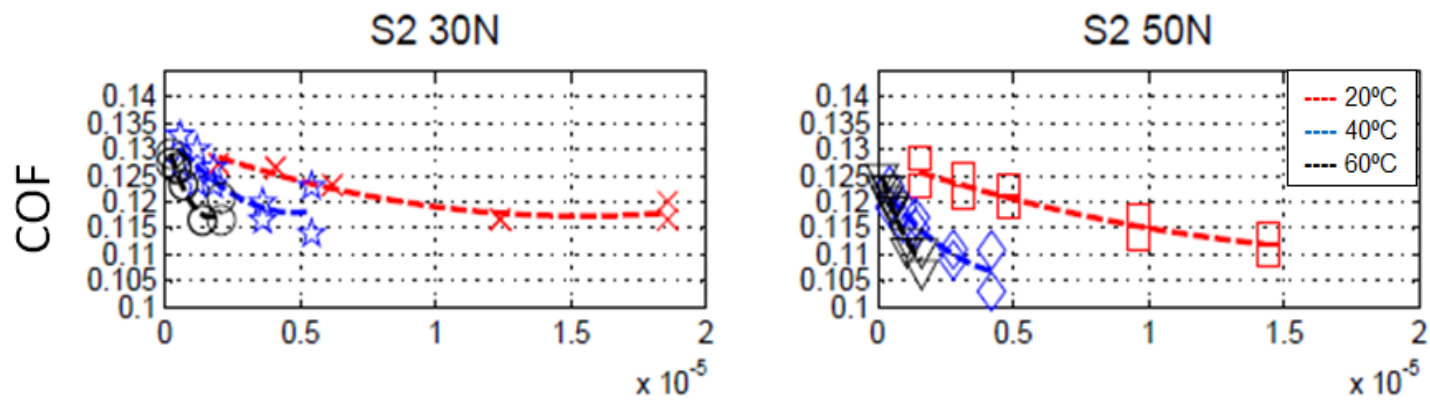

Modified Stribeck
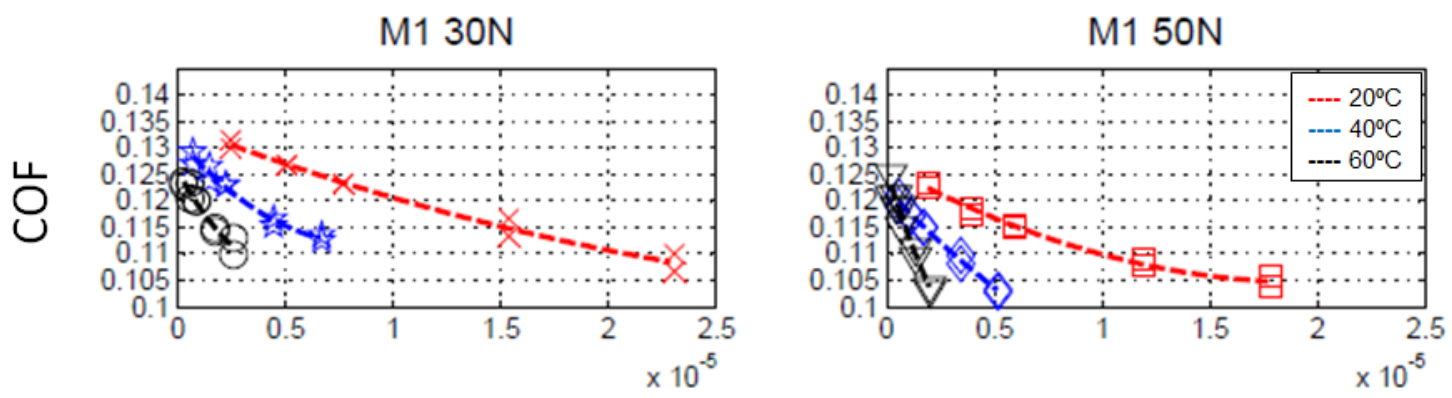

Modified Stribeck 